UNIVERSIDADE DE BRASÍLIA

FACULDADE DE TECNOLOGIA

DEPARTAMENTO DE ENGENHARIA MECÂNICA

\section{COMPENSADOR HIDROPNEUMÁTICO SEMIATIVO PARA SISTEMAS DE PERFURAÇÃO OFFSHORE}

\section{WILLIAM HUMBERTO CUELLAR SANCHEZ}

ORIENTADOR: EUGENIO FORTALEZA

DISSERTAÇÃO MESTRADO EM SISTEMAS MECATRÔNICOS

PUBLICAÇÃO:ENM.DM - 79 A/14

BRASÍLIA/ DF: OUTUBRO - 2014 


\section{COMPENSADOR HIDROPNEUMÁTICO SEMIATIVO PARA SISTEMAS DE PERFURAÇÃO OFFSHORE}

WILLIAM HUMBERTO CUELLAR SANCHEZ DISSERTAÇ̃̃O DE MESTRADO SUBMETIDA AO DEPARTAMENTO DE ENGENHARIA MECÂNICA DA FACULDADE DE TECNOLOGIA DA UNIVERSIDADE DE BRASÍLIA COMO PARTE DOS REQUISITOS NECESSÁRIOS PARA A OBTENÇÃO DO GRAU DE MESTRE EM SISTEMAS MECATRÔNICOS.

APROVADA POR:

Prof. Eugênio Fortaleza, Dr. (ENM-UnB)

(orientador)

Prof. Guilherme Caribé de Carvalho, Dr. (ENM-UnB)

(Examinador Interno)

Prof. Marcus Vinicius Girão de Morais, Dr. (UnB-ENM)

(Examinador Externo)

BRASÍLIA/DF, 29 DE OUTUBRO DE 2014 


\section{FICHA CATALOGRÁFICA}

\section{CUELLAR SANCHEZ, WILLIAM HUMBERTO}

Compensador Hidropneumático Semiativo para Sistemas de Perfuração Offshore. [Distrito Federal] 2014.

xiv, 84p, 210 x 297 mm (ENM/FT/UnB, Mestre, Sistemas Mecatrônicos, 2014).

Dissertação de Mestrado- Universidade de Brasília. Faculdade de Tecnologia. Departamento de Engenharia Mecânica.

1. Mecatrônica

2. Perfuração Offshore.
I. ENM/FT/UnB
II. Título

\section{REFERÊNCIA BIBLIOGRÁFICA:}

CUELlAR, William A. (2014). Compensador Hidropneumático Semiativo para Sistemas de Perfuração Offshore. Dissertação de Mestrado em Sistemas Mecatrônicos, Publicação ENM.DM-79A/14, Departamento de Engenharia Mecânica, Universidade de Brasília, Brasília, DF, 84p.

\section{CESSÃO DE DIREITOS}

AUTOR: William Humberto Cuellar Sanchez

TÍTULO: Compensador Hidropneumático Semiativo para Sistemas de Perfuração Offshore.

GRAU: Mestre

ANO: 2014

É concebida á Universidade de Brasília permissão para reproduzir cópias desta dissertação de mestrado e para emprestar ou vender tais cópias somente para propósitos acadêmicos e científicos. O autor reserva outros direitos de publicação e nenhuma parte dessa dissertação de mestrado pode ser reproduzida sem autorização por escrito do autor.

William Humberto Cuellar Sanchez 


\section{Agradecimentos}

Agradeço especialmente a Deus, pelo seu amor, proteção e por iluminar meus caminhos a cada dia.

A Minha querida familia pelo amor e apoio incondicionais. Por terem sido parte fundamental dessa conquista e me darem a certeza que sempre estariam comigo, mesmo a alguns quilômetros de distância, estando presentes em pensamentos e oraçôes.

Ao meu professor, amigo e orientador o doutor Eugênio Fortaleza pela sua paciência, disposição, tempo, apoio e ensino.

ANP, FINEP, MCT e Petrobras pelo apoio financeiro para a realização do curso de mestrado.

WILLIAM HUMBERTO CUELLAR SANCHEZ 
Durante a perfuração de um poço offshore, o bloco de coroamento e a coluna de perfuração são suportados por um compensador, este impedindo que o movimento da plataforma gerado pelas ondas seja transmitido ao bloco de coroamento. Se o compensador não for eficiente, o movimento do bloco de coroamento é transferido à coluna de perfuração, gerando variações de carga sobre a broca, pistoneio e flambagem da coluna de perfuração. Estes problemas podem danificar a broca, a coluna de perfuração, as paredes do poço e causar um influxo dos fluidos do reservatório para o poço. Assim, a perfuração deve ser interrompida para evitar o risco de acidentes graves, perdendose tempo de operação e dinheiro. Por isso, um sistema compensador para atenuar as vibrações transmitidas pela plataforma ao bloco de coroamento é de extrema importância.

Este documento mostra como foi projetado o sistema compensador de heave (movimento de afundamento) para um processo de perfuração offshore de $6 \mathrm{~km}$ de profundidade e apresenta o controle semiativo. O compensador é projetado com duas configurações de suspensão hidropneumática, a primeira é uma suspensão hidropneumática simples e a segunda é uma suspensão hidropneumática simples em série com uma mola mecânica. A modelagem foi feita para cada sistema de suspensão e encontrou-se a respectiva função de transferência. Os polos dessas funções de transferência foram projetados para terem os mesmos polos sugeridos para um filtro Butterworth passa-baixas de segunda e terceira ordem.

O objetivo deste controle semiativo é manter um desempenho aceitável do compensador quando a massa da coluna de perfuração é modificada, pois essa mudança afeta o comportamento do sistema de suspensão hidropneumático. A ação de controle é executada apenas por uma válvula servo comandada e esta ação modifica o valor do amortecimento do sistema e, assim, o comportamento do compensador é mantido um nível aceitável. Esta válvula é a única parte móvel do sistema de controle e, portanto, este sistema é mais robusto em relação às falhas mecânicas ou elétricas e possui um baixo consumo de energia.

Os resultados são obtidos com uma simulação feita em MATLAB. As respostas em frequência mostram melhores resultados quando é usado o controle semiativo para o compensador de heave que foi projetado com a suspensão hidropneumática simples, quando a massa da coluna de perfuração for alterada, este compensador pode funcionar sem sistemas ativos obtendo um comportamento aceitável. Com base na simulação, verificou-se que o compensador projetado com a suspensão hidropneumática simples em série com uma mola mecânica não é realizável ao aplicar a metodologia proposta nesta dissertação. 


\begin{abstract}
During the drilling of an offshore well, the crown block and the drill string are supported by a compensator, which prevents movement of the crown block, due to the platform heave. Without an efficient compensator, the displacement of the drill string can generate load variations on the drill bit, swabbing, and buckling of the drill string. These problems can generate drill bit damage, drill string damage, collapse of the borehole wall and well kick. If the compensator is not able to satisfactorily compensate the heave, the drilling is stopped to avoid the risk of major accidents.

Stopping the drilling causes loss of operation time and money. Thus, a compensator system, which mitigates the vibrations transmitted by the platform to the crown block, is of utmost importance.

This work shows the designing of a heave compensation system and a semi-active control according to the requirements drilling $6 \mathrm{~km}$ deep offshore. Two approaches for compensator design are studied, the first is the basic hydropneumatic suspension and the second is the basic hydropneumatic suspension in series with the mechanical spring. The modelling of each suspension was made to find the transfer function and the poles of compensator transfer function were designed to have the suggested pole by the Butterworth filter low-pass.

The goal of this semi-active control is to maintain an acceptable performance of the system when the drill string mass changes, which also changes the performance of the hydropneumatic system. The control action is executed just by a servo valve, which modifies the system damping to optimize the compensator performance. This servo valve is the only moving part of the control system and therefore, this system is more robust regarding mechanical/ electrical failures and it has low consumption energy.

The results show a better and satisfactory frequency response of semi-active control for heave compensator that was designed with the basic hydropneumatic suspension, when the drill string mass is changed, this compensator can work without active systems. The designed compensator with the basic hydropneumatic suspension in series with the spring was not feasible with the applied methodology.
\end{abstract}




\section{SUMÁRIO}

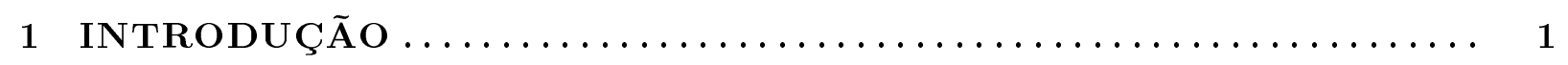

1.1 JUSTIFICATIVA DO TRABALHO …................................ 3

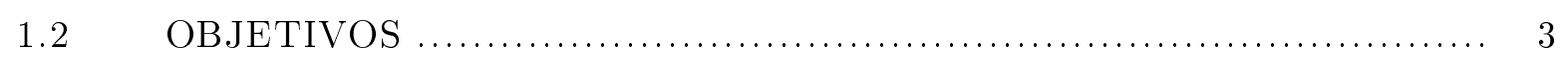

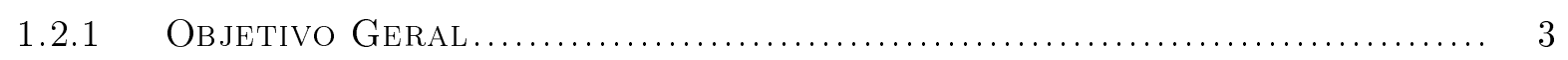

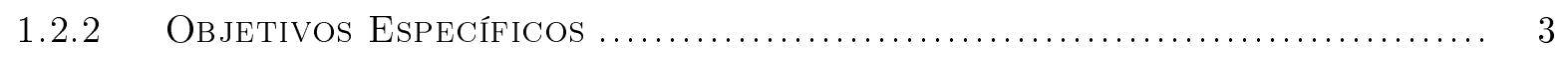

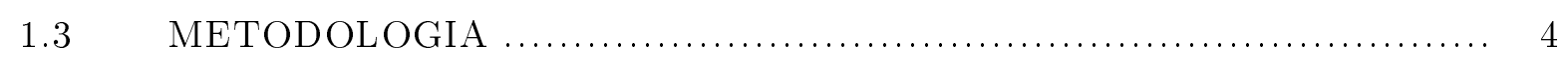

1.4 ESTRUTURA DO DOCUMENTO ................................ 4

2 REVISÃO BIBLIOGRÁFICA $\ldots \ldots \ldots \ldots \ldots \ldots \ldots \ldots \ldots \ldots \ldots \ldots \ldots \ldots$

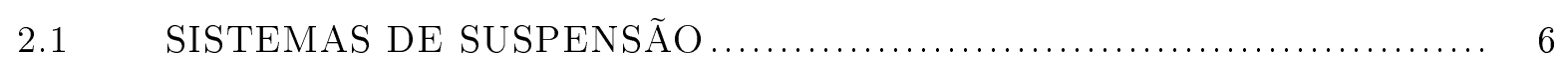

2.2 CLASSIFICAÇÃO DE SISTEMAS DE SUSPENSÃO $\ldots \ldots \ldots \ldots \ldots \ldots \ldots \ldots \ldots$

$2.2 .1 \quad$ SUSPENSÃO PASSIVA ..................................................... 8

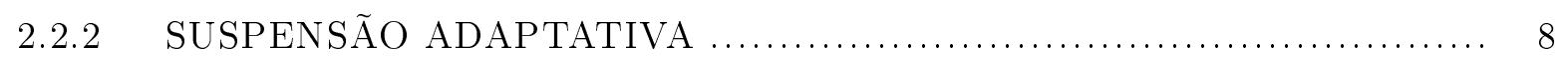

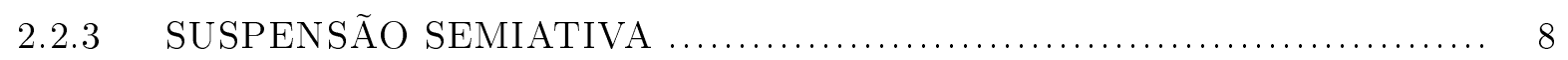

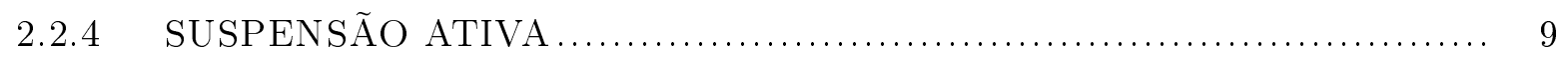

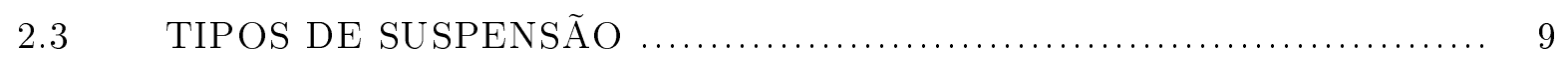

2.4 SISTEMAS DE SUSPENSÃO HIDROPNEUMÁTICO ................... 13

2.5 SISTEMA DE SUSPENSÃO HIDROPNEUMÁTICO EM SÉRIE COM UMA MOLA MECÂNICA. .......................................... 15

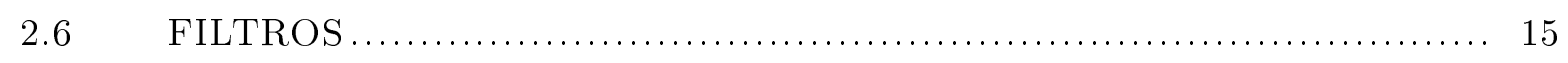

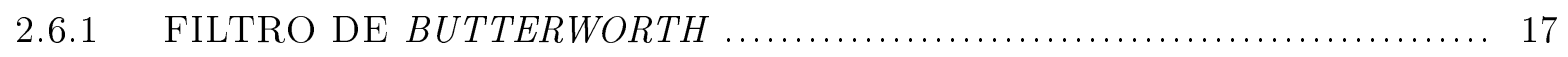

$2.7 \quad$ ALGORITMOS DE CONTROLE SEMIATIVO …..................... 19

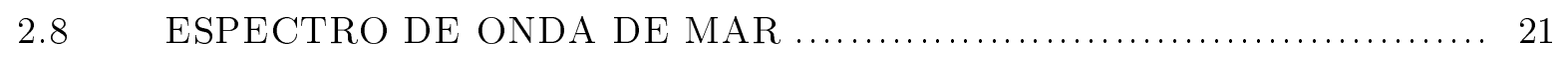

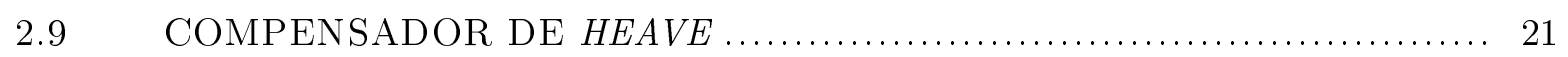

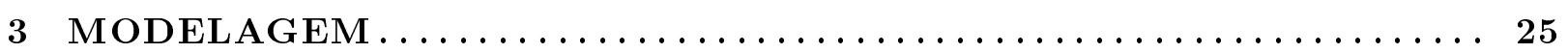

3.1 FUNÇÃO DE TRANSFERENCIA DO SISTEMA DE SUSPENSÃO HIDROPNEUMÁTICO SEM MOLA …............................... 25

3.2 PARÂMETROS DO SISTEMA HIDROPNEUMÁTICO SEM MOLA EM FUNÇÃO DOS PARÂMETROS DO FILTRO DE BUTTERWORTH. ...... 29 
3.3 FUNÇÃO DE TRANSFERÊNCIA DO SISTEMA DE SUSPENSÃO HIDROPNEUMÁTICO EM SÉRIE COM UMA MOLA MECÂNICA ....... 30

3.4 PARÂMETROS DO SISTEMA HIDROPNEUMÁTICO EM SÉRIE COM UMA MOLA MECÂNICA EM FUNÇÃO DOS PARÂMETROS DO FILTRO DE BUTTERWORTH....................................... 33

3.5 VARIAÇÃO DO SISTEMA PARA MASSA VARIÁVEL ................. 34

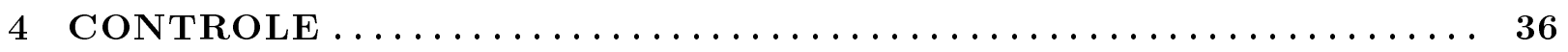

4.1 AMORTECEDOR PARA COMPENSADOR HIDROPNEUMÁTICO SEM

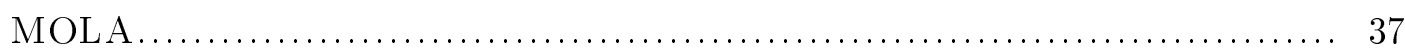

4.2 AMORTECEDOR PARA COMPENSADOR HIDROPNEUMÁTICO EM

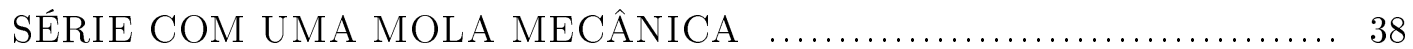

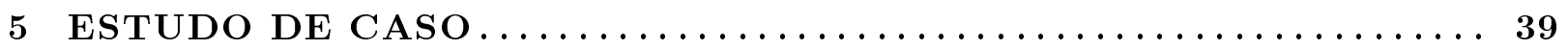

5.1 COMPORTAMENTO DESEJADO DO COMPESADOR DE HEAVE .... 39

5.2 CONFIGURAÇÕES HIDROPNEUMATICAS ESCOLHIDAS ............. 40

5.3 CONDIÇÕES DE TRABALHO DO COMPENSADOR $\ldots \ldots \ldots \ldots \ldots \ldots \ldots . . . \ldots 1$

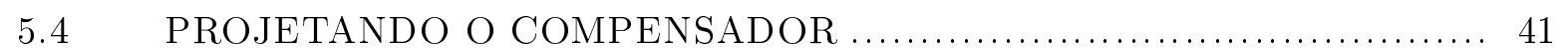

5.4 .1 PRESSÃO MÁXIMA PERMITIDA.................................... 42

$5.4 .2 \quad$ ALTURA DO CILINDRO .......................................... 43

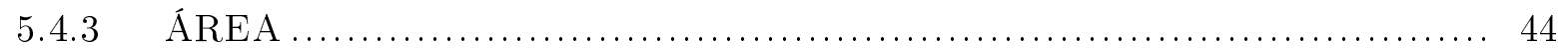

5.4 .4 VOLUME DO ACUMULADOR ........................................ 44

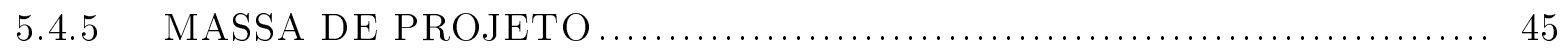

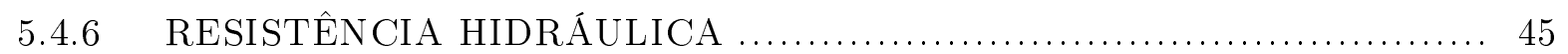

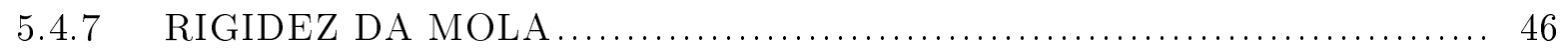

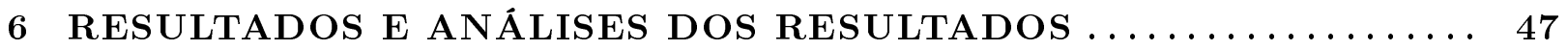

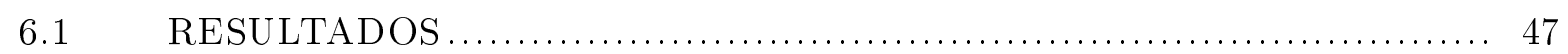

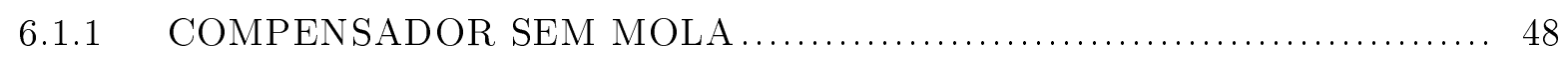

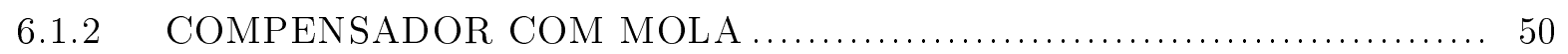

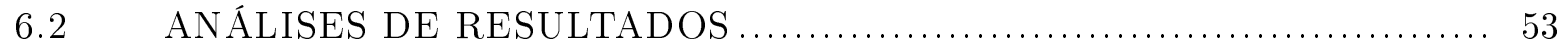

7 COMPENSADOR COM CREMALHEIRA .................. 59

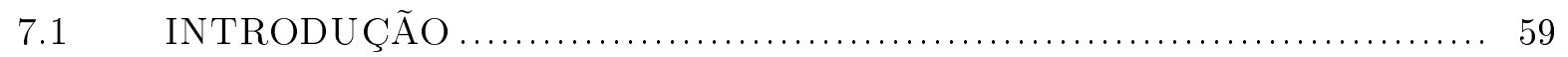

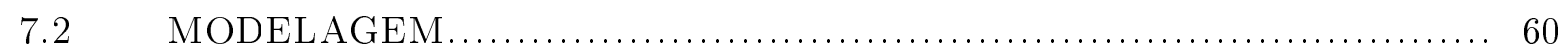

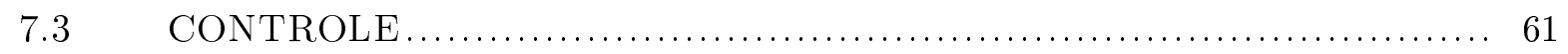

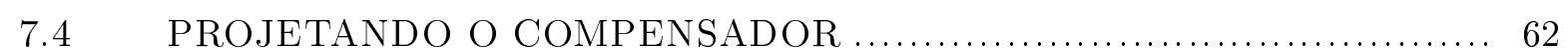

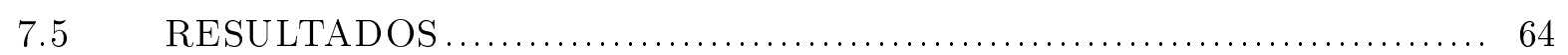

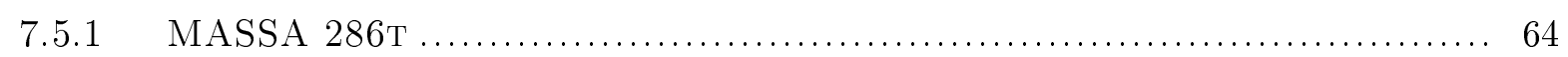

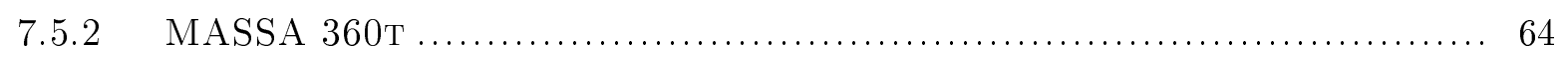

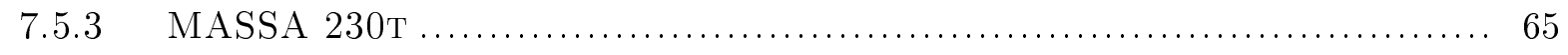

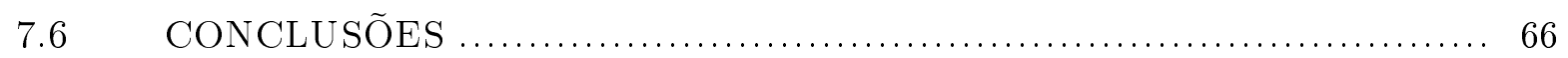


8 COMPENSADOR COM CONTROLE SEMIATIVO CONTINUO . . . . 68

8.0.1 PERDA DE PRESSÃO POR PLACA DE ORIFÍCIO................... 68

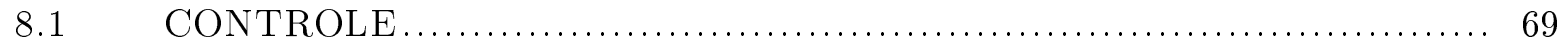

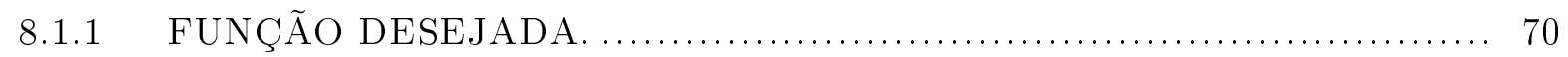

8.1.2 OBTENDO A FUNÇÃO DESEJADA ................................ 71

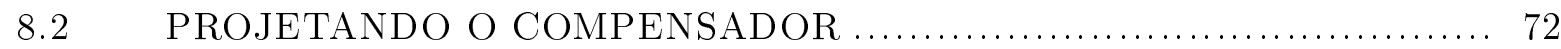

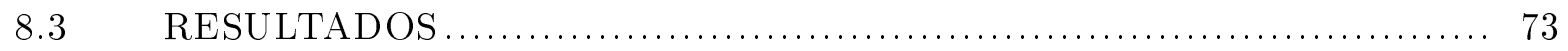

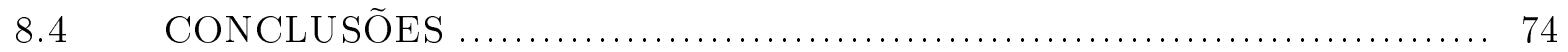

9 Conclusões $\ldots \ldots \ldots \ldots \ldots \ldots \ldots \ldots \ldots \ldots \ldots \ldots \ldots \ldots \ldots \ldots \ldots \ldots \ldots$

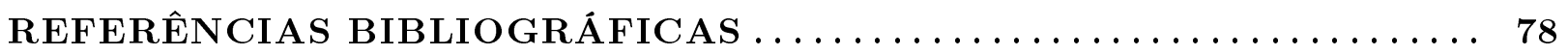

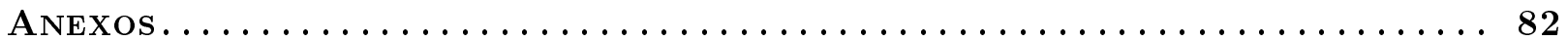

I Diagramas Esquemáticos $\ldots \ldots \ldots \ldots \ldots \ldots \ldots \ldots \ldots \ldots \ldots \ldots \ldots$

I.1 FrequênCIA nATURAL do Compensador SEM MOLA..................... 83

I.2 Frequência natural do Compensador COM MOla. .................... 84 


\section{LISTA DE FIGURAS}

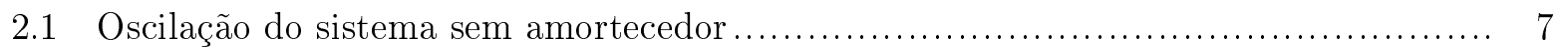

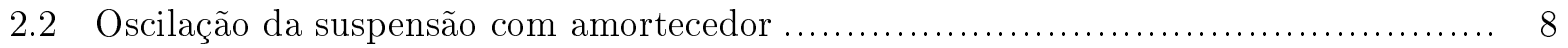

2.3 Configuração geral de um sistema de suspensão ..................................... 9

2.4 Área de desempenho sistemas de suspensão: a) Passiva, b) Adaptativa, c) Semiativa,

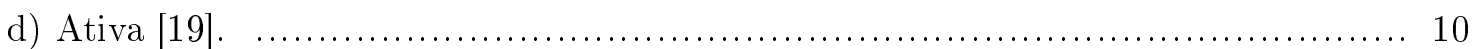

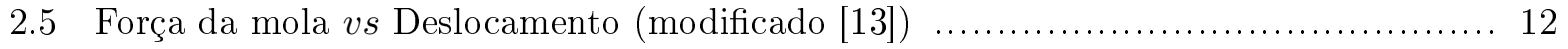

2.6 Rigidez da Mola vs Massa Suportada (modificado [13]) ............................ 12

2.7 Frequência natural do sistema vs Massa suportada (modificado [13]) ................. 13

2.8 Esquema Suspensão. A) Compressão. B) Expansão ................................ 14

2.9 Suspensão Sistema Hidropneumático com mola mecânica.......................... 16

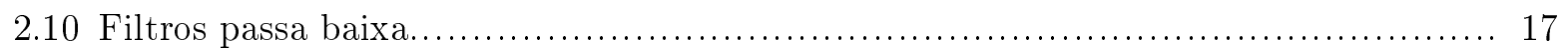

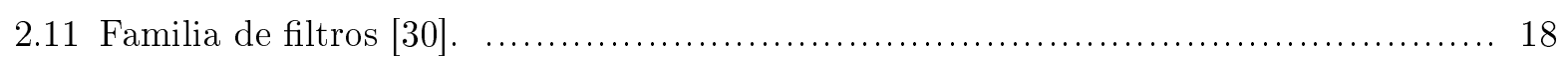

2.12 Filtro de Butterworth de ordem 1 até 5 [32]. .................................. 19

2.13 Polos do Filtro Butterworth de ordem 4. .......................................... 20

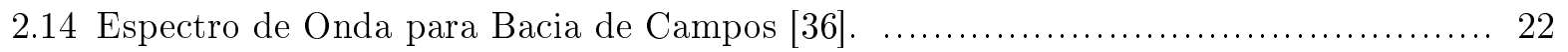

2.15 Magnitude da resposta em frequência de um compensador passivo para 570t [15] ... 23

2.16 Exemplos de compensadores. A) Empresa Control flow Inc [43]. B) Empresa Asker

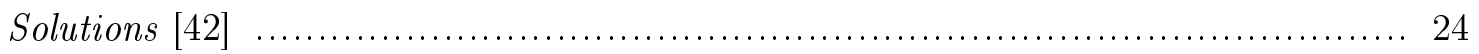

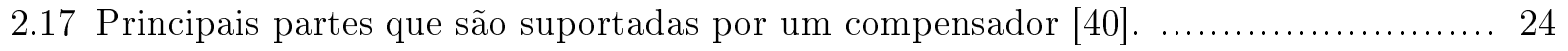

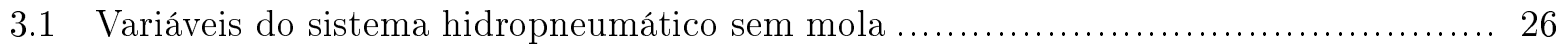

3.2 Variáveis do sistema hidropneumático e mola mecânica em série ..................... 31

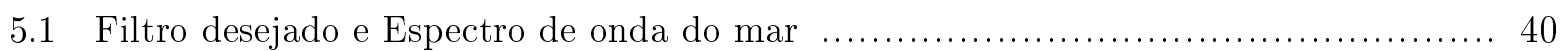

5.2 Processo de Perfuração A) Mínima profundidade. B) Máxima Profundidade ......... 43

6.1 Resposta em frequência para a massa de projeto, compensador sem mola ............. 48

6.2 Resposta ao degrau para a massa de projeto, compensador sem mola. ................. 49

6.3 Resposta em frequência para a massa máxima, compensador sem mola ............... 50

6.4 Resposta ao degrau para a massa máxima, compensador sem mola ................... 51

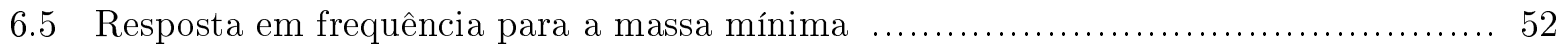

6.6 Resposta ao degrau para a massa mínima, compensador sem mola .................. 53

6.7 Resposta em frequência para a massa de projeto, compensador com mola ............ 54

6.8 Resposta ao degrau para a massa de projeto, compensador com mola ................ 55 
6.9 Resposta em frequência para a massa máxima, compensador com mola ............... 56

6.10 Resposta ao degrau para a massa máxima, compensador com mola ................. 57

6.11 Resposta em frequência para a massa mínima, compensador com mola................ 58

6.12 Resposta ao degrau para a massa mínima, compensador com mola .................... 58

7.1 Esquema do compensador com cremalheira ...................................... 60

7.2 Esquema do controle implementado para o compensador com cremalheira ............ 61

7.3 Resposta em frequência para a massa de projeto, compensador com cremalheira ..... 65

7.4 Resposta em frequência para a massa máxima, compensador com cremalheira ........ 66

7.5 Resposta em frequência para a massa mínima, compensador com Cremalheira ........ 67

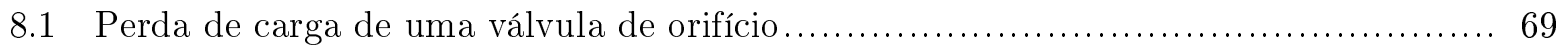

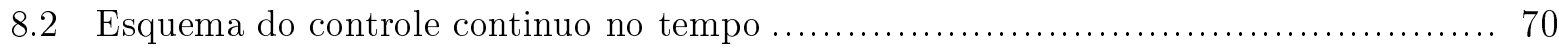

8.3 Resposta em frequência do filtro desejado e da função de transferência do compen-

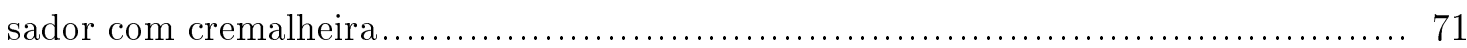

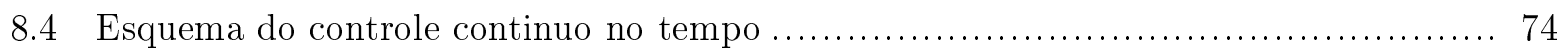

8.5 Resposta em frequência do compensador com controle continuo ...................... 75

8.6 Resposta do compensador para um deslocamento da plataforma gerado pelo movi-

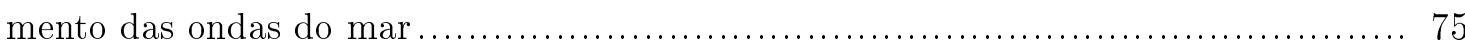




\section{LISTA DE TABELAS}

2.1 Comparação tipos de suspensão: ++ muito bom, + bom, 0 aceitável, e - ruim [13]. 11

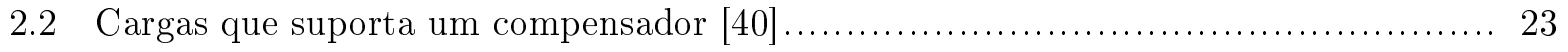

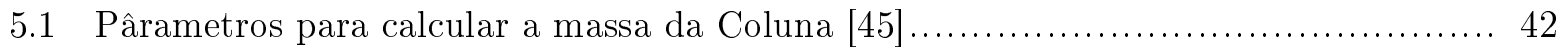

5.2 Valores dos pârametros para os compensadores no ponto de projeto ................. 42

6.1 Resumo comportamento compensador sem mola ................................ 56

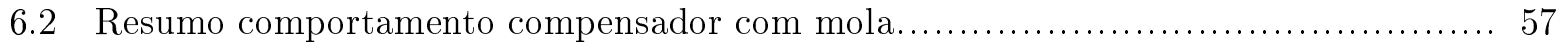

7.1 Valores dos pârametros para os compensador com cremalheira no ponto de projeto... 63

8.1 Valores dos pârametros para os compensadores no ponto de projeto com controle continuo 


\section{LISTA DE SÍMBOLOS}

$B$

$b_{2}$

$b_{1}$

C

$f_{c}$

$f_{c s t}$

$f_{m}$

$f_{m s t}$

$f_{\text {cdin }}$

$F_{c d i n}$

G

$g$

H

j

$k_{2}$

$k_{o}$

$m$

$m_{s t 1}$

$m_{\min }$

$m_{\max }$

$N$

$P_{s t}$

$P_{s t 1}$

$P_{c}$

$P_{A c}$

$\triangle P$

$q_{A c}(t)$

$R$

$r$

$s$

$S v$

$S_{\text {saida }}$

$S_{\text {entrada }}$

Conjunto de funções de Butterworth

Coeficiente viscoso de amortecimento do compensador

Coeficiente de atrito da cremalheira

Capacitância do acumulador

Força feita pela cilindro no domínio do tempo

Força estática que gera o cilindro

Força feita pela mola, domínio do tempo

Força estática feita pela mola, domínio do tempo

Força dinâmica feita pela cilindro no domínio do tempo, sem a força estática

Força dinâmica feita pela cilindro no domínio de frequência, sem a força estática

Ganho máximo obtido na resposta em frequência

Gravidade

Magnitude da função

Unidade imaginaria

Rigidez do acumulador ou rigidez da mola hidropneumática

Rigidez da mola mecânica

Massa suportada pelo compensador

Massa suportada pelo compensador depois de ter sido mudada

Mínima massa suportada pelo compensador

Máxima massa suportada pelo compensador

Ordem do filtro

Pressão estática do cilindro

Pressão estática no acumulador ao variar a massa do sistema.

Pressão no cilindro

Pressão no acumulador

Queda de pressão entre o cilindro e o acumulador

Fluxo que passa pela válvula

Resistencia hidráulica

Expoente adiabático

Parâmetro no domínio de frequência

Área do cilindro

Sinal de saída

Sinal de entrada 
$V_{s t} \quad$ Volume estático do acumulador

$V_{s t 1} \quad$ Volume estático do acumulador ao variar a massa

$w \quad$ Frequência

$w_{n} \quad$ Frequência de corte

$w_{n} \quad$ Frequência natural

O ganho complexo da função de transferência

O complexo conjugado do ganho da função de transferência

Amortecimento

Posição da massa suportada pelo compensador no domínio do tempo Velocidade da massa suportada pelo compensador no domínio do tempo Aceleração da massa suportada pelo compensador no domínio do tempo

Posição da massa suportada pelo compensador no domínio de frequência Posição do navio no eixo vertical, domínio do tempo

Posição no ponto de operação do navio no eixo vertical, domínio do tempo

Velocidade do navio no eixo vertical, domínio do tempo

Posição da massa suportada pelo compensador no domínio de frequência

Posição do ponto de operação da parte superior do cilindro,

Posição da parte superior do cilindro, no domínio do tempo

Velocidade da parte superior do cilindro, no domínio do tempo

Tempo de acomodação 


\section{Capítulo 1}

\section{INTRODUÇÃO}

Petróleo, palavra formada pela união dos termos em latim petra (pedra) e oleum (óleo), é um produto resultante da decomposição de matéria orgânica armazenada em sedimentos que migram através de aquíferos e ficam aprisionados em reservatórios. Esses reservatórios podem ser encontrados em terra ou no fundo dos oceanos. Quando os reservatórios são encontrados nos oceanos, são chamados de reservatórios offshore. O compensador desenvolvido nessa dissertação foi projetado para a perfuração desse tipo de reservatórios. No Brasil são produzidos 30.081,8 milhões de barris de petróleo por ano, e desse número 28.505,5 milhões são extraídos de reservatórios offshore segundo os dados de 2011 [1] da Agencia Nacional do Petróleo (ANP), do Brasil.

No caso dos reservatórios offshore, cada vez são exploradas águas mais profundas e em lugares mais afastados como tem demonstrado a história do petróleo [2]. Como possíveis soluções para atingir águas mais profundas apareceram plataformas estáticas e não estáticas. As ondas do mar afetam somente as plataformas não estáticas.

Com as plataformas não estáticas aparece um problema: as ondas geram um movimento no navio e parte desse movimento é transmitido para a coluna de perfuração afetando-a. A estabilidade da coluna de perfuração é afetada pelo movimento da sonda que é deslocada pelas ondas. O compensador trabalhado nesta dissertação considera apenas o movimento de afundamento (heave), este movimento é o movimento vertical da sonda e pode gerar os seguintes problemas na perfuração: variações na carga sobre a broca, altas e tensões variáveis sobre a coluna, e pode acontecer de o fluido de perfuração, a lama, entrar no reservatório. Os seguintes parágrafos descreverão brevemente o processo de perfuração e explicarão mais detalhadamente os problemas citados anteriormente.

O processo de perfuração é feito pela ação da rotação e do peso da coluna aplicados sobre uma broca. Para a broca ter uma maior vida útil e trabalhar com o melhor desempenho deve ser aplicada uma força calculada a partir da taxa de penetração e do desgaste da broca, estes parâmetros devem estar no intervalo especificado pelo fabricante da broca. No caso das brocas novas, as variações de força permitidas são mínimas para obter um melhor desempenho. O movimento da coluna pode gerar variações na força aplicada sobre a broca diminuindo a eficiência do processo, a vida útil da broca e em casos extremos chegando a danificá-la [3], [4]. 
O peso da coluna é o elemento que gera a força sobre a broca e transmite o movimento de rotação para a broca que se encontra na extremidade inferior da coluna. As profundidades atingidas pela perfuração tem magnitudes de $1 \mathrm{~km}$ a $10 \mathrm{~km}$ e o peso da coluna está na ordem de 500t. Quando a coluna está fixada na parte inferior do poço e o navio se movimenta são geradas grandes e variáveis tensões na coluna que podem produzir fadiga no material e flambagem ou encurvadura da coluna [5].

A interação da broca com a rocha gera fragmentos de rocha que são removidos constantemente através da lama. O fluido de perfuração é injetado por bombas para o interior da coluna de perfuração e retorna na superfície. Ao atingir a profundidade desejada, a coluna de perfuração é retirada do poço e uma coluna de revestimento de aço, de diâmetro inferior ao da broca, é descida no poço. O espaço entre os tubos de revestimento e o poço é cimentado com a finalidade de isolar as rochas atravessadas, permitindo então o avanço da perfuração com segurança. Após a operação de cimentação, a coluna de perfuração é descida no poço, tendo na sua extremidade uma nova broca de diâmetro menor que a do revestimento para o prosseguimento da perfuração [6].

Na perfuração, além da troca de broca mencionada anteriormente, existe outro procedimento que se chama manobra, no qual a broca fica sem peso por algum tempo. Esse procedimento é a conexão de um novo tubo de perfuração à coluna (o tamanho de um tubo varia entre $5,49 \mathrm{~m}$ e $16,50 \mathrm{~m}$ ), aumentando a massa da coluna. O procedimento se realiza do seguinte modo: a coluna é retirada e todo o peso dela é suportado pela sonda, especificamente pela mesa rotativa e em seguida é acrescentado um novo tubo na parte superior da coluna e ela é descida para continuar a perfuração do poço.

Durante o procedimento anterior e o procedimento de cimentação é retirada a coluna e são criadas pressões negativas, fenômeno este denominado pistoneio [7]. Se essa pressão for menor que a pressão dos fluidos confinados nos poros das formações e a formação for permeável ocorrerá influxo desses fluidos para o poço. Então, diz-se que o poço está em kick, caso contrário, o poço está em blow-out, ou seja, fluxo descontrolado de fluido do reservatório para a superfície [8].

Como já foram explicadas as consequências do movimento da coluna de perfuração, há necessidade de um sistema de compensação de heave que atenue as vibrações transmitidas pela sonda ao bloco de coroamento de maneira que a coluna de perfuração oscile o mínimo possível.

Os sistemas de compensação podem ser mecânicos [9], pneumáticos [10] ou hidropneumáticos [11]. O compensador projetado trabalha com o princípio da suspensão hidropneumática. Esta suspensão é muito usada na produção de carros pela empresa francesa Citroen [12]. No sistema hidropneumático, o típico conjunto mola/amortecedor em paralelo é substituído por um pistão hidráulico que se comunica com um cilindro de nitrogênio através de uma válvula. A frequência natural e o valor da rigidez da mola dos sistemas hidropneumáticos, também chamada rigidez do acumulador, variam de acordo com as variações da massa [13]. Por isso, uma válvula servocomandada é usada para mudar o valor do amortecimento, assim, o sistema consegue se adaptar melhor às variações de massa. 


\subsection{JUSTIFICATIVA DO TRABALHO}

Os compensadores semiativos e ativos precisam de sistemas elétricos, mecânicos, hidráulicos ou pneumáticos, na maioria das vezes sistemas complexos, como pode ser visto nas patentes em [3], [14]. Esses compensadores precisam de muita energia para trabalhar [15]. O sistema proposto não precisa de sistemas complexos e o consumo de energia é baixo, porque precisa apenas de uma servo válvula comandada para mudar o amortecimento do sistema. Em caso de falha mecânica ou elétrica, o compensador é robusto, pois a posição da válvula e amortecimento do compensador são mantidos constantes no último nível controlado, permitindo continuar com o processo de perfuração.

Além das vantagens de robustez e baixo consumo do controlador projetado neste trabalho, propõe-se um controle semiativo diferente para compensadores e um enfoque diferente na metodologia para projetar compensadores hidropneumáticos.

O controle semiativo projetado se diferencia dos controles encontrados na literatura em que o controle realizado mantêm as características do sistema constantes enquanto a massa não for mudada, ou seja, não controla diretamente a posição, velocidade ou aceleração como é realizado na maioria dos compensadores ativos e semiativos [15], [16], [17], [18].

Na metodologia usada normalmente para projetar sistemas hidropneumáticos, primeiro é escolhido o volume do acumulador e, como consequência, o desempenho. Esse volume é escolhido considerando o espaço disponível do sistema [13] ou de modo que o sistema atinja um comportamento aceitável com o menor volume possível [12] . A metodologia que foi usada neste trabalho tem como critério principal o melhor desempenho e como consequência, o tamanho do acumulador. Essa metodologia foi escolhida com a finalidade de projetar a melhor resposta teórica possível oferecida pelos dois sistemas estudados, calculando o tamanho do acumulador ao em vez de escolhê-lo.

\subsection{OBJETIVOS}

\subsubsection{Objetivo Geral}

Este trabalho tem como objetivo projetar um compensador de heave com duas configurações hidropneumáticas e realizar um controle semiativo para que o compensador se adapte às mudanças de massa da coluna. Consegue-se, assim, diminuir as oscilações transmitidas à coluna de perfuração, para as diferentes configurações da coluna de perfuração.

\subsubsection{Objetivos Específicos}

Estabelecem-se os seguintes objetivos específicos:

- Fazer a modelagem do sistema hidropneumático e do sistema hidropneumático em série com uma mola mecânica para obter as duas funções de transferência.

- Relacionar as funções de transferência dos sistemas com a função de transferência do filtro 
Butterworth passa baixas para que o compensador projetado possua os pólos desse filtro, pois este tem a resposta mais plana na faixa de passagem.

- Fazer o estudo de caso para um processo de perfuração de $6 \mathrm{~km}$ de profundidade, achar a resposta desejada do compensador e projetar o compensador.

- Desenvolver uma estratégia de controle semiativo que permita que a resposta em frequências do compensador para qualquer valor de massa seja similar à resposta em frequência no caso da massa de projeto.

- Simular o comportamento do compensador.

\subsection{METODOLOGIA}

A metodologia utilizada no desenvolvimento do presente trabalho é a seguinte:

- Determinar o modelo matemático que descreve o comportamento do sistema hidropneumático sem mola mecânica e o comportamento do sistema hidropneumático em série com uma mola. Depois, obter as funções de transferência dos sistemas e a função que caracteriza as mudança no sistema ao ser modificada a massa suportada pelo compensador.

- Estudar as caraterísticas da resposta em frequência para que os compensadores tenham um comportamento ideal e projetar os filtros de Butterworth para obter esse comportamento.

- Colocar os parâmetros dos compensadores em função dos parâmetros do filtro de Butterworth que foi encontrado no item anterior. Achar os valores dos parâmetros para que o denominador da função de transferência do compensador seja equivalente ao filtro de Butterworth e poder atingir o comportamento desejado.

- Fazer um estudo de caso para um processo de perfuração de $6 \mathrm{~km}$ extraindo as variáveis importantes e seus possíveis intervalos durante esse processo e, baseado nisso, projetar o compensador com os polos sugeridos pelo filtro de Butterworth para uma massa na qual exista um compromiso entre o comportamento desejado e o volume do acumulador.

- Desenvolver uma estratégia de controle semiativo para manter o comportamento desejado dos compensadores quando a massa da coluna é modificada, através de uma válvula servo comandada que permite mudar o valor de amortecimento do sistema.

- Simular a resposta em frequência do compensador e ao degrau com controle e sem controle para a massa máxima e mínima do processo de perfuração, Analisar e comparar as respostas obtidas.

\subsection{ESTRUTURA DO DOCUMENTO}

O documento apresentado encontra-se dividido em sete capítulos: no Capítulo 2 é apresentada a revisão bibliográfica onde se apresentam e definem conceitos que são fundamentais para a abor- 
dagem e compreensão da dissertação; no Capítulo 3 é realizada a modelagem matemática para os dois compensadores, chegando à função de transferência de cada um destes, além disso, encontra-se a função que descreve a variação dos parâmetros do compensadores quando a massa suportada é modificada; no Capitulo 4 descreve as estratégias de controle para os dois compensadores, tentando manter o comportamento quando a massa é mudada.

A parte mais analítica é feita nos seguintes capítulos: no Capítulo 5 o estudo de caso, onde se descreve o comportamento desejado do compensador, as condições de trabalho e explica-se como foi projetado cada parâmetro do compensador. O Capítulo 6 mostra os resultados obtidos na simulação da resposta para os dois compensadores com e sem controle para a máxima e mínima massa suportadas pelo compensador, terminando com as análises das respostas obtidas. As conclusões do trabalho e algumas propostas para trabalhos futuros são apresentadas no Capítulo 8 . 


\section{Capítulo 2}

\section{REVISÃO BIBLIOGRÁFICA}

\subsection{SISTEMAS DE SUSPENSÃO}

Os sistemas de suspensão permitem um deslocamento relativo entre o objeto suportado e a base. Estes sistemas de suspensão são utilizados em diferentes aplicações diariamente, sem que as pessoas percebam. Por exemplo, os carros têm complexos sistemas de suspensão, as bicicletas têm sistemas simples de suspensão e muitas cadeiras de escritorio são munidas de uma mola de gás.

O sistema de suspensão das bicicletas são os pneus e atuam como uma mola. Se eles têm uma quantidade apropriada de ar, a viagem vai ser mais confortável. Quando os pneus têm menos quantidade de ar, o ciclista vai sentir os choques das rodas com as irregularidades da estrada. Se os pneus têm mais ar, os choques vão ser transferidos diretamente ao ciclista.

Assim, pode-se definir um dos objetivos dos sistemas de suspensão: proteger dos movimentos e das acelerações da base (estrada, roda) os componentes da parte isolada (motorista, chassis). Algumas partes mecânicas do lado isolado podem danificar-se ao suportar frequências e acelerações e o ser humano pode sentir-se desconfortável, cansado ou vir a adoecer (gastrite, problemas cardíacos, doenças de movimento) se tiver que suportar frequências de vibrações (desde $0.1 \mathrm{~Hz}$ até $0.5 \mathrm{~Hz}$, enjôo) e valores de acelerações por muito tempo $\left(0.5 \mathrm{~m} / \mathrm{s}^{2}\right.$ desconfortável, $2 \mathrm{~m} / \mathrm{s}^{2}$ extremamente desconfortável) [13]. Então, o sistema de suspensão se projeta para garantir o isolamento das vibrações, obtendo conforto e respeitando a saúde do motorista, além de prevenir danos nos componentes mecânicos da parte isolada.

Os sistemas atuais de suspensão para carros têm complexos sistemas eletrônicos de monitoramento e de controle, mas na essência, todo sistema de suspenção equivale a uma mola e um amortecedor. A mola, devido sua propriedade elástica, seria sozinha capaz de desacoplar e compensar os movimentos e as acelerações da parte de entrada, mas devido a seu deslocamento, a mola armazena energia. Daí surge o problema de como dissipar essa energia.

Para o sistema composto só por uma mola, sem amortecedor, o decaimento é baixo, pois o amortecimento deve-se ao fato de a mola real não é totalmente elástica. Porém, gera-se um movimento oscilatório permanente ou de decaimento lento (Figura 2.1). 


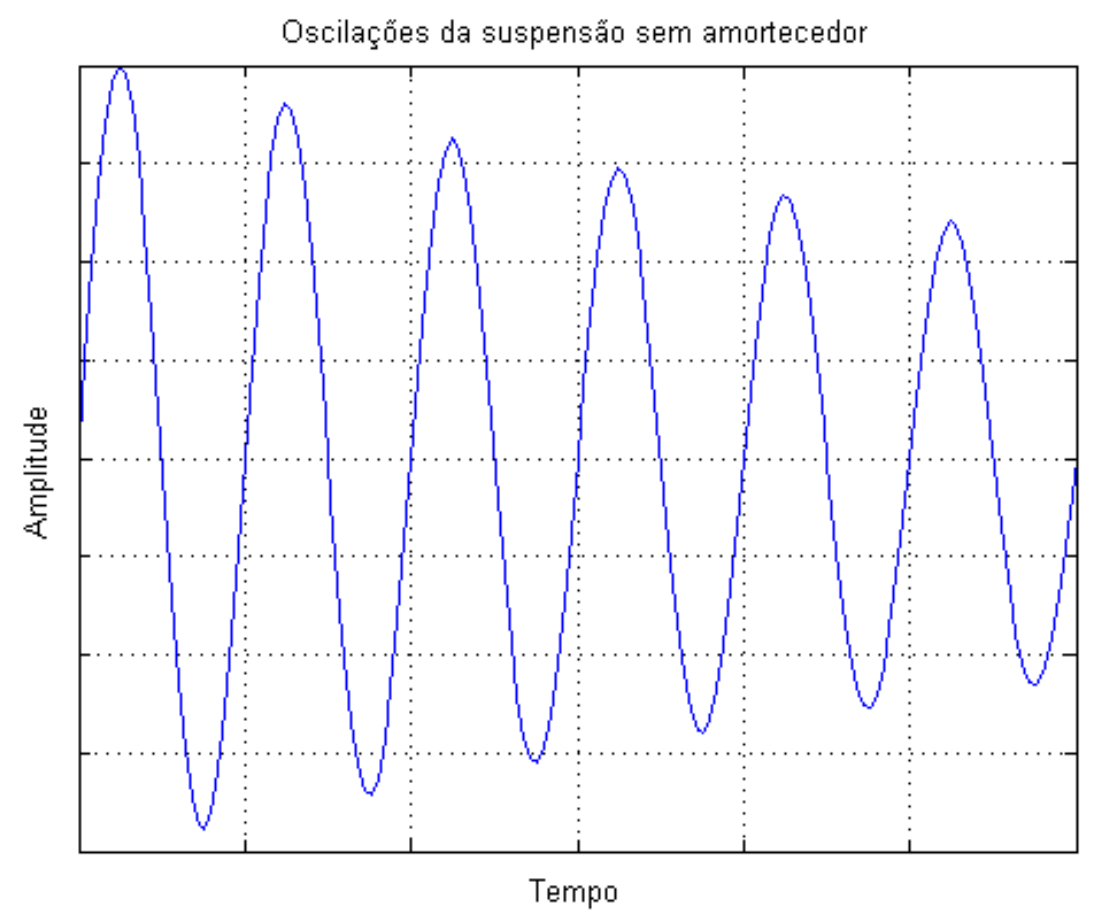

Figura 2.1: Oscilação do sistema sem amortecedor

Por isso, as molas são usadas junto com os amortecedores. O amortecedor transforma em calor a energia que foi armazenada pela mola e a amplitude da oscilação decai (Figura 2.2). Se o amortecimento for grande, o decaimento será rápido. A maioria dos amortecedores é do tipo hidráulico e usa o deslocamento de um fluido para gerar as forças de amortecimento. Nos sistema de suspensão, normalmente o amortecedor e a mola estão em paralelo.

Uma mola e um amortecedor em paralelo (Figura 2.3) constituem um sistema de suspensão. Se ao sistema se introduz uma perturbação de entrada, ela se transmite pela mola e pelo amortecedor, perdendo energia e depois atinge a massa que se deseja isolar. Por isso que a resposta de deslocamento e de aceleração é menor em comparação com os sinais da entrada [13].

\subsection{CLASSIFICAÇÃO DE SISTEMAS DE SUSPENSÃO}

Os sistemas de suspensão podem ser classificados em: suspensão passiva, suspensão adaptativa, suspensão semiativa e suspensão ativa. Esta classificação tem relação com a quantidade de energia usada pelo sistema [19]. Essa energia pode ser fornecida por uma bomba hidráulica, um circuito elétrico ou só elementos como válvulas. Com o uso de energia, as suspensões podem atingir um maior desempenho. A região de trabalho no grafico da Figura 2.4 é a força que precisaria gerar o sistema para os valores de velocidade ou de deslocamento da massa, afim do sistema apresentar a resposta ótima. Na Figura 2.4 a área trabalho esta representada pela cor cinza, no eixo X se tem a velocidade ou o deslocamento e no eixo Y se tem a força. 


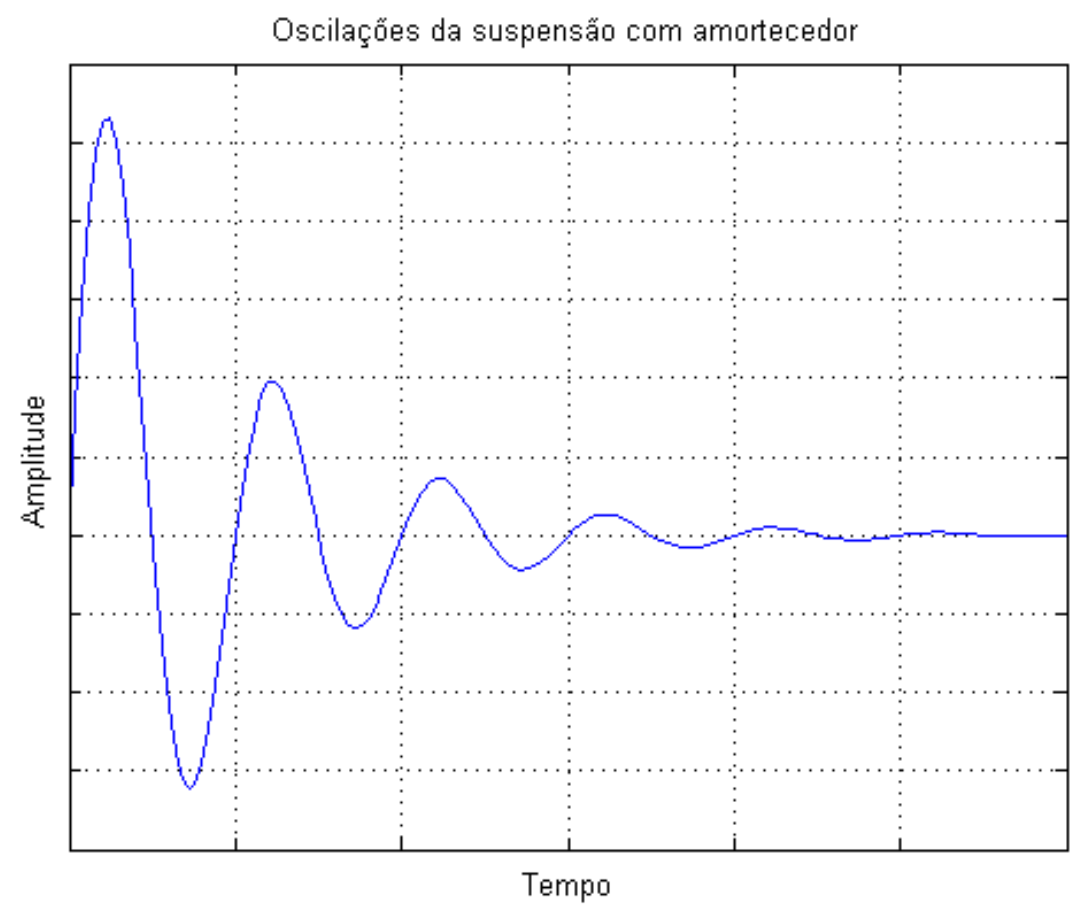

Figura 2.2: Oscilação da suspensão com amortecedor

\subsubsection{SUSPENSÃO PASSIVA}

O sistema de suspensão passiva não precisa de uma fonte externa de energia. A desvantagem desse sistema é que não se pode mudar o valor da rigidez do acumulador nem o valor do amortecimento. Como consequência, o desempenho, que está representado pela curva da Figura 2.4 a, é muito restrito. Observa-se que é atingida apenas uma das infinitas opções de força para cada deslocamento ou velocidade.

\subsubsection{SUSPENSÃO ADAPTATIVA}

A suspensão adaptativa tem a mesma área de trabalho da suspensão passiva, mas se observa na Figura 2.4 b que o sistema adaptativo tem uma área maior de desempenho (área entre as duas curvas), o que quer dizer que para uma posição ou uma velocidade se pode gerar uma força entre um intervalo no mesmo sentido que o deslocamento. Esta capacidade se deve à possibilidade de o sistema de suspensão adaptativa mudar suas características.

\subsubsection{SUSPENSÃO SEMIATIVA}

O sistema de suspensão semiativa diferencia-se do sistema adaptativo na medida em que precisa de mais energia para mudar a força mediante a variação da rigidez da mola, mas as mudanças são mais rápidas. Além disso, é possível mudar o valor do amortecimento. Na Figura 2.4 c observa-se que a resposta é quase a mesma. 


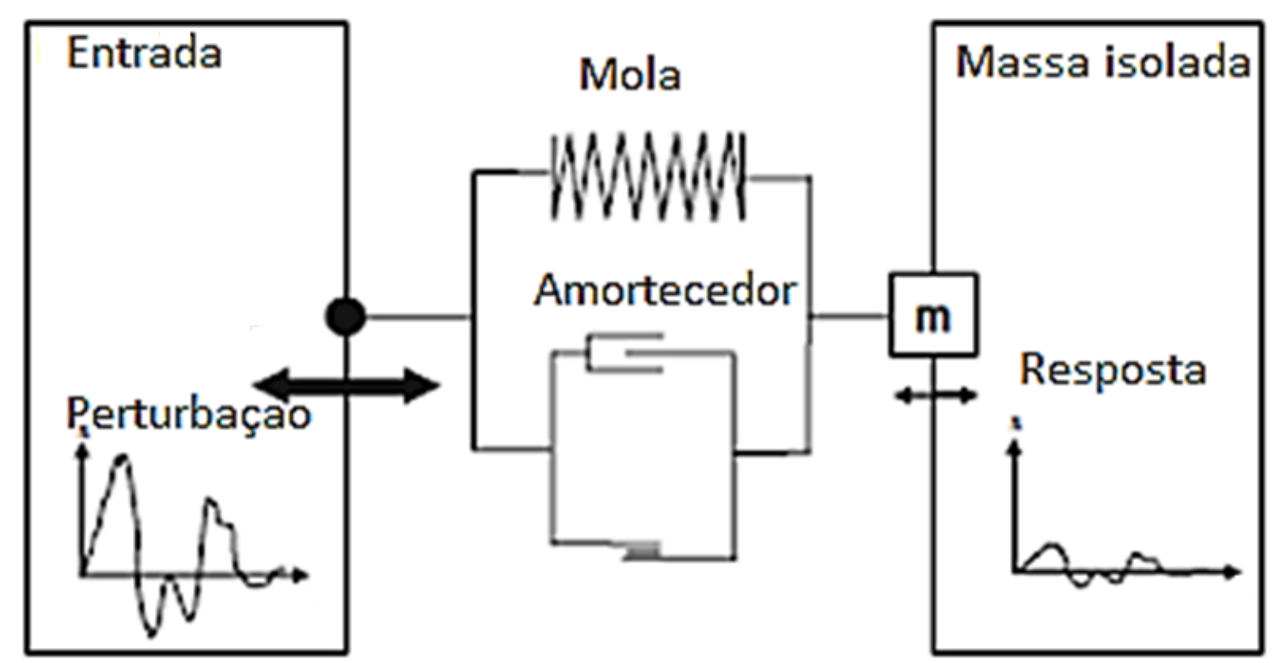

Figura 2.3: Configuração geral de um sistema de suspensão

\subsubsection{SUSPENSÃO ATIVA}

O sistema ativo pode trabalhar em qualquer quadrante (Figura $2.4 \mathrm{~d}$ ), a área de trabalho é tão grande quanto a área de desempenho porque é o único sistema que pode gerar forças positivas e negativas, sem importar o sentido do deslocamento. Este sistema tem a capacidade de armazenar, dissipar e introduzir energia no sistema; pelo que precisa sempre de uma fonte de potência externa e, dependendo da aplicação, pode consumir muita energia, como no caso dos compensadores de heave [15].

\subsection{TIPOS DE SUSPENSÃO}

Há três tipos de suspensão mais comuns: sistemas de suspensão pneumáticos, sistemas de suspensão mecânica e sistemas de suspensão hidropneumáticos. Além desses três, existem outros tipos como o colchão de ar e suspensão magnética que são usados em aplicações muito específicas.

Na continuação, descrevem-se brevemente as partes básicas de cada sistema e comparam-se alguns parâmetros importantes para os três sistemas. Esses parâmetros são: o controle de altura, o custo do sistema, a manutenção, as dimensões, a variação da rigidez da mola, o amortecedor. A Tabela 2.1 resume a comparação dos sistemas para os parâmetros anteriores.

O sistema de suspensão mecânica clássica é uma mola em paralelo com um amortecedor. As molas podem trabalhar por flexão (feixes de mola) ou por torção (mola helicoidal) [20]. Na maioria dos sistemas mecânicos, não se consegue adaptar o valor da altura nem mudar a rigidez da mola sem adicionar outros elementos. Consegue-se mudar a altura só para sistemas com grande nível de automação ou complexidade. Por exemplo na patente de Ohki [21], que tem duas molas em série e um mecanismo para escolher o espaço que vai ter cada uma. $\mathrm{O}$ valor econômico de sistemas mecânicos é o menor entre os três, devido a que são os mais antigos e otimizaram-se especialmente 

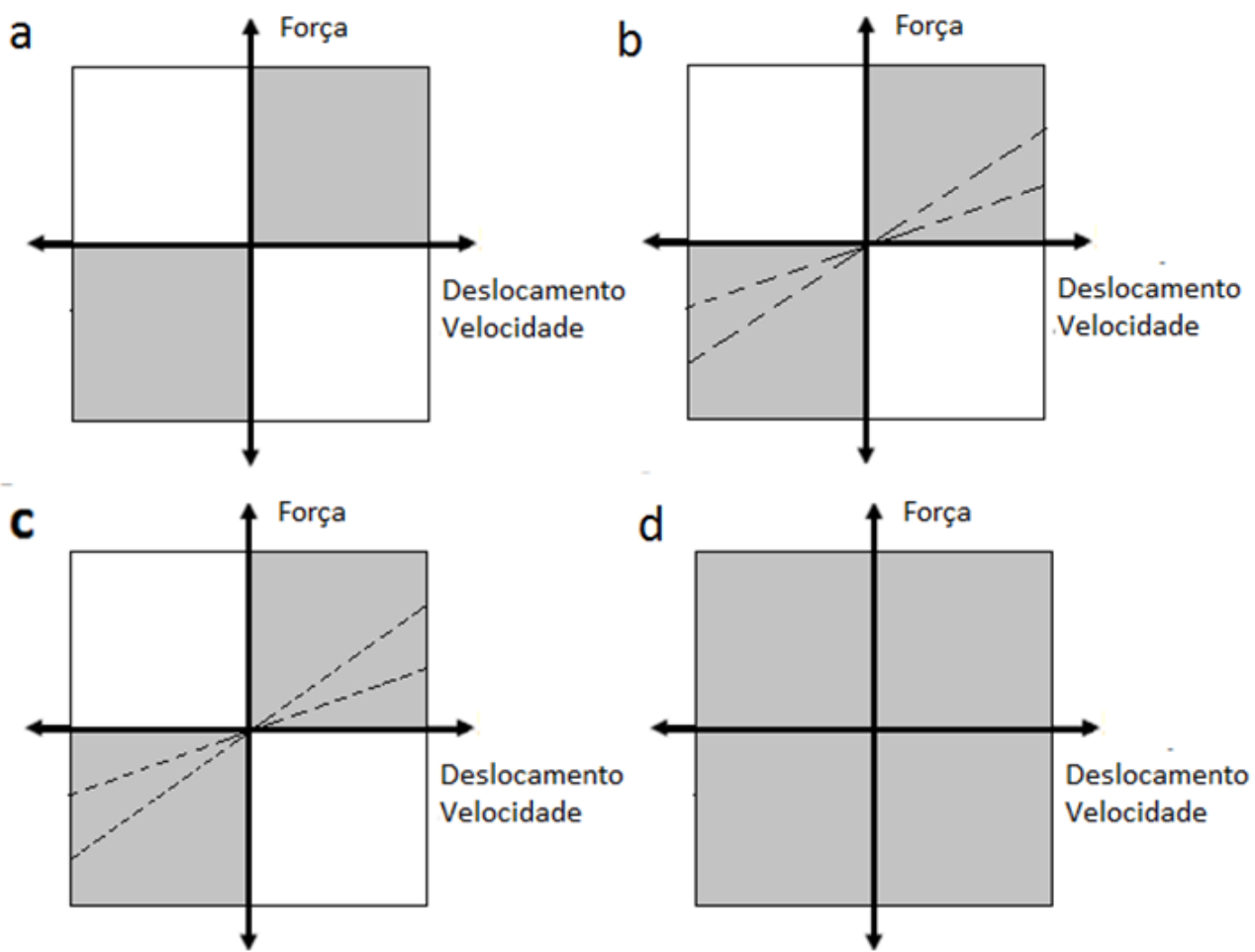

Área de trabalho é representada pela cor cinza.

Figura 2.4: Área de desempenho sistemas de suspensão: a) Passiva, b) Adaptativa, c) Semiativa, d) Ativa [19].

no preço. Estes sistemas precisam de pouca manutenção: só trocar o óleo do amortecedor será suficiente, mas a dimensão é maior que nos outros sistemas.

No sistema de suspensão pneumática, a típica mola mecânica é trocada por um acumulador de ar. Isso permite, ao variar a quantidade de ar, o sistema se adaptar na altura desejada. Além disso, ao mudar o valor da rigidez da mola possibilita adaptar as diferentes condições de desempenho ou variações de massa isolada. Este sistema é complexo e de valor elevado porque precisa de vários componentes e de ar comprimido para seu funcionamento. Suspensões pneumáticas precisam de muita manutenção porque a sujeira e as pequenas partículas devem ser filtradas do ar e este ar deve ser trocado depois de um certo número de horas de uso. Os sistemas pneumáticos têm a mesma dimensão que os sistema mecânico, mas precisa mais componentes para o controle de altura.

No sistema de suspensão hidropneumática, troca-se a mola da suspensão mecânica por uma esfera com uma membrana que divide uma parte de ar de uma de líquido. O líquido vai da esfera até um cilindro e o fluxo deste líquido se limita, conseguindo-se, desse jeito, o amortecimento do sistema. Alterando a quantidade de líquido pode se adaptar a altura (o funcionamento será explicado melhor na frente). Este sistema como o sistema pneumático é complexo e de valor elevado em comparação com as suspensões mecânicas. A diferença com o sistema pneumático é que o elemento que vai ser injetado para controlar o nível será um óleo e não ar. 
Tabela 2.1: Comparação tipos de suspensão: ++ muito bom, + bom, 0 aceitável, e - ruim [13].

\begin{tabular}{c|c|c|c}
\hline & $\begin{array}{c}\text { Suspensão } \\
\text { Mecânica }\end{array}$ & $\begin{array}{c}\text { Suspensão } \\
\text { Pneumática }\end{array}$ & $\begin{array}{c}\text { Suspensão } \\
\text { Hidropneumática }\end{array}$ \\
\hline Rigidez da Mola & 0 & ++ & ++ \\
Amortecimento & ++ & ++ & + \\
Controle de Nível & - & + & ++ \\
Custo & ++ & 0 & - \\
Dimensões & 0 & - & + \\
Manutenção & + & 0 & 0 \\
\hline
\end{tabular}

A dimensão do sistema hidropneumático é a menor dos três sistemas, pois integra a variação do nível no mesmo sistema e trabalha com pequenos cilindros e altas pressões, devido ao princípio hidropneumático com que trabalha. Além disso, não precisa que a esfera e o cilindro estejam juntos. A manutenção dos sistemas hidropneumáticos consiste em primeiro verificar, a pressão no gás, porque pela membrana pode-se gerar difusão e a pressão do gás cair; o segundo é trocar o óleo quando sua viscosidade tenha mudado. Por suas vantagens em espaço, controle de nível e variação do valor de amortecimento, os sistemas de suspensão hidropneumáticos são encontrados na indústria de veículos como na Citroen [12], na agricultura para uso de máquinas agrícolas [22], em tratores [23] e em sistemas offshore como compensadores de heave.

Foram descrito os sistemas de suspensão. Logo, com o objetivo de ter uma ideia mais clara do comportamento dos sistemas projetam-se os três sistemas de suspensão com o mesmo valor de rigidez da mola, a mesma carga e a mesma posição de operação. Esta posição se escolhe na metade do cilindro entre os limites físicos de deslocamento [13]. Para os sistemas de suspensão projetados, se analisaram a frequência natural e a rigidez da mola quando a carga do sistema varia, e o valor da força quando se desloca o sistema do ponto de operação.

A Figura 2.5 mostra a força da mola versus o deslocamento. A força é linearmente proporcional para a mola mecânica e tem sempre a mesma rigidez dentro dos limites físicos da mola. Nos sistemas com gás, há variações não lineares quando as oscilações estão perto do ponto de projeto; as não linearidades não são tão grandes, mas quando a amplitude é maior, o valor da força é muito maior prevenindo o sistema de danos por atingir o fim do curso do pistão. O sistema hidropneumático tem um comportamento similar ao pneumático, mas o comportamento é simétrico com referência ao ponto de operação [13].

Na Figura 2.6, a rigidez da mola versus a carga. A mola mecânica tem sempre a mesma rigidez, sem importar o valor da massa. A variação na rigidez para sistemas pneumáticos é linear e para os sistemas hidropneumáticos é quase quadrática. Isso se devendo ao diferente jeito de ajustar a posição. Quando altera a massa isolada no sistema pneumático, deve-se introduzir gás na bolsa de ar gerando variações no volume e na pressão do gás. No caso hidropneumático, a medida que a massa é modificada, deve-se introduzir óleo no cilindro modificando o volume do ar da esfera. Mas a massa do ar permanece constante permitindo pequenas mudanças de volume para grandes 


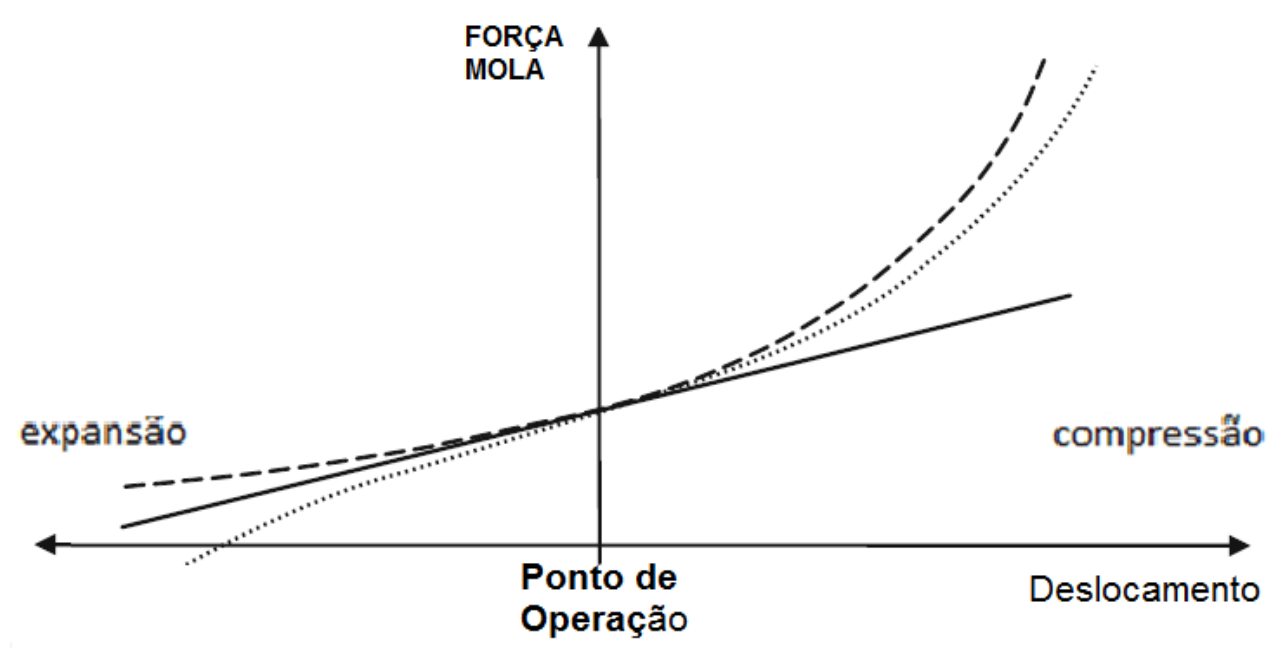

— Mecânico --- Pneumático -.....-Hidropneumático

Figura 2.5: Força da mola vs Deslocamento (modificado [13])

mudanças de carga.

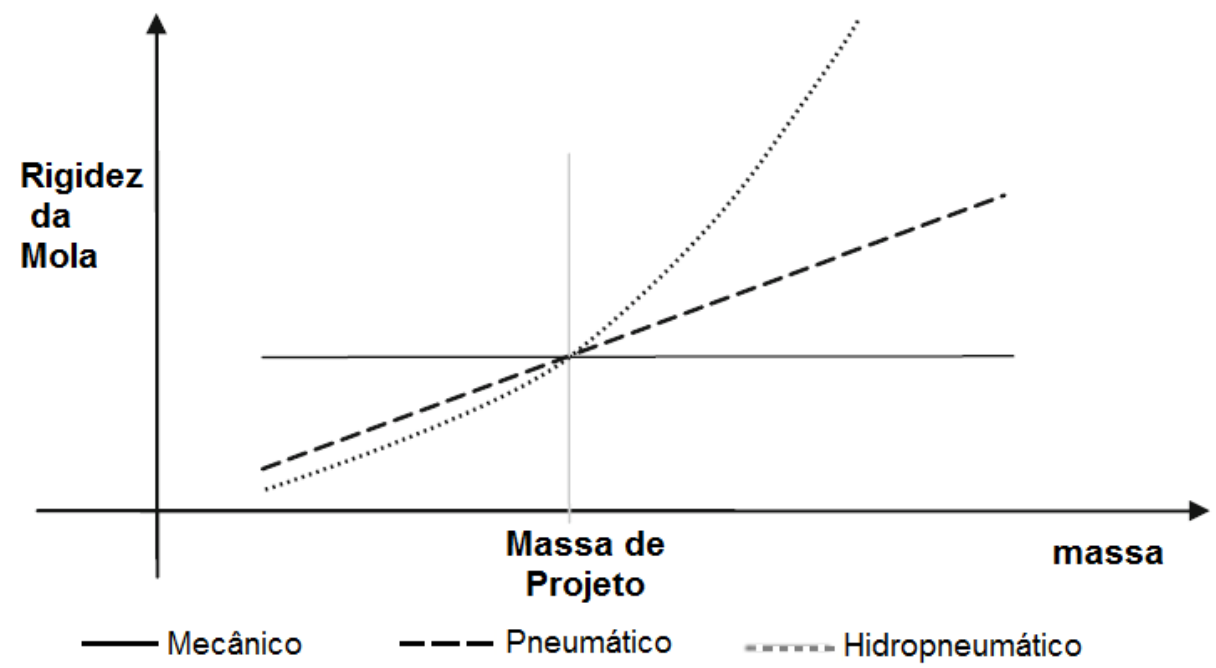

Figura 2.6: Rigidez da Mola vs Massa Suportada (modificado [13])

Na Figura 2.7, a frequência natural versus a massa suportada, a frequência do sistema pneumático fica constante, independente do valor da massa suportada. Para os sistemas mecânico e hidropneumático, a frequência natural do sistema varia, o que não é muito conveniente, porque para isolar o sistema, as frequências de entrada não devem estar no intervalo das possíveis frequências naturais, pois o sistema pode entrar em ressonância. 


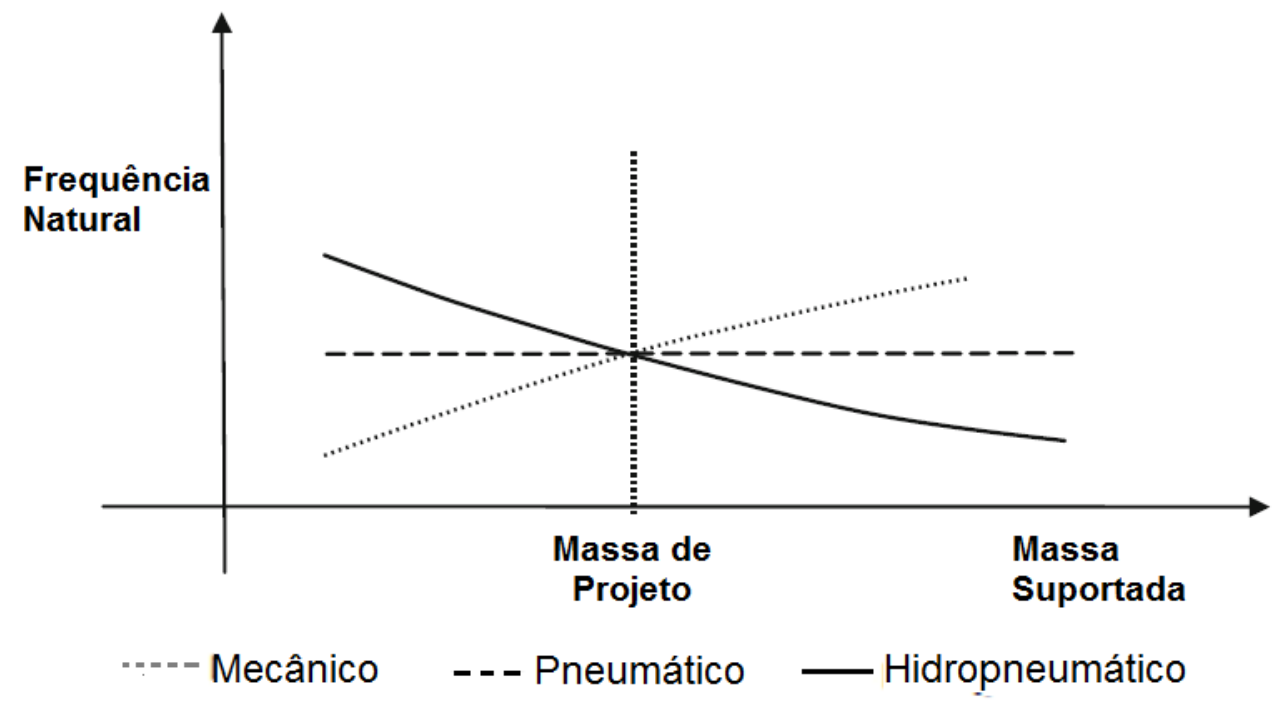

Figura 2.7: Frequência natural do sistema vs Massa suportada (modificado [13])

\subsection{SISTEMAS DE SUSPENSÃO HIDROPNEUMÁTICO}

O primeiro modelo de suspensão surgiu no século XVI nas carruagens. Estas eram constituídas de barras de metal curvadas e ficavam presas no eixo das rodas e nas extremidades da carroceria [22]. Anos mais tarde, com a invenção do carro, os sistemas de suspenção tiveram que melhorar; como opções apareceram as suspensões pneumáticas e, depois, as suspensões hidropneumáticas.

O primeiro carro com sistema de suspenção hidropneumático foi produto de uma pesquisa das empresas alemãs, Frieseke e Hopfner e Borgwald [24]. Obviamente, antes muitos outros veículos militares tiveram sistemas hidropneumáticos, mas estes tinham problemas e vida curta dos componentes mecânicos [19].

Nos anos 50, a empresa automotiva Citroen iniciou o uso de sistema de suspenção hidropneumático não pré-carregado [13]. Essa empresa continuou usando esses sistemas, melhorando-os e integrando-os as novas tecnologias da eletrônica. Atualmente, os carros da Citroen seguem usando suspensões hidropneumáticas e se destacam por serem confortáveis e terem bom comportamento na estrada [12].

O sistema de suspensão hidropneumática não pré-carregado desenvolvido pela Citroen tem o seguinte princípio de funcionamento: a esfera contém um gás e um óleo, divididos por uma membrana. A esfera está conectada a um cilindro instalado entre a parte a isolar e a parte do suporte. O cilindro bombea o óleo da esfera para o cilindro e vice-versa, conforme o sentido do movimento.

No sentido ascendente do fluido, o pistão se desloca na mesma direção, fazendo com que o óleo do cilindro seja bombeado para a esfera, mas antes, passa pelo amortecedor, que dissipa energia cinética do fluído em calor (como o fluido é viscoso há friç̧ão). Então, na esfera, o gás se comprime e a pressão aumenta (Figura 2.8 a). No sentido descendente do fluido, o embolo do cilindro se 
movimenta no sentido descendente fazendo com que o óleo da esfera seja bombeado para o cilindro, mas antes passa pelo amortecedor. Finalmente, o fluido chega à esfera, em seguida o gás se expande e a pressão diminui (Figura $2.8 \mathrm{~b}$ ).
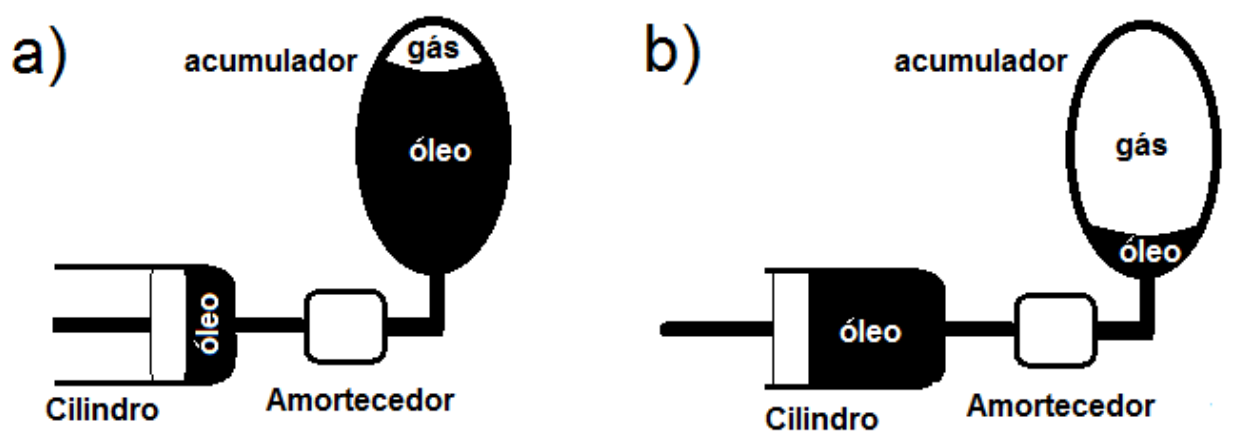

Figura 2.8: Esquema Suspensão. A) Compressão. B) Expansão

Agora, as principais partes do sistema serão descritas. Estas partes são o cilindro, a esfera e o amortecedor. O cilindro é o transmissor de carga, transmite a força no eixo longitudinal entre a parte isolada e a parte de entrada protegendo a massa suspensa. O tamanho do cilindro é muito importante, pois a área do cilindro define a pressão do trabalho, sendo que esta pressão é inversamente proporcional à área. A altura do cilindro define os pontos limites da perturbação de entrada, ou seja, o valor mínimo e máximo que pode atingir o deslocamento relativo entre a base e o objeto suspenso.

O acumulador é o elemento que fornece a propriedade elástica para a função da mola. Seu interior se divide em duas partes, uma para o gás e outra para o óleo. O gás deve ser compressível, comumente são usados nitrogênio ou tetrafluormetano CF4 [13]. Esses gases são responsáveis pelo valor da rigidez do acumulador e pelo volume do acumulador que geralmente é o elemento de maior tamanho na suspensão hidropneumática.

O amortecedor como já foi mencionado é um meio de gerar forças dissipativas. O amortecedor pode ou não ser variável. Caso seja variável, permite uma melhor adaptação do sistema às variações de massa e ao sinal de entrada. O principio físico com que trabalha o amortecedor usualmente é o principio de fricção. Pode ser fricção de contorno ou fricção do fluido, também chamado atrito viscoso. A fricção de contorno aparece pelo contato entre duas superfícies, como o deslocamento do pistão, e a friç̧ão hidráulica aparece quando se coloca um elemento que se opõe à passagem, se colocando entre a linha de fluido que comunica o acumulador e o cilindro. $\mathrm{O}$ amortecedor do compensador projetado é variável e varia a resistência ao fluxo. 


\subsection{SISTEMA DE SUSPENSÃO HIDROPNEUMÁTICO EM SÉ- RIE COM UMA MOLA MECÂNICA.}

Atualmente, a suspensão hidropneumática básica continua funcionando com um acumulador, um cilindro e um amortecedor, mas se têm desenvolvido diferentes configurações e até complexas estruturas, conforme a patente [25]. Uma das configurações mais conhecidas é o sistema hidropneumático com pré-carga, ouseja, tendo um sistema hidropneumático em paralelo com uma mola mecânica ou uma mola pneumática ou outro sistema hidropneumático [13]. Outra configuração menos conhecida é o sistema hidropneumático em série com uma mola. Esta é uma das duas configurações com que foi projetado o compensador.

O sistema hidropneumático em série com uma mola foi desenvolvido pela Citroen em 1983 para o modelo de carro $B X$. Este sistema tem sido estudado principalmente em aplicações de suspensões de carros e suspensões de tratores. O desempenho desta configuração é mostrado sempre em companhia de um controle. Portanto o desempenho do sistema sozinho não é muito estudado. A resposta do sistema só é aceitável depois de aplicar um controle. A modelagem do sistema é feita com grafos ou com equações diferenciais, [26], [27], [28]. Para realizar essa modelagem devem-se conhecer as partes do sistema e o funcionamento.

As partes do sistema hidropneumático em série com uma mola são mostradas na Figura 2.9. As partes constituentes deste sistema são quase as mesmas das partes do sistema hidropneumático clássico: um acumulador, um amortecedor e um cilindro, mas além dessas partes há uma mola em série. Esta mola mecânica encontra-se entre a saída do sistema hidropneumático e a massa a isolar. A parte da entrada do sistema hidropneumático continua inalterada.

O funcionamento do sistema com a mola em série é o mesmo que o funcionamento do sistema clássico, a diferença é que a atenuação do sinal de saída não se transmite diretamente à massa isolada, antes deve passar pela mola. Esta mola com suas propriedades elásticas permite um desacoplamento entre o sinal de saída do sistema hidropneumático e a massa isolada, dando a possibilidade de diminuir as acelerações transmitidas à massa. Um valor muito grande de rigidez aproxima o sistema com mola em série ao sistema hidropneumático simples.

\subsection{FILTROS}

Um filtro é um sistema que modifica um sinal que o cruza. Em essência, um filtro converte uma entrada numa saída que contêm só algumas caraterísticas desejadas do sinal de entrada, atenuando ou, no caso ideal, excluindo da saída as caraterísticas indesejadas [29].

Os filtros podem ser classificados dependendo da característica desejada no sinal de saída. Se for desejado só um intervalo de frequências, os filtros são classificados em passa baixa, passa faixa, passa alta, e rejeita faixa. Neste trabalho usa-se um filtro passa baixa que permite passar as frequências até um limite de frequência superior, chamado frequência de corte. O intervalo de frequências que podem passar, se chama faixa de passagem (parte cinza no Figura 2.10). O 


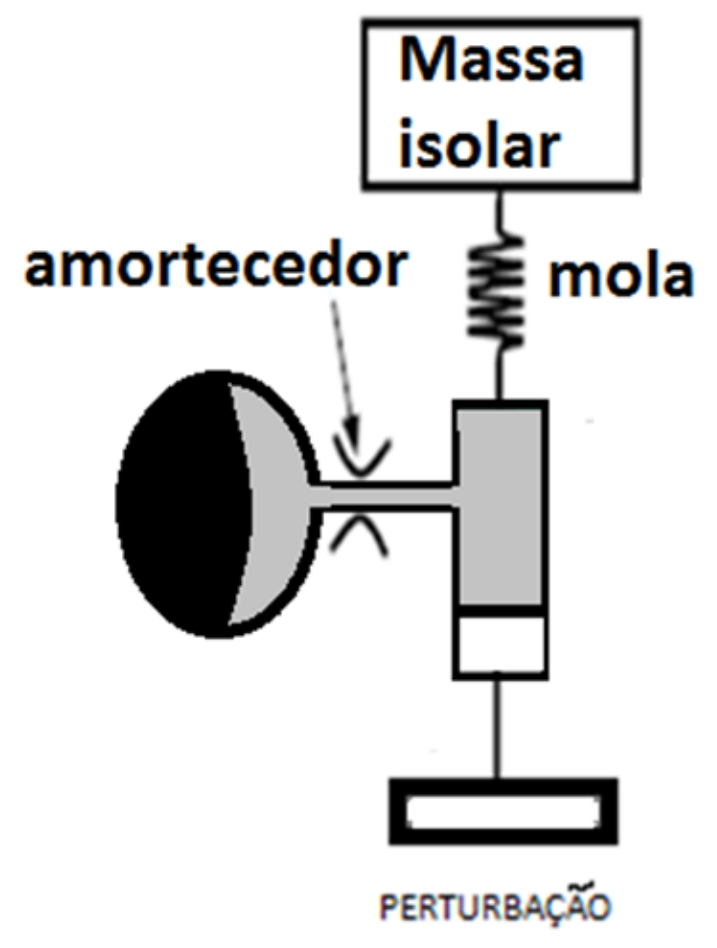

Figura 2.9: Suspensão Sistema Hidropneumático com mola mecânica.

intervalo de frequências excluidas, se chama faixa de rejeição.

Na Figura 2.10 a mudança entre a faixa de passagem e faixa de rejeição é imediata, isso só acontece com os filtros ideais. Infelizmente, os filtros ideais não são fisicamente realizáveis. Os filtros reais tem uma faixa de transição entre a faixa de passagem e faixa de atenuação e consequentemente, a mudança entre faixas não é instantânea. O comportamento do sistema nas faixas pode-se descrever mediante uma função de transferência, Equação (2.1). Esta relaciona a saída em função da entrada.

$$
\frac{S_{\text {saida }}}{S_{\text {entrada }}}=\frac{1}{1+s}
$$

O máximo expoente do denominador da função de transferência é equivalente à ordem do filtro. A ordem do filtro, o número de zeros, e a posição de polos e zeros no plano complexo determinam o tipo e a qualidade da resposta em frequência do filtro. Entre as muitas funções de transferência que podem atingir a resposta em frequência desejada, existem famílias cujo desempenho é bem conhecido e tem sido bem estudado [29]. As famílias de filtros analógicos mais conhecidas são: filtro de Bessel, filtro de Chebyshev, filtro elíptico e filtro de Butterworth. A Figura 2.11 mostra a resposta em frequência para as quatro famílias. Cada filtro tem a mesma frequência de corte, $\mathrm{e}$ são de ordem 5.

Cada família de filtros tem características na resposta em frequência que a distinguem das outras. Os filtro de Chebyshev tem oscilações na faixa de passagem (Chebyshev tipo 1) ou na faixa de rejeição (Chebyshev tipo 2). O filtro elíptico tem oscilações na faixa de passagem e na faixa 


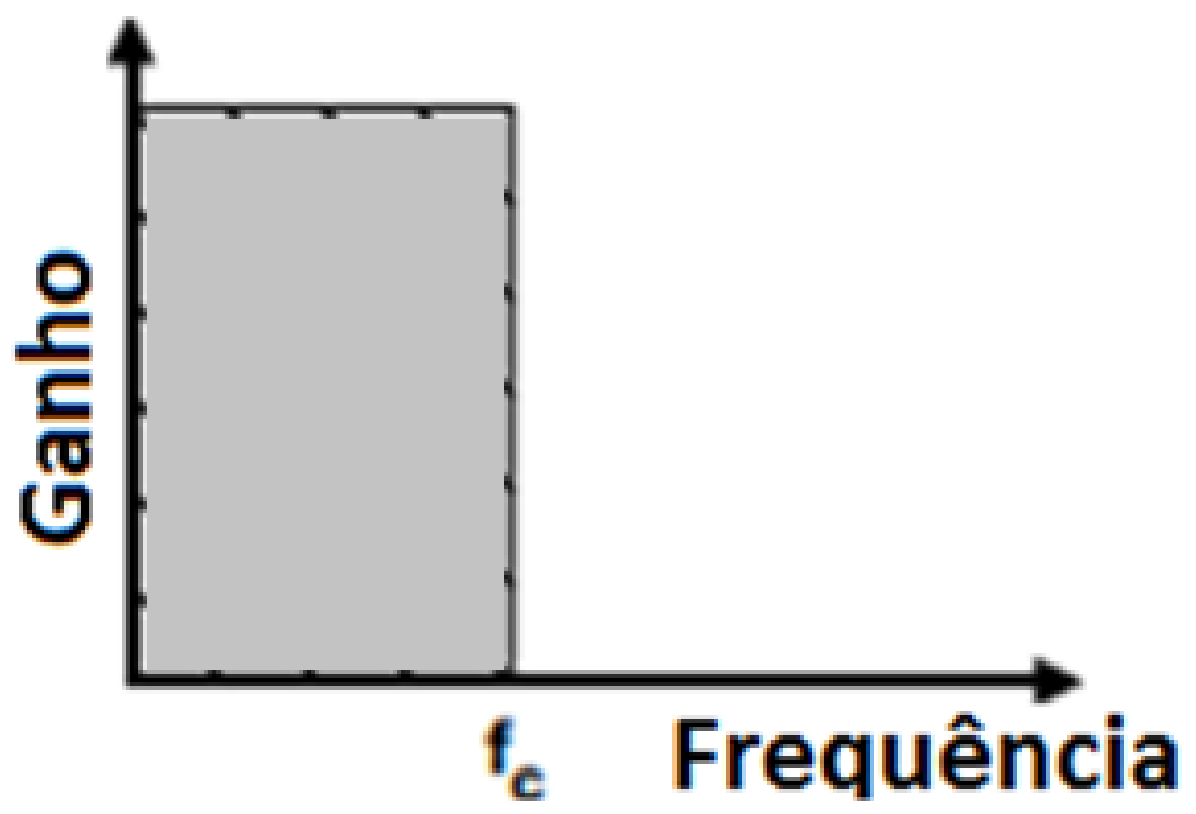

Figura 2.10: Filtros passa baixa.

de rejeição e sua queda na faixa de passagem é a mais abrupta dos quatro filtros. O filtro de Butterworth e o filtro de Bessel não têm oscilações em nenhuma das faixas, mas o último tem uma baixa atenuação da amplitude na faixa de transição porque seu principal objetivo é manter a fase linear. O compensador foi projetado para obter um comportamento similar ao do filtro passa baixa de Butterworth, sem oscilações em nenhuma das faixas e com uma atenuação aceitável durante a faixa de transição.

\subsubsection{FILTRO DE BUTTERWORTH}

O filtro de Butterworth foi primeiramente descrito pelo engenheiro britânico S. Butterworth em 1930 [31]. A aproximação usada para o filtro passa baixa de Butterworth é o conjunto de funções de Butterworth representada por $B$. Esta função é o quadrado da magnitude $H$ em função da frequência e da ordem do filtro, $w$ e $N$ respectivamente.

$$
B(w)=|H(j w)|^{2}=\frac{1}{\left(1+w^{2 N}\right)}
$$

A Figura 2.12 mostra que quando a ordem do filtro Butterworth é maior, a resposta é similar à resposta do filtro ideal passa baixa; e quando a ordem do filtro Butterworth é menor, a faixa de transição aumenta, o que quer dizer que a resposta se afasta do filtro ideal.

O filtro de Butterworth, sem importar a ordem, tem algumas propriedades que o caracterizam. A primeira propriedade é que a magnitude decresce monotonamente para frequências maiores do que zero. Por isso tem um valor máximo de amplitude de $1 \mathrm{~dB}$ e acontece em $w=0$, um valor 

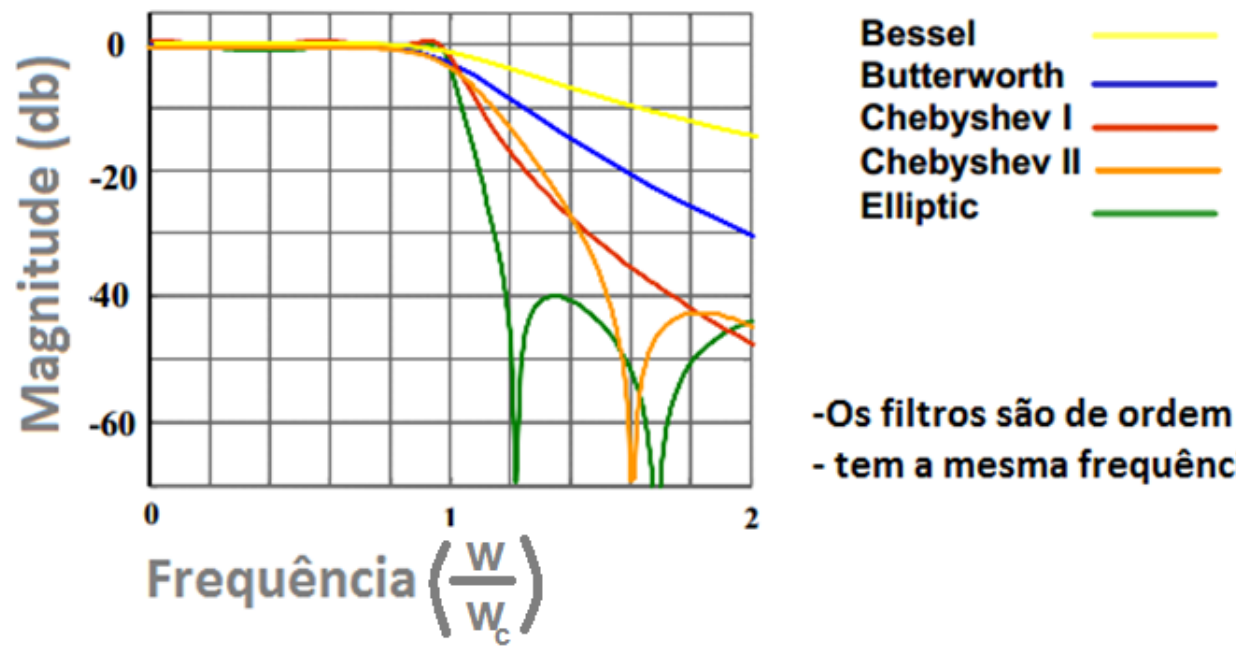

Figura 2.11: Familia de filtros [30].

mínimo de 0 em $w=\infty$ e um valor de $0.5 \mathrm{~dB}$ ou $-3 \mathrm{~dB}$ para a frequência de corte. A propriedade das derivadas diz que as primeiras $(2 N-1)$ derivadas serão iguais a zero para $w=0$. À vista disso, a resposta em frequência é maximamente plana na faixa de passagem e o ganho é unitário nessa banda. A última propriedade se refere à função de transferência do filtro, o valor do numerador é um e os polos estão localizados a uma distância equidistante do centro do plano complexo (Figura $2.13)$.

Para obter a função de transferência com as propriedades anteriores se deve fazer $w=\frac{s}{j}$ na função de Butterworth $B$ e expandir o polinômio da Equação (2.2). Será desenvolvido um exemplo para um polinômio de ordem três.

Seja:

$$
B(w)=\frac{1}{\left(1+(-1)^{n} s^{2 N}\right)}
$$

Para $n=3$ a função fica:

$$
B(w)=\frac{1}{\left(1-s^{6}\right)}
$$

Que é equivalente à:

$$
\frac{1}{\left(1-s^{6}\right)}=\frac{1}{(1+s)\left(1+s+s^{2}\right)(1-s)\left(1-s+s^{2}\right)}
$$

Usando a seguinte propriedade [29]:

$$
H(s) H(-s)=|H(j w)|^{2}
$$




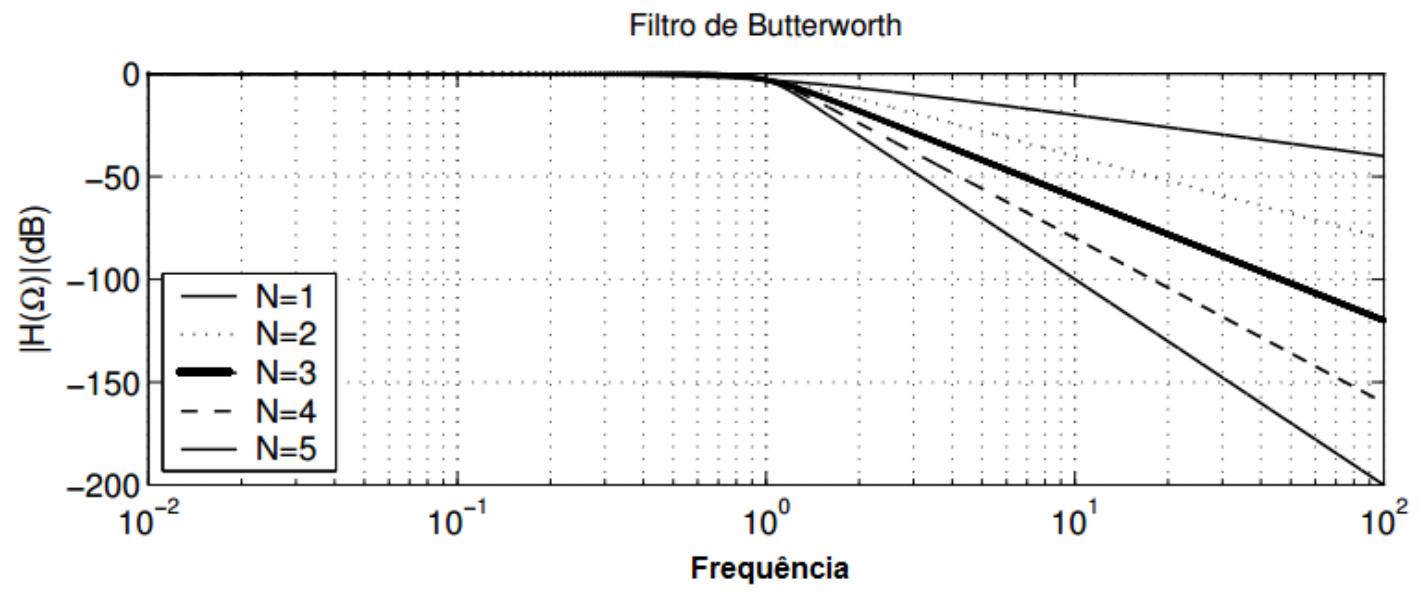

Figura 2.12: Filtro de Butterworth de ordem 1 até 5 [32].

Com a propriedade anterior é encontrada a função de transferência para um filtro de Butterworth de ordem três, isto é:

$$
H(s)=\frac{1}{(1+s)\left(1+s+s^{2}\right)}
$$

Para qualquer frequência $w_{n}$, o valor do amortecimento $z$ é de 0,5 para o filtro de ordem três e a expressão é a seguinte:

$$
H(s)=\frac{w_{n}^{3}}{\left(1+w_{n} s\right)\left(w_{n}^{2}+2 z w_{n} s+s^{2}\right)}
$$

Usando o mesmo procedimento pode-se chegar na função de transferência para um filtro de Butterworth de segunda ordem, onde $\mathrm{z}$ tem o valor de $1 / \operatorname{sqrt}(2), 0,707$ :

$$
H(s)=\frac{w_{n}^{2}}{w_{n}^{2}+2 z w_{n} s+s^{2}}
$$

\subsection{ALGORITMOS DE CONTROLE SEMIATIVO}

O compensador projetado está formado por uma suspensão semiativa. Por conseguinte os algoritmos de controle semiativos que são usados para controlar esse tipo de sistemas.

O objetivo desses algoritmos de controle é obter o valor do parâmetro variável do sistema que gere uma força para atingir uma resposta desejada de posição ou de velocidade. O parâmetro variável do sistema pode modificar o valor da rigidez do acumulador ou o valor do amortecimento do sistema. Para cumprir seu objetivo, os sistemas semiativos precisam ter conhecimento do valor do sinal medido, ou seja, a malha fechada de controle [33]. 


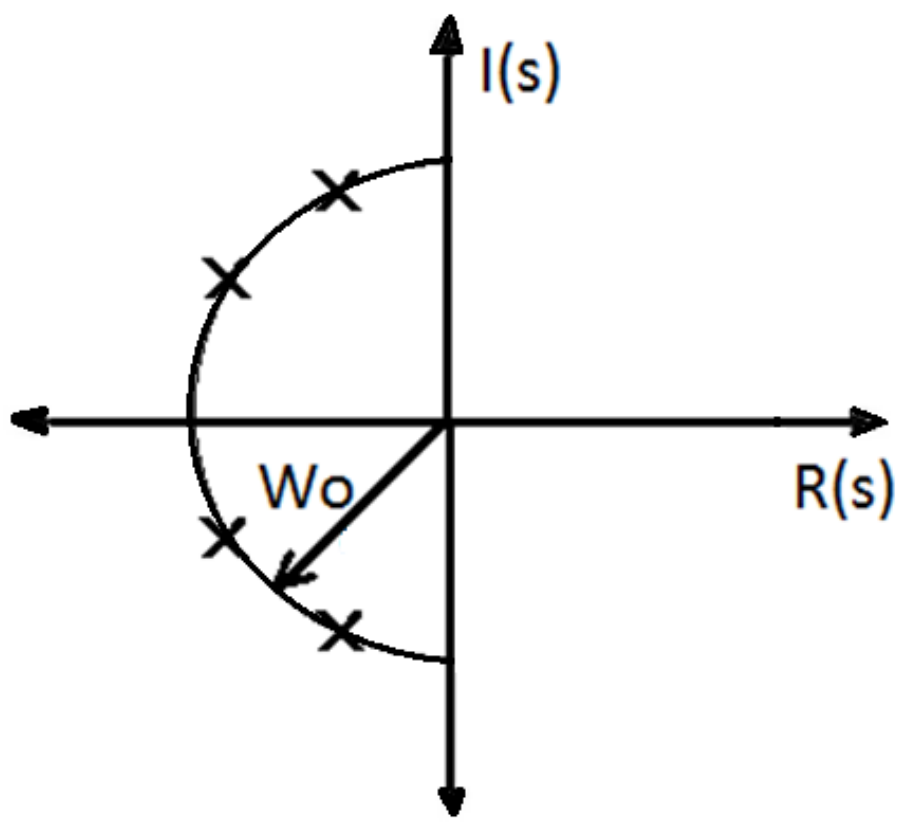

Figura 2.13: Polos do Filtro Butterworth de ordem 4.

Os controladores que permitem cumprir o objetivo do controle semiativo podem-se classificar em três famílias de controladores: Controlador Proporcional Integral Derivativo (PID), controlador adaptativo e controlador robusto. Em seguida, expõem-se algumas da caraterísticas de cada um desses controladores.

O controlador PID é um dos controladores mais usados na indústria, podendo ser analógico ou digital. Existem diversas técnicas para sintonia do controlador PID que são usadas dependendo se consegue ou não fazer uma modelagem matemática do sistema. Se não se conhece a modelagem matemática, pode-se usar a estratégia de Ziegler e Nichols; se a modelagem do sistema é conhecida, pode-se analisar a resposta da função de transferência em malha fechada mediante lugar das raízes, diagrama de Bode ou diagrama de Nyquist [34].

O controlador adaptativo é usado se os parâmetros do sistema não são conhecidos, porque mudam no tempo e a resposta de controladores estáticos não é aceitável. Processos como robótica móvel e metalurgia são ideais para aplicar estes controladores. O controlador adaptativo estima os parâmetros do sistema mediante medidas de sinais do sistema e depois esses parâmetros são usados para sintetizar o controlador. Esta técnica pode ser usada com o controlador PID: o controle adaptativo obtém os valores do modelo do sistema e calcula os parâmetros do controlador PID.

O controlador robusto é usado para sistemas com uma incerteza no valor de algum parâmetro da modelagem matemática, mas se sabe qual pode ser intervalo em que se encontra esse valor de incerteza. O controle robusto pode ser dividido em controle $H_{\infty}$ e controladores de estrutura variável. O controle do sistema por controle $H_{\infty}$ é conveniente para rejeição de distúrbios na forma de sinais com energia limitada e para expressar especificações no domínio da frequência tais como faixa de passagem e ganho em baixas frequências [33]. 
Os controladores de estrutura variável têm diferentes funções de controle que são modificadas dependendo da lei de controle estabelecida. Existem controladores de estrutura variável como os seguintes: balance lógico, Skyhook, Groundhook, Displacement-based OnOff Groundhook Logic, Hybrid SkyhookGroundhook Logic [33].

\subsection{ESPECTRO DE ONDA DE MAR}

As ondas no mar são irregulares e aleatórias em amplitude, período e fase. Por isso, uma onda do mar não pode ser descrita por uma onda senoidal. Essas ondas irregulares podem ser caracterizadas por um espectro de onda que descreve a altura em relação a sua frequência. Isso é importante para ter uma ideia de como será o ambiente de trabalho do compensador de heave.

O espectro de onda pode ser obtido através de análises de históricos de onda no tempo ou de modelos de espectro obtidos por expressões analíticas descritas por parâmetros estatísticos de amplitude de onda e período de onda. Alguns dos espectros mais utilizados na descrição de tipos de mares são: JONSWAP, Pierson \& Moskowitz [35], entre outros.

O modelo de Pierson \& Moskowitz é o modelo mais simples de espectro de onda. Neste modelo, assume-se que o vento sopra constantemente por um longo tempo em uma grande área no mar e as ondas entram em equilíbrio com ele. Este é o conceito de um mar totalmente desenvolvido [35].

No modelo de JONSWAP o espectro de onda nunca é totalmente desenvolvido. Este continua se desenvolvendo através de interações onda-onda não-lineares e nunca entra em equilibrio com o vento, mesmo para tempos e distâncias muito longos [35].

O espectro de JONSWAP teve origem num projeto no Mar do Norte de onde vem seu nome Join North Sea Wave Project. A Petrobras propôs empregar o espectro de JONSWAP ajustado para as condições de mar da Bacia de Campo. A Figura 2.14 ilustra o espectro de onda para algumas alturas de ondas $H s$ e alguns periodos de onda $T p$. A porcentagem de ocorrência da altura de 1,75 é de $34,51 \%$, da altura 1,25 é de $22,96 \%$ e da altura de 2,25 é de $22,21 \%$ [36].

\subsection{COMPENSADOR DE HEAVE}

Os compensadores de heave são sistemas cujo objetivo é diminuir ou isolar as oscilações transmitidas no eixo vertical pelo navio ao sistema que se deseja isolar. Estes compensadores são compostos em essência por uma suspensão.

Existem compensadores que trabalham com princípios de suspensão mecânica, pneumática e hidropneumática. Da mesma forma que as suspensões, os compensadores podem ser classificados em compensadores passivos, ativos ou semiativos [11]. Então, o comportamento do compensador depende do princípio de funcionamento da suspensão e da classificação do compensador anterior. Este comportamento pode ser escolhido para atingir os requisitos de cada aplicação.

Atualmente, os compensadores são usados em diferentes aplicações. As mais comuns são: no 
ESPECTROS DE MAR (JONSWAP - Ajustado para Bacia de Campos)

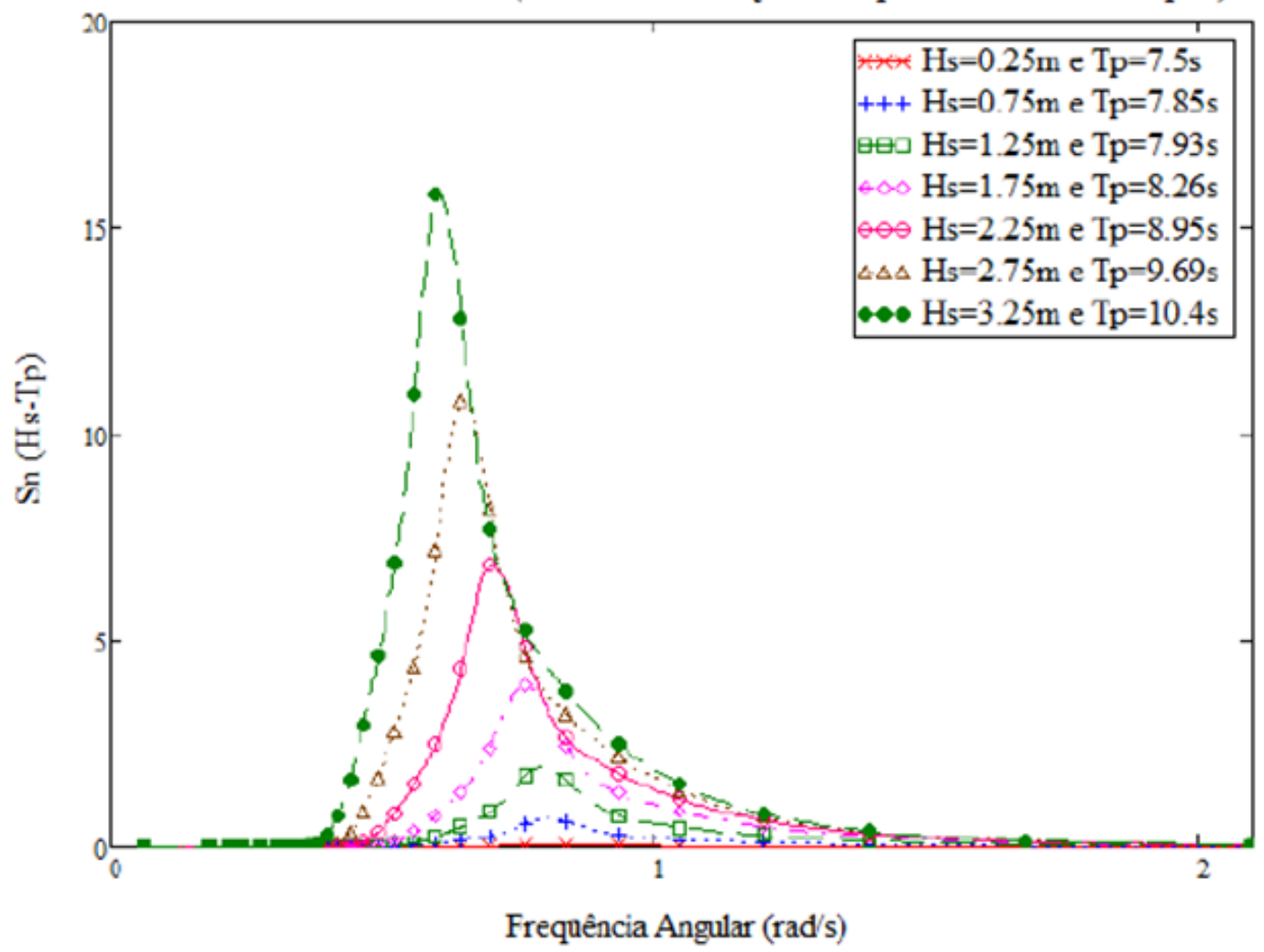

Figura 2.14: Espectro de Onda para Bacia de Campos [36].

processo de perfuração offshore [37], na instalação de módulos submarinos em águas profundas [9] e no uso de guindastes em operações marinas [38], [39].

Os compensadores que são projetados para processos de perfuração offshore devem ser muito eficientes, pois cada dia as profundidades atingidas no processo são maiores. Os compensadores passivos tem uma eficiência na atenuação de $40 \%$ para ondas menores que $1.8 \mathrm{~m}$ e $85 \%$ para ondas maiores que $3.6 \mathrm{~m}$ [37]. A Figura 2.15 apresenta a resposta em frequência de um compensador passivo projetado para uma massa de 570t. Esse compensador tem dois acumuladores, então o volume total do acumulador é o valor que se encontra no gráfico multiplicado por dois. A resposta escolhida pelo projetista foi a de volume $20 \mathrm{~m}^{3}$ ( $40 \mathrm{~m}^{3}$ porque são dois acumuladores), a resposta tem uma frequência de corte de $0.07 \mathrm{~Hz}$ e um ganho máximo de $12 \mathrm{~dB}$. O projetista recomenda usar o compensador passivo com apoio de um sistema ativo. Na maioria das vezes, os compensadores passivos atuam com sistemas ativos em paralelo [40] ou em série [41] para conseguir o desempenho desejado e ter magnitudes físicas razoáveis.

Para os compensadores ativos, encontram-se sempre na literatura controles de posição, velocidade e aceleração para uma massa determinada e a atenuação conseguida é de $95 \%$ ou mais [37]. Mas o consumo de energia desse tipo de controle é muito alto. Os compensadores semiativos têm um baixo consumo de energia como os compensadores passivos e um comportamento semelhante ao comportamento dos compensadores ativos. 


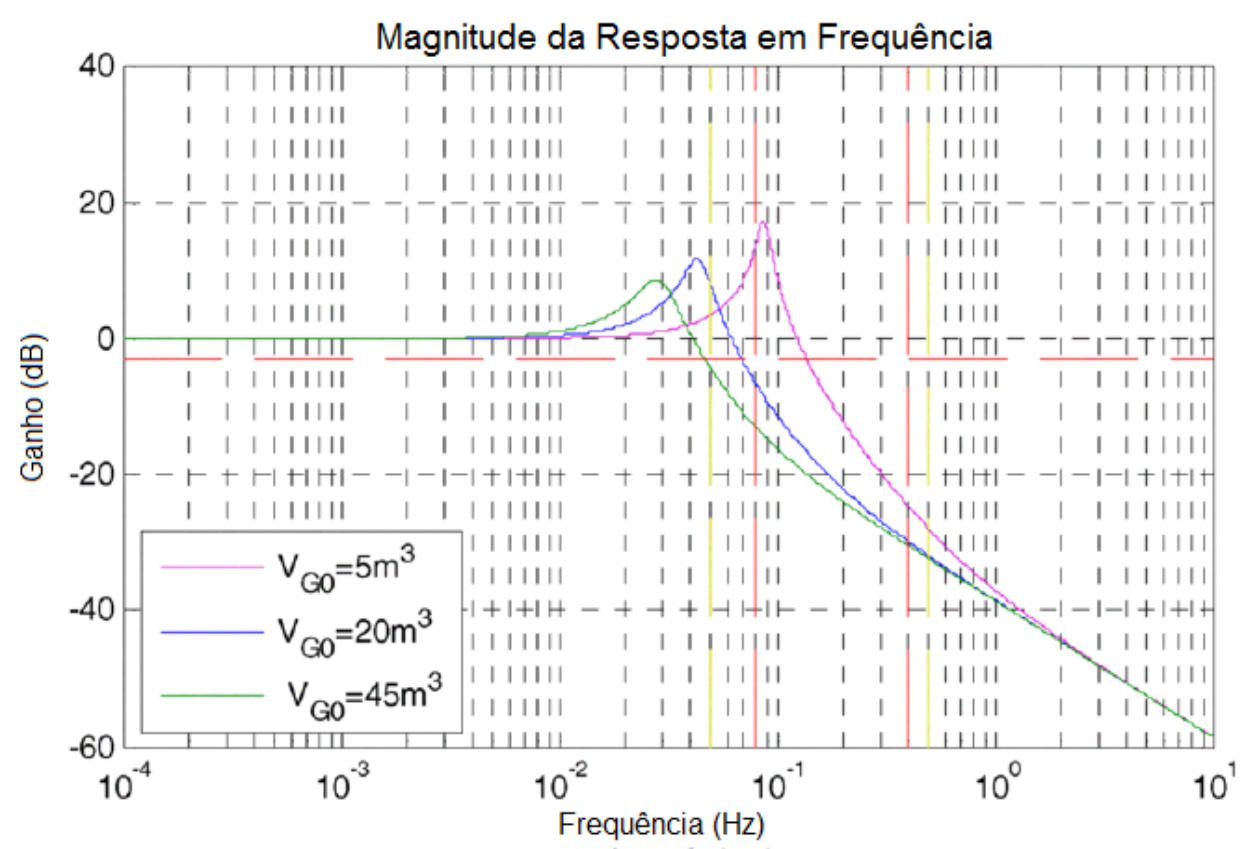

Figura 2.15: Magnitude da resposta em frequência de um compensador passivo para 570t [15]

Tabela 2.2: Cargas que suporta um compensador [40]

\begin{tabular}{c|c}
\hline Elemento & Massa (t) \\
\hline Coluna & 80 \\
Cilindro & 10 \\
Broca de Perfuração & 3 \\
Motor & 30 \\
Bloco de Coroamento & 20 \\
Catarina & 20 \\
& \\
\hline
\end{tabular}

Os compensadores semiativos têm suas vantagens, mas os compensadores para processos de perfuração offshore que foram encontrados na indústria possuem controles ativos e têm partes hidropneumáticas. Por exemplo, a empresa Asker Solutions oferece compensadores de heave para perfuração (ver Figura 2.16 b). Este compensador suporta uma massa estática de até $670 \mathrm{t}$ e tem uma pressão máxima de $20,7 \mathrm{~N} / \mathrm{m}^{2}$ [42], tem uma altura de 7,65 metros, encontra-se na parte superior da torre de perfuração e o volume do acumulador é de $13,5 \mathrm{~m}^{3}$. A empresa Control flow Inc tem um compensador para uma massa estática de 500t [43] (ver Figura 2.16 a).

A massa estática que deve suportar um compensador de heave é a soma das massas dos elementos da Tabela 2.2, mas para a coluna, o valor da massa muda em função da profundidade que deve ser atingida. A Figura 2.17 apresenta um esquema do compensador com as partes que deve suportar, sendo que o cilindro forma parte do compensador passivo. 

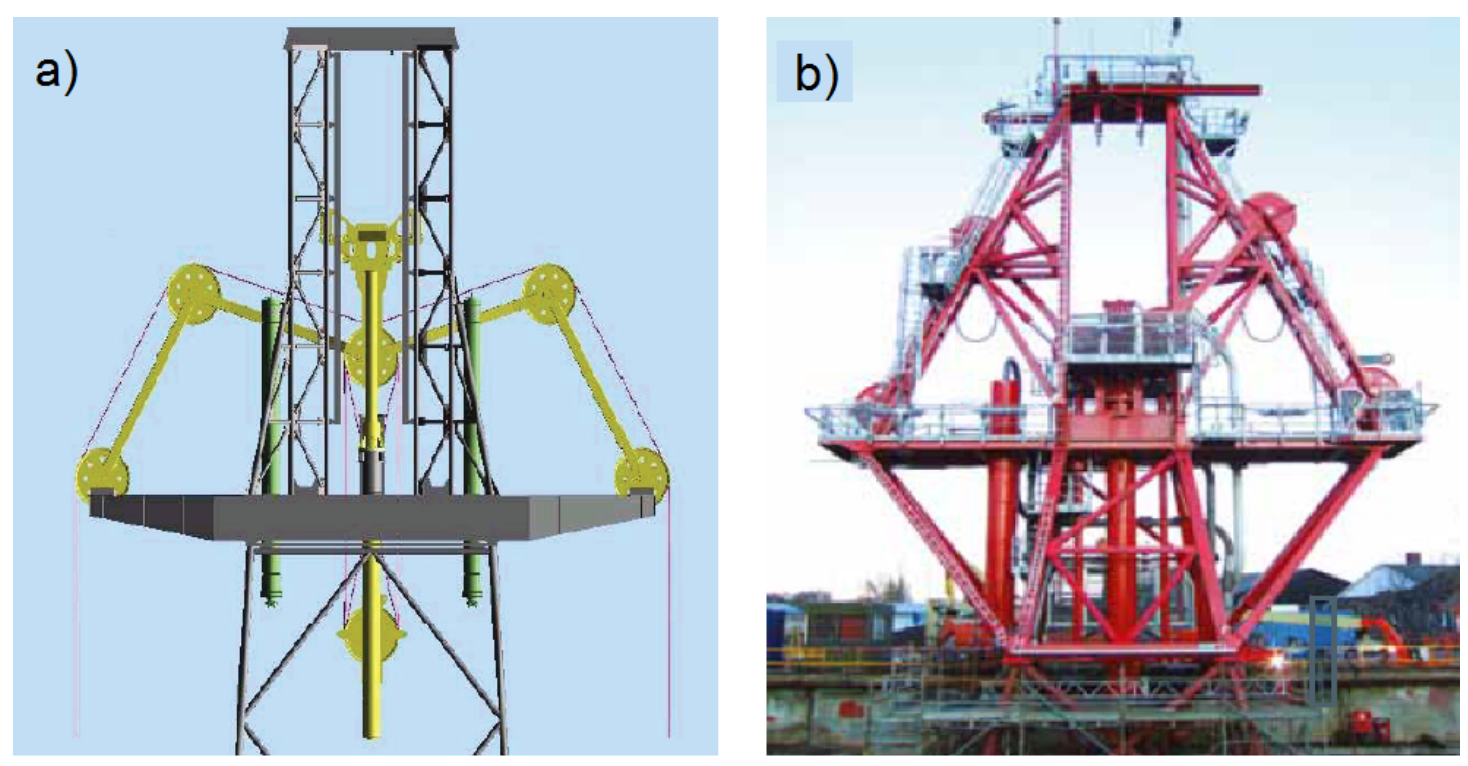

Figura 2.16: Exemplos de compensadores. A) Empresa Control flow Inc [43]. B) Empresa Asker Solutions [42]

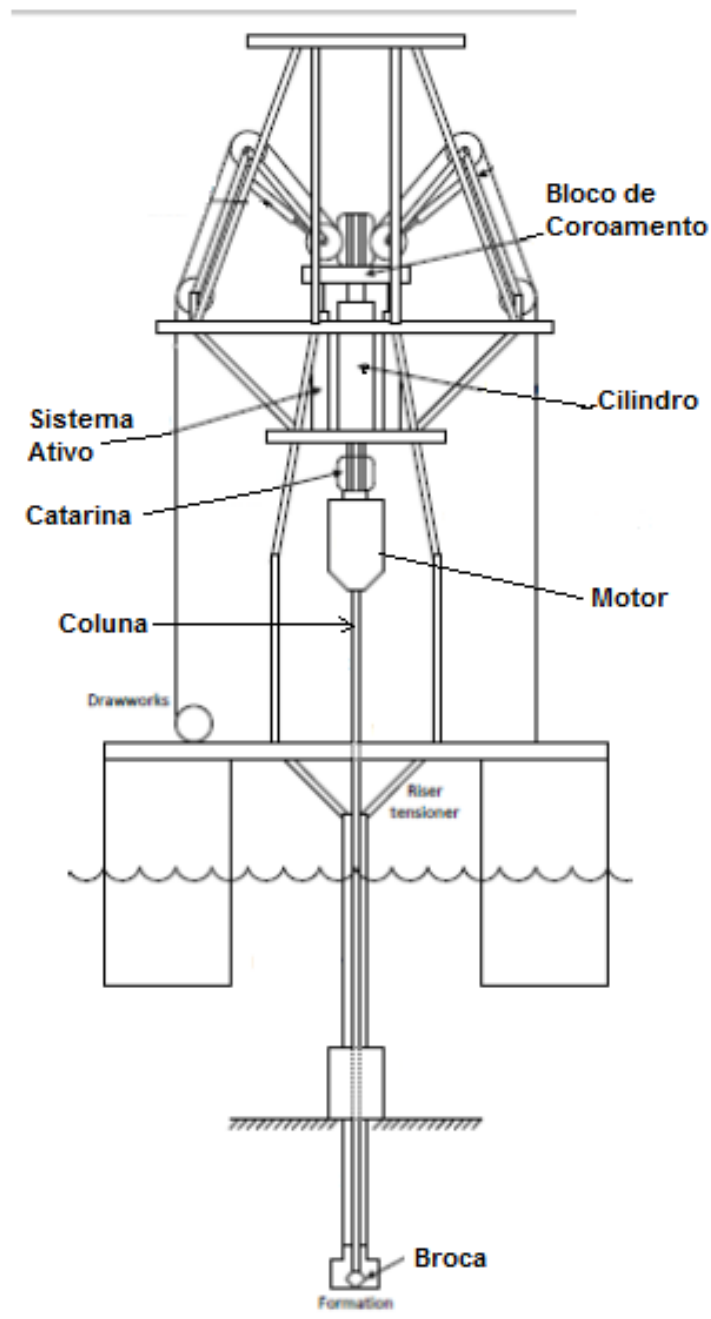

Figura 2.17: Principais partes que são suportadas por um compensador [40]. 


\section{Capítulo 3}

\section{MODELAGEM}

Neste capítulo, analisa-se a modelagem matemática do sistema de suspensão hidropneumático sem mola e a modelagem do sistema hidropneumático em série com uma mola mecânica. Estes dois sistemas são usados para projetar o compensador. Para cada sistema, obteve-se uma função de transferência que representa a relação entre o movimento do navio e o movimento da massa suportada pelo sistema. Esta função de transferência só é válida quando a massa suportada pelo sistema permanece constante. Na Seção 3.1, expõem-se as principais suposições que foram tidas em conta para realizar a modelagem do sistema hidropneumático sem mola. Estas suposições são usadas novamente para o sistema com mola na Seção 3.3, supondo a rigidez da mola mecânica linear.

Com essas hipóteses foram obtidas as funções de transferência dos sistemas. Depois, foi encontrada uma relação para expressar os parâmetros do denominador das funções de transferência dos sistemas em termos dos parâmetros do filtro de Butterworth (Seção 3.2 e 3.4). Esta relação permite calcular na Seção 5.4, os valores dos parâmetros físicos do compensador no ponto de projeto em função dos parâmetros do filtro de Butterworth desejado para a massa de projeto e conseguindo desse modo, filtrar os sinais do espectro de onda de mar que têm maior energia (Seção 2.6).

No final do capítulo, analisa-se o que acontece quando se projetam os sistemas para uma massa de projeto e o valor da massa suportada pelo sistema muda. Isso é importante devido a que as funções de transferência achadas na Seções 3.1 e 3.3 não serão mais válidas se os parâmetros não forem recalculados. Além das análises feitas, encontra-se uma equação para os parâmetros que mudam nos sistemas em função da massa. Essas equações são iguais, porque em condições estáticas os dois sistemas têm o mesmo comportamento na parte hidropneumática (Seção 3.5).

\subsection{FUNÇÃO DE TRANSFERÊNCIA DO SISTEMA DE SUS- PENSÃO HIDROPNEUMÁTICO SEM MOLA}

Na Seção 2.5 o funcionamento e as principais partes do sistema hidropneumático. Desenvolvese aqui a modelagem desse sistema com o objetivo de obter a função de transferência. Expõem-se 


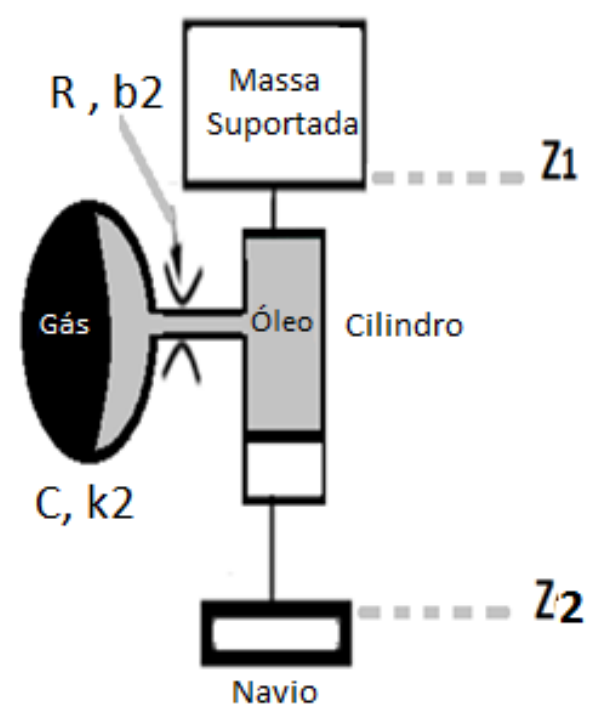

Figura 3.1: Variáveis do sistema hidropneumático sem mola

as seguintes hipóteses. Estas suposições são tomadas da modelagem feita por Moreau [26] e do livro de Bauer [13].

1. O óleo que está dentro do cilindro é não compressível.

2. Não existe friç̧ão entre as paredes do cilindro e o êmbolo. Portanto, ela é gerada, unicamente, pelo amortecedor.

3. O volume do óleo que entra e sai do acumulador é muito pequeno em comparação com o volume do acumulador.Isso quando a massa suportada pelo compensador se mantiver constante.

4. A massa suportada pelo compensador é constante. Caso contrário, a condição anterior não seria válida e a função de transferência não descreveria o comportamento real do sistema.

5. A influência da pressão ambiental é desprezada, já que a pressão do acumulador é consideravelmente maior do que a pressão ambiental.

6. Não existe troca de calor do gás com o ambiente [13]. O processo é uma transformação adiabática.

Expostas as suposições desta modelagem, começa-se a mesma mostrando na Figura 3.1 as partes básicas do sistema hidropneumático sem mola e também identificam-se as variáveis de deslocamento: $z_{1}$ corresponde ao deslocamento da massa que precisa ser compensada; $z_{2}$ é o deslocamento do navio, que representa o sinal de entrada que perturba o sistema. Para achar a relação entre $z_{1}$ e $z_{2}$, escrevem-se as equações de forças sobre a massa para o caso em que a massa se encontra em repouso, caso estático, e para o caso em que a massa está sofrendo uma aceleração. 
As forças que atuam sobre a massa no caso estático são o peso da massa e a força que é gerada pelo cilindro. O peso é dado pela massa $m$ multiplicada pela gravidade $g$. A força estática que gera o cilindro $f_{c s t}$ depende da pressão estática $P_{s t}$ e da área do cilindro $S v$ :

$$
\begin{gathered}
0=m g-f_{c s t} \\
f_{c s t}=P_{s t} S v
\end{gathered}
$$

A expressão para a pressão estática é dada por:

$$
P_{s t}=\frac{m g}{S v}
$$

Logo, aplicando a lei fundamental da dinâmica, consegue-se chegar na equação de movimento da massa:

$$
m z_{1}^{\prime \prime}(t)=P_{c}(t) S v-m g
$$

As forças aplicadas no caso dinâmico são as mesmas que no caso estático, mas a pressão no cilindro $P_{c}$ não é estática, ela é o resultado da soma da pressão dentro do acumulador $P_{A c}$ e a queda de pressão $\triangle P$ que acontece ao óleo passar pela válvula:

$$
P_{c}(t)=\triangle P(t)+P_{A c}(t)
$$

A queda de pressão pode ser linearizada assumindo-se pequenas variações no fluxo que passa pela válvula $q_{A c}(t)$. A resistência hidráulica $R$ representa a queda de pressão para determinado fluxo e esse parâmetro está associado com a abertura da válvula:

$$
\triangle P(t)=R q_{A c}(t)
$$

O movimento do navio e da massa suportada causa um deslocamento no êmbolo do cilindro. Então, o óleo que está no interior do cilindro é impulsionado em direção ao acumulador. Assim, gera-se o fluxo $q_{A c}$, que pode ser calculado pela multiplicação da área do cilindro pela diferença entre as posições do navio e da massa suportada:

$$
q_{A c}(t)=S v\left(z_{2}^{\prime}(t)-z_{1}^{\prime}(t)\right)
$$

Substituindo a expressão anterior do fluxo na Equação (3.6), é obtida a seguinte expressão para a queda de pressão $\triangle P$ :

$$
\triangle P=R S v\left(z_{2}^{\prime}(t)-z_{1}^{\prime}(t)\right)
$$

Retornando à pressão do acumulador, esta pode ser descrita pela Equação (3.9). Essa equação representa uma mudança adiabática e permite conhecer o próximo estado do acumulador, partindose de um estado conhecido como a pressão estática $P_{s t}$ e o volume estático $V_{s t}$. A não linearidade da equação é percebida no expoente adiabático $r$ que é 1,66 para gases monoatômicos, 1,4 para gases biatômicos e 1,3 para gases triatômicos [13]:

$$
P_{A c}(t) V(t)^{r}=P_{s t} V_{s t}^{r}
$$


Como a massa é constante, assumem-se pequenas variações de volume e pressão no acumulador. Por isso, a pressão no acumulador pode ser linearizada ao redor do ponto de pressão estática $P_{s t}$, essa linearização é feita com o polinômio de Taylor de primeiro grau.

$$
P_{A c}(t)=P_{s t}+\left.\frac{d P}{d V}\right|_{P=P_{s t}, V=V_{s t}} d V(t)
$$

A derivada parcial é achada ao redor do ponto de operação $\left(P_{s t}, V_{s t}\right)$ e este resultado é substituído pela expressão capacidade pneumática do acumulador $C$, que representa a relação entre o volume estático e a pressão estática.

$$
\left.\frac{d P}{d V}\right|_{P=P_{s t}, V=V_{s t}}=-r \frac{P_{s t}}{V_{s t}}=-r \frac{1}{C}
$$

A variação do volume do gás no acumulador é igual à variação de volume no cilindro, mas com sinal negativo. A variação de volume no cilindro $d V(t)$ pode ser calculada mediante a integração do fluxo que vai do cilindro para o acumulador representado pela Equação (3.7).

$$
d V(t)=-\int_{0}^{t} S v\left(z_{2}^{\prime}(t)-z_{1}^{\prime}(t)\right) d t
$$

Ao substituir-la na Equação (3.10), consegue-se encontrar uma expressão para a pressão no acumulador em função do deslocamento da massa suportada, do deslocamento do navio e dos parâmetros conhecidos do sistema:

$$
P_{A c}(t)=P_{s t}+r \frac{S v}{C} \int_{0}^{t}\left(z_{2}^{\prime}(t)-z_{1}^{\prime}(t)\right) d t
$$

Agora, a pressão do cilindro é obtida ao substituir a expressão anterior na Equação (3.5)

$$
P_{c}(t)=R S v\left(z_{2}^{\prime}(t)-z_{1}^{\prime}(t)\right)+P_{s t}+r \frac{S v}{C} \int_{0}^{t}\left(z_{2}^{\prime}(t)-z_{1}^{\prime}(t)\right) d t
$$

A expressão da força que o cilindro gera é a seguinte:

$$
f_{c}(t)=S v P_{s t}+R S v^{2}\left(z_{2}^{\prime}(t)-z_{1}^{\prime}(t)\right)+r \frac{S v^{2}}{C} \int_{0}^{t}\left(z_{2}^{\prime}(t)-z_{1}^{\prime}(t)\right) d t
$$

Colocando a Equação (3.14) da pressão no cilindro na Equação (3.4) dinâmica da massa suportada, tem-se o seguinte:

$$
m z_{1}^{\prime \prime}(t)=r \frac{S v^{2}}{C} \int_{0}^{t}\left(z_{2}^{\prime}(t)-z_{1}^{\prime}(t)\right) d t+R S v^{2}\left(z_{2}^{\prime}(t)-z_{1}^{\prime}(t)\right)+S v P_{s t}-m g
$$

Com o objetivo de simplificar a equação e de poder fazer analogia mais na frente com sistemas conhecidos, são feitas algumas mudanças de variáveis na Equação (3.17). Onde $b_{2}$ é o coeficiente viscoso de amortecimento e $k_{2}$ é a rigidez do acumulador ou rigidez da mola hidropneumática.

$$
b_{2}=R S v^{2} \quad k_{2}=\frac{r S v^{2}}{C}
$$

Antes de continuar com a modelagem para obter a função de transferência, encontra-se o volume do acumulador em função da rigidez do acumulador. Logo, substitui-se na expressão da rigidez do acumulador a capacitância achada na Equação (3.11): 


$$
k_{2}=\frac{r S v^{2}}{V} P_{s t}
$$

Isolando o volume desta equação e substituindo a pressão obtida na Equação (3.3), tem-se o volume da esfera em função da rigidez do acumulador:

$$
V=\frac{r S v m g}{k_{2}}
$$

Voltando com a modelagem, as mudanças de variáveis da Equação (3.17) são introduzidas na Equação (3.16); mas antes, considerando-se a Equação (3.1), o peso $m g$ é cancelado com a força estática do cilindro $S v P_{s t}$.

$$
m z_{1}^{\prime \prime}(t)=k_{2} \int_{0}^{t}\left(z_{2}^{\prime}(t)-z_{1}^{\prime}(t)\right) d \tau+b_{2}\left(z_{2}^{\prime}(t)-z_{1}^{\prime}(t)\right)
$$

Finalmente, calculando a transformada de Laplace [34] da equação anterior com condições iniciais iguais a zero e simplificando, obteve-se a função de transferência do sistema.

$$
\frac{Z_{1}(s)}{Z_{2}(s)}=\frac{\left(\frac{b_{2}}{m} s+\frac{k_{2}}{m}\right)}{\left(s^{2}+\frac{b_{2}}{m} s+\frac{k_{2}}{m}\right)}
$$

Esta função de transferência é de ordem dois com um zero e tem um valor final ou ganho estático unitário, este ganho unitário é uma propriedade intrínseca dos sistemas de suspensão e independente dos valores escolhidos para os parâmetros do sistema.

\subsection{PARÂMETROS DO SISTEMA HIDROPNEUMÁTICO SEM MOLA EM FUNÇÃO DOS PARÂMETROS DO FILTRO DE BUTTERWORTH.}

Obteve-se a função de transferência para o sistema hidropneumático sem mola. Nesta Seção, acha-se uma relação entre os parâmetros do sistema hidropneumático e os parâmetros do filtro de Butterworth de ordem dois. O objetivo de achar essa relação é permitir que o compensador seja projetado para ter um desempenho semelhante ao comportamento do filtro, dado que o filtro de Butterworth permite uma melhor separação entre as frequências, o comportamento do filtro foi visto na Seção 2.6 .

Para começar, os denominadores das funções são igualados. Na parte esquerda está o denominador do filtro (2.9) e na parte direita da igualdade está o denominador da função de transferência do sistema hidropneumático (3.21):

$$
\frac{1}{\left(s^{2}+2 z w_{n} s+w_{n}^{2}\right)}=\frac{1}{\left(s^{2}+\frac{b_{2}}{m} s+\frac{k_{2}}{m}\right)}
$$


Igualando os coeficientes do mesmo expoente, obteve-se da equação anterior as seguintes igualdades:

$$
\begin{gathered}
2 z w_{n}=\frac{b_{2}}{m} \\
w_{n}^{2}=\frac{k_{2}}{m}
\end{gathered}
$$

Solucionando o sistema de equações, as expressões para $b_{2}$ e $k_{2}$ em termo da massa e dos parâmetros do filtro são as seguintes:

$$
\begin{gathered}
b_{2}=2 z w_{n} m \\
k_{2}=w_{n}^{2} m
\end{gathered}
$$

Encontra-se o volume do acumulador em função dos parâmetros do filtro substituindo a expressão anterior EM (3.19):

$$
V=\frac{r S v g}{w_{n}^{2}}
$$

Observa-se nesta equação que o valor do volume para o ponto de projeto não depende diretamente da massa de projeto. Ele depende diretamente da frequência de corte que se deseja obter e da área do cilindro.

Acha-se a resistência hidráulica em função dos parâmetros do filtro substituindo a Equação (3.25) na Equação (3.17). Para projetar a resistência hidráulica, tem-se que este parâmetro é proporcional à massa do sistema, a frequência de corte desejada e o coeficiente de amortecimento $z$ :

$$
R=\frac{2 z w_{n} m}{S v^{2}}
$$

\subsection{FUNÇÃO DE TRANSFERÊNCIA DO SISTEMA DE SUS- PENSÃO HIDROPNEUMÁTICO EM SÉRIE COM UMA MOLA MECÂNICA}

Descreve-se o funcionamento e as principais partes do sistema hidropneumático em série com uma mola mecânica. Agora, desenvolve-se a modelagem tendo em base a modelagem que foi feita para o sistema hidropneumático sem mola na Seção 3.2. As hipóteses para a modelagem deste sistema são as mesmas que as feitas para o sistema sem mola, mas adiciona-se a seguinte suposição: o deslocamento da mola mecânica está no intervalo onde se considera que sua rigidez é linear.

Depois da suposição acrescentada, começa-se a modelagem mostrando as partes básicas e as variáveis do sistema hidropneumático em série com uma mola (Figura 3.2) $z_{1}$ corresponde ao deslocamento da massa que precisa ser compensada, $z_{2}$ é o deslocamento do navio e $z_{o}$ é o deslocamento ao redor da posição de equilíbrio do ponto de união do cilindro e a mola. Para achar a relação entre $z_{1}$ e $z_{2}$, escrevem-se as equações dinâmicas para o caso em que a massa se encontra em estado estático e para o caso em que a massa está sofrendo uma aceleração. 


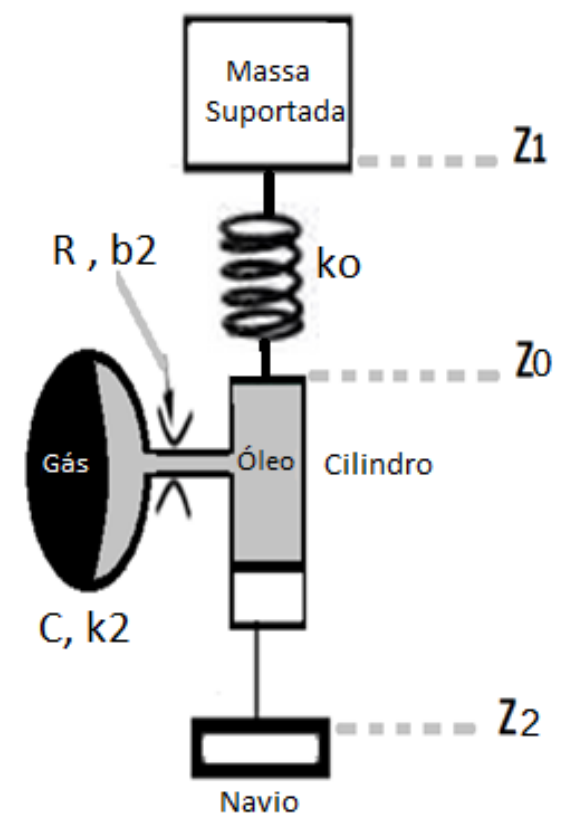

Figura 3.2: Variáveis do sistema hidropneumático e mola mecânica em série

As forças que atuam sobre a massa no caso estático são o peso da massa e a força estática da mola. O peso é dado pela massa $m$ multiplicada pela gravidade $g$ e a força estática da mola $f_{m s t}$ é o produto entre o deslocamento $\left(z_{0 s t}-z_{2 s t}\right)$ multiplicado pelo valor da sua rigidez $k_{o}$ :

$$
\begin{aligned}
0 & =f_{m s t}-m g \\
f_{m s t} & =k_{o}\left(z_{0 s t}-z_{2 s t}\right)
\end{aligned}
$$

Das duas equações anteriores é obtida a expressão para a força da mola no caso estático:

$$
f_{m s t}=m g
$$

A força feita pela mola sobre o cilindro é a mesma que a força feita pelo cilindro sobre a mola, então essas forças são iguais:

$$
f_{m s t}=P_{s t} S v
$$

Isolando a pressão estática, obteve-se que a expressão da pressão estática para o sistema em série com uma mola é a mesma que para um sistema sem mola (ver Equação (3.3) e Equação (3.33)).

$$
P_{s t}=\frac{m g}{S v}
$$

Agora, aplicando a lei fundamental da dinâmica é obtida a equação de forças sobre a massa:

$$
m z_{1}^{\prime \prime}(t)=f_{m}(t)-m g
$$

A força da mola $f_{m}$ é a soma da força estática da mola $f_{m s t}$ e da força do deslocamento no ponto estático.

$$
f_{m}(t)=f_{m s t}+k_{o}\left(z_{0}(t)-z_{2}(t)\right)
$$


Como no caso estático a força feita pela mola é a mesma que é feita pelo cilindro $f_{c}$ sobre a mola, então essas forças são iguais:

$$
f_{m}(t)=f_{c}(t)
$$

Aproveita-se que a força no cilindro já foi calculada para o sistema sem mola na Equação (3.15) em função da saída $z_{1}$ (deslocamento da massa). Então, a saída do cilindro neste sistema é $z_{0}$ (deslocamento do cilindro do compensador) e trocando a variável $z_{1}$ por $z_{0}$, a força fica assim:

$$
f_{c}(t)=R S v^{2}\left(z_{2}^{\prime}(t)-z_{0}^{\prime}(t)\right)+S v P_{s t}+r \frac{S v^{2}}{C} \int_{0}^{t}\left(z_{2}^{\prime}(t)-z_{0}^{\prime}(t)\right) d t
$$

Isolado o parâmetro $z_{0}(3.37)$, mas antes a força estática da mola $F_{m s t}$ se cancela com a força de pressão estática, isso se baseando na Equação (3.32):

$$
z_{o}(t)=z_{2}(t)+\frac{R}{k_{o}} S v^{2}\left(z_{2}^{\prime}(t)-z_{0}^{\prime}(t)\right)+r \frac{S v^{2}}{C k_{o}} \int_{0}^{t}\left(z_{2}^{\prime}(t)-z_{0}^{\prime}(t)\right) d t
$$

Para simplificar a notação se faz a seguinte substituição, onde o sentido fisico de $f_{c d i n}$ é a força que o cilindro faz sobre a mola, mas sem considerar a parte estática.

$$
f_{c d i n}=R S v^{2}\left(z_{2}^{\prime}(t)-z_{0}^{\prime}(t)\right)+r \frac{S v^{2}}{C} \int_{0}^{t}\left(z_{2}^{\prime}(t)-z_{0}^{\prime}(t)\right) d t
$$

Substituindo a Equação (3.34) na Equação (3.37) é obtida a expressão da força do cilindro em termo da força estática $S v P_{s t}$ e da força dinâmica $f_{c d i n}$.

$$
f_{c}(t)=f_{c d i n}+S v P_{s t}
$$

Como $f_{c}=f_{m}$ substui-se na Equação (3.34), a parte da força estática cancela-se com o peso (ver Equação (3.32)) e o resultado é:

$$
m z_{1}^{\prime \prime}(t)=f_{c d i n}(t)
$$

Substituindo $f_{\text {cdin }}$ na Equação (3.38), tem-se:

$$
z_{o}=z_{2}+\frac{f_{c d i n}(t)}{k_{o}}
$$

A transformada de Laplace [34] das três expressões anteriores com condições iniciais iguais a zero e fazendo a mudança de variáveis da Equação (3.17), tem-se:

$$
\begin{gathered}
F_{c d i n}(s)=\left(b_{2} s+k_{2}\right)\left(Z_{2}(s)-Z_{0}(s)\right) \\
Z_{1}(s)=\frac{F_{c d i n}(s)}{m s^{2}} \\
Z_{o}(s)=Z_{1}(s)+\frac{F_{c d i n}(s)}{k_{o}}
\end{gathered}
$$


Introduz-se a Equação (3.45) na Equação (3.43) para obter a seguinte expressão de $F_{\text {cdin }}$ em termos dos deslocamento $Z_{1}$ e $Z_{2}$ :

$$
F_{c d i n}(s)=\frac{\left(b_{2} s+k_{2}\right)\left(Z_{2}(s)-Z_{1}(s)\right)}{\frac{b_{2}}{k_{0}} s+\frac{\left(k_{2}+1\right)}{k_{0}}}
$$

A equação anterior é introduzida na Equação (3.44). Isolando $Z_{1}$ e simplificando a equação, chega-se a uma função de transferência de ordem três com um zero e de ganho estático unitário. Este ganho unitário é uma propriedade intrínseca da função e acontece sempre, sem importar quais valores dos parâmetros sejam escolhidos.

$$
\frac{Z_{1}(s)}{Z_{2}(s)}=\frac{\frac{k_{0}}{m} s+\frac{k_{0} k_{2}}{b_{2} m}}{s^{3}+\frac{\left(k_{2}+k_{0}\right)}{b_{2}} s^{2}+\frac{k_{0}}{m} s+\frac{k_{0} k_{2}}{b_{2} m}}
$$

\subsection{PARÂMETROS DO SISTEMA HIDROPNEUMÁTICO EM SÉRIE COM UMA MOLA MECÂNICA EM FUNÇÃO DOS PARÂMETROS DO FILTRO DE BUTTERWORTH.}

Na seção anterior foi obtida a função de transferência para o sistema hidropneumático em série com uma mola mecânica. Nesta seção acha-se uma relação entre os parâmetros do sistema hidropneumático e os parâmetros do filtro de Butterworth de ordem três.

Para começar, os denominadores das funções são igualados. Na parte esquerda está o denominador do filtro que foi expandido da Equação (2.8) e na parte direita da igualdade está o denominador da função de transferência do sistema hidropneumático com mola:

$$
\frac{1}{s^{3}+\left(w_{n}+2 z w_{n}\right) s^{2}+\left(2 z w_{n}^{2}+w_{n}^{2}\right) s+w_{n}^{3}}=\frac{1}{s^{3}+\frac{\left(k_{2}+k_{0}\right)}{b_{2}} s^{2}+\frac{k_{0}}{m} s+\frac{k_{0} k_{2}}{b_{2} m}}
$$

Igualando os coeficientes da equação anterior são obtidas as seguintes expressões:

$$
\begin{gathered}
w_{n}^{3}=\frac{k_{0} k_{2}}{b_{2} m} \\
\left(2 z w_{n}^{2}+w_{n}^{2}\right)=\frac{k_{0}}{m} \\
\left(w_{n}+2 z w_{n}\right)=\frac{\left(k_{2}+k_{0}\right)}{b_{2}}
\end{gathered}
$$

Solucionando o sistema de equações, as expressões para $b_{2}, k_{0}$ e $k_{2}$ em termo da massa e dos parâmetros do filtro são as seguintes:

$$
k_{0}=(2 z+1) w_{n}^{2} m
$$




$$
\begin{gathered}
b_{2}=\frac{-k_{0}^{2}}{\left(w_{n}^{3} m-(1+2 z) w_{n} k_{0}\right)} \\
k_{2}=m w_{n}^{2}\left(\frac{\left.(2 z+1)^{3}\right)}{1-(1+2 z)^{2}}-(2 z+1)\right)
\end{gathered}
$$

Encontra-se o volume em função dos parâmetros do filtro substituindo a expressão anterior na Equação (3.19).

$$
V=\frac{r S v g}{w_{n}^{2}\left(\frac{(2 z+1)^{3}}{1-(1+2 z)^{2}}-(2 z+1)\right)}
$$

O valor do volume não depende diretamente da massa. Como no caso do sistema sem mola, a relação é mais complexa, mas o volume também é inversamente proporcional ao quadrado da frequência de corte desejada.

Acha-se a resistência hidráulica em função dos parâmetros do filtro, substituindo (3.53) em (3.17). Esta expressão é proporcional à frequência natural do filtro e a massa suportada pelo compensador. A expressão é diferente da obtida para o sistema sem mola, pois depende de uma função do amortecimento:

$$
R=-\frac{(2 z+1)^{2}}{\left(1-(1+2 z)^{2}\right)} \frac{w_{n} m}{S v^{2}}
$$

\subsection{VARIAÇÃO DO SISTEMA PARA MASSA VARIÁVEL}

Na introdução desta dissertação foi descrito o processo de perfuração. Foi dito que para proseguir a perfuração é adicionado um tubo na coluna de perfuração. Então a massa suportada pelo compensador muda e novamente continua o processo de perfuração. Como o compensador foi projetado com sistemas de suspensão hidropneumática, é importante saber o que acontece com esses sistemas ao variar a massa suportada.

Na Figura 6 da Seção 2.3, observa-se que quando a massa suportada pelos sistemas hidropneumáticos muda, também muda o valor da rigidez da mola, sendo que essa mudança é não linear. Então, nesta seção, discute-se o que acontece fisicamente nos dois sistemas hidropneumáticos quando a massa muda. Além disso, encontra-se uma expressão para representar essas mudanças no volume do acumulador e da rigidez do acumulador $k_{2}$.

Analisando-se fisicamente o sistema hidropneumático, percebe-se que algumas variáveis do sistema não têm nenhuma relação com a massa. Por exemplo: o valor da rigidez da mola mecânica $k_{0}$ será o mesmo para qualquer valor de massa, simplesmente a mola se comprimirá ou se alongará. O valor da resistência hidráulica depende do tipo de válvula, da abertura desta e das propriedades do óleo do cilindro. Ao mudar a massa, nenhuma dessas caraterísticas é modificada, portanto o valor da resistência hidráulica não muda. 
Foram analisados os parâmetros do sistema hidropneumático que não mudam quando se modifica o valor da massa suportada pelo sistema. Agora, consideram-se os parâmetros que variam. Estes parâmetros são o volume, a pressão do acumulador e a rigidez do acumulador. A variação nestes parâmetros pode ser explicada da seguinte maneira: quando se tem uma variação de massa, imediatamente, a pressão no cilindro muda no caso estático e a pressão do cilindro fica igual à pressão do acumulador; consequentemente o valor do volume muda e, como a rigidez do acumulador é função do volume, essa rigidez muda também.

Descreveram-se quais são as mudanças que acontecem no sistema quando a massa muda. Daqui em diante, encontrar-se-ão as expressões que relacionam as mudanças nos parâmetros do sistema em função da massa.

Começa-se com a expressão da pressão no acumulador. Esta expressão já foi encontrada na Equação (3.3) para o sistema sem mola e na Equação (3.33) para o sistema em série com a mola mecânica. Essas equações são iguais, portanto as mudanças na pressão estática do acumulador são iguais para os dois sistemas e consequentemente o volume do acumulador e a rigidez do acumulador mudam do mesmo modo para os dois sistemas.

O volume do acumulador é representado pela Equação (3.9). Para facilitar o desenvolvimento da modelagem, muda-se a notação desta equação, onde $P_{s t 1}$ e $V_{s t 1}$ são os valores de pressão e volume estático no acumulador ao variar a massa do sistema do anterior estado $P_{s t}$ e $V_{s t}$. Tem-se:

$$
P_{s t 1}\left(V_{s t 1}\right)^{r}=P_{s t} V_{s t}^{r}
$$

Isolando da equação anterior o volume $V_{s t 1}$ quando a massa tem mudado, tem-se:

$$
\left(V_{s t 1}\right)^{r}=\frac{P_{s t} V_{s t}^{r}}{P_{s t 1}}
$$

Substituim-se as pressões estáticas $P_{s t}$ (na Equação (3.3)) e $P_{s t 1}$ (na Equação (3.59)). A massa no ponto de projeto será $m$ e quando a massa muda é $m_{s t 1}$. É obtida a Equação (3.60) do volume do acumulador quando a massa suportada pelo compensador é diferente da massa de projeto:

$$
\begin{gathered}
P_{s t 1}=\frac{m_{s t 1} g}{S v} \\
V_{s t 1}=V_{s t}\left(\frac{m}{m_{s t 1}}\right)^{\frac{1}{r}}
\end{gathered}
$$

Finalmente, substitui-se a equação anterior na Equação (3.19) e isola-se a rigidez do acumulador.

$$
k_{2}=\frac{r S v g m_{s t 1}}{V_{s t}}\left(\frac{m_{s t 1}}{m}\right)^{\frac{1}{r}}
$$




\section{Capítulo 4}

\section{CONTROLE}

Na seção 2.3 foi dito que a frequência natural dos sistemas hidropneumáticos muda ao variar a massa suportada. Além disso, na última seção do capítulo anterior foi analisado o que acontece nos sistemas de suspensão hidropneumáticos quando a massa suportada pelo compensador é modificada. Neste capítulo, explica-se o objetivo do controle semiativo proposto, o parâmetro que é variado fisicamente no sistema para realizar o controle e acham-se as expressões do amortecimento em função dos parâmetros do sistema e da frequência de corte desejada para os dois compensadores projetados com e sem mola.

Uma vez projetado o compensador, a quantidade de ar do acumulador fica constante. Então, o objetivo do controle é manter o desempenho desejado no domínio da frequência do compensador para todo o intervalo de massa usada durante o processo de perfuração offshore, este desempenho desejado e resume-se em manter um ganho de 0,707 ou -3dB para a frequência de corte desejada, $0,056 \mathrm{~Hz}$. Este objetivo é diferente e não permite usar as técnicas de controle semiativos da seção 2.7 , pois nesses controles e nos trabalhos de compensadores ativos e compensadores semiativos que foram encontrados o objetivo era controlar a posição e manter a massa suportada numa posição de referência [16], [33]. Portanto, esses controles devem trabalhar cada vez que uma onda consiga alterar a posição de referência.

O controle semiativo proposto atua só quando a massa suportada pelo compensador muda, pois enquanto a massa estiver constante o sinal de controle ficará fixo no mesmo valor. O processo do controle é o seguinte: o controle semiativo permite escolher um valor de amortecimento para cada massa, tentando manter um desempenho aceitável do compensador; este amortecimento permanece constante até a massa ser alterada novamente. Então, para cada massa se tem um compensador passivo, cujo valor do amortecimento foi escolhido pelo controle semiativo para atingir o comportamento desejado no domínio da frequência.

O atuador é uma servo válvula comandada, situada entre o acumulador e o cilindro (ver Fig. 2.8). A abertura desta válvula se relaciona com a resistência hidráulica e esta com o amortecimento do compensador. A válvula modifica o valor da resistência hidráulica cada vez que a massa suportada for mudada, consequentemente, o amortecimento do compensador muda. Este valor ficará constante até a massa mudar novamente. 
A vantagem do valor da servo válvula ficar constante enquanto a massa não mudar é que o consumo energético deste controle semiativo e o esforço da válvula são mínimos. Além disso, a válvula escolhida deve manter sua última posição no caso de falha elétrica ou mecânica, desta maneira o compensador continuará trabalhando com o último valor de amortecimento, dando uma robustez ao compensador em caso de falha.

\subsection{AMORTECEDOR PARA COMPENSADOR HIDROPNEU- MÁTICO SEM MOLA}

Para fazer o controle semiativo precisa-se da expressão do amortecimento $b_{2}$ em função dos parâmetros do sistema e do parâmetro do comportamento desejado que será a frequência de corte (ver seçao 5.1).

Para começar, a propriedade da norma [44] é a seguinte:

$$
\|x\|^{2}=x^{*} x
$$

A propiedade anterior é aplicada na função de transferência do compensador sem mola Equação (3.21). Onde, $x$ é o numero complexo resultante de substituir $s=j w$ na função de transferência e $x^{*}$ é o seu complexo conjugado. Com essa expressão, encontra-se a magnitude da resposta do compensador sem mola ao quadrado $\|x\|^{2}$ para qualquer frequência $w$.

$$
\|x\|^{2}=\frac{\left(\frac{k_{2}}{m}+\frac{b_{2}}{m} j w\right)}{\left(\frac{b_{2}}{m} j w-w^{2}+\frac{k_{2}}{m}\right)} \frac{\left(\frac{k_{2}}{m}-\frac{b_{2}}{m} j w\right)}{\left(-\frac{b_{2}}{m} j w-w^{2}+\frac{k_{2}}{m}\right)}
$$

Simplificando a Equação (4.2) que é a multiplicação entre a função complexa conjugada e a não conjugada da função de transferência do compensador, obtem-se:

$$
\|x\|^{2}=\frac{\frac{k_{2}^{2}}{m^{2}}+\frac{b_{2}^{2}}{m^{2}} w^{2}}{\left(\frac{k_{2}}{m}-w^{2}\right)^{2}+w^{2} \frac{b_{2}^{2}}{m^{2}}}
$$

Agora isolando $b_{2}$, consegue-se uma expressão do valor de amortecimento $b_{2}$ para obter um ganho de valor $x$ numa frequência $w$.

$$
b_{2}=\sqrt{\frac{m^{2}}{w^{2}\left(\|x\|^{2}-1\right)}\left(\frac{k_{2}^{2}}{m^{2}}\left(1-\|x\|^{2}\right)+2 \frac{k_{2}}{m} w^{2}\|x\|^{2}-w^{4}\|x\|^{2}\right)}
$$




\subsection{AMORTECEDOR PARA COMPENSADOR HIDROPNEU- MÁTICO EM SÉRIE COM UMA MOLA MECÂNICA}

Já foi encontrada a expressão do amortecimento para o compensador sem mola. Agora, no caso do compensador com mola mecânica é similar o processo para obter a expressão do amortecimento $b_{2}$ em função dos parâmetros do sistema e do parâmetro do comportamento desejado, que é o valor do ganho na frequência de corte.

Aplica-se na função de transferência do sistema com mola (3.47) a Equação (4.1). Encontra-se a magnitude do compensador com mola ao quadrado na seguinte equação:

$$
\|x\|^{2}=\frac{\frac{k_{0} k_{2}}{b_{2} m}+\frac{k_{0}}{m} j w}{\left(\frac{k_{0} k_{2}}{b_{2} m}-\frac{\left(k_{2}+k_{0}\right)}{b_{2}} w^{2}\right)+j\left(\frac{k_{0}}{m} w-w^{3}\right)} \frac{\frac{k_{0} k_{2}}{b_{2} m}-\frac{k_{0}}{m} j w}{\left(\frac{k_{0} k_{2}}{b_{2} m}-\frac{\left(k_{2}+k_{0}\right)}{b_{2}} w^{2}\right)-j\left(\frac{k_{0}}{m} w-w^{3}\right)}
$$

Fazendo a operação de multiplicação entre a função complexa conjugada e a não conjugada, é obtido:

$$
\|x\|^{2}=\frac{\frac{1}{b_{2}^{2}}\left(\frac{k_{0} k_{2}}{m}\right)^{2}+\left(\frac{k_{0}}{m} w\right)^{2}}{\frac{1}{b_{2}^{2}}\left(\frac{k_{0} k_{2}}{m}-\left(k_{2}+k_{0}\right) w^{2}\right)^{2}+\left(\frac{k_{0}}{m} w-w^{3}\right)^{2}}
$$

Agora, isolando $b_{2}$ obteve-se a Equação (4.7).

$$
b_{2}=\sqrt{\frac{\|x\|^{2}\left(\frac{k_{0} k_{2}}{m}-\left(k_{2}+k_{0}\right) w^{2}\right)^{2}-\left(\frac{k_{0} k_{2}}{m}\right)^{2}}{\left(\frac{k_{0}}{m} w\right)^{2}-\|x\|^{2}\left(\frac{k_{0}}{m} w-w^{3}\right)^{2}}}
$$

Esta equação relaciona o valor do amortecimento em função dos parâmetros do compensador e do valor do ganho para determinada frequência. 


\section{Capítulo 5}

\section{ESTUDO DE CASO}

O compensador de heave deve ter as seguintes caraterísticas: o comportamento desejado para as condições de trabalho, um volume admisível do acumulador para ser instalado com facilidade e sem ocupar muito espaço, uma pressão de trabalho pequena para ter um sistema seguro e que a espessura das paredes do acumulador e do cilindro não seja grande.

Neste capítulo, apresenta-se o comportamento desejado do compensador, explica-se porque foram escolhidas as duas configurações hidropneumáticas com e sem mola para projetar o compensador, descreve-se as condições de trabalho nas quais deve trabalhar o compensador e, finalmente, projeta-se cada parâmetro do compensador.

\subsection{COMPORTAMENTO DESEJADO DO COMPESADOR DE HEA VE}

O objetivo do compensador é diminuir as oscilações transmitidas no eixo vertical pelo navio ao sistema que se deseja isolar Seção 2.9. No caso de estudo, a coluna de perfuração dos movimentos do navio.

O compensador projeta-se como um filtro cujo objetivo é atenuar o movimento transmitido à coluna de perfuração pelas ondas do mar que possuem maior energia. As ondas do mar têm maior energia para um intervalo de frequências (Seção 2.8), entre 0,37rad e 1,50 rad $(0,06 \mathrm{~Hz}$ e $0,25 \mathrm{~Hz}$ Figura 2.14). Este intervalo concentra a maior parte da energia do espectro de onda do mar para a Bacia de Campos.

Deseja-se que o compensador filtre o deslocamento da coluna que seria gerado pelas ondas do mar de maior energia, por isso, projeta-se o compensador de heave para obter o comportamento de um filtro passa baixas com frequência de corte de $0.056 \mathrm{~Hz}$. Nesta frequência o ganho do compensador deve ser de -3dB. A Figura 5.1 apresenta de forma didática o comportamento desejado do compensador (similar ao filtro) e o espectro de onda do mar. Observa-se que o filtro começa atenuar os sinais quando o espectro de onda do mar começa ser representativo, em $0.05 \mathrm{~Hz}$.

O compensador projeta-se para ter os mesmos polos que um filtro de Butterworth. Anterior- 


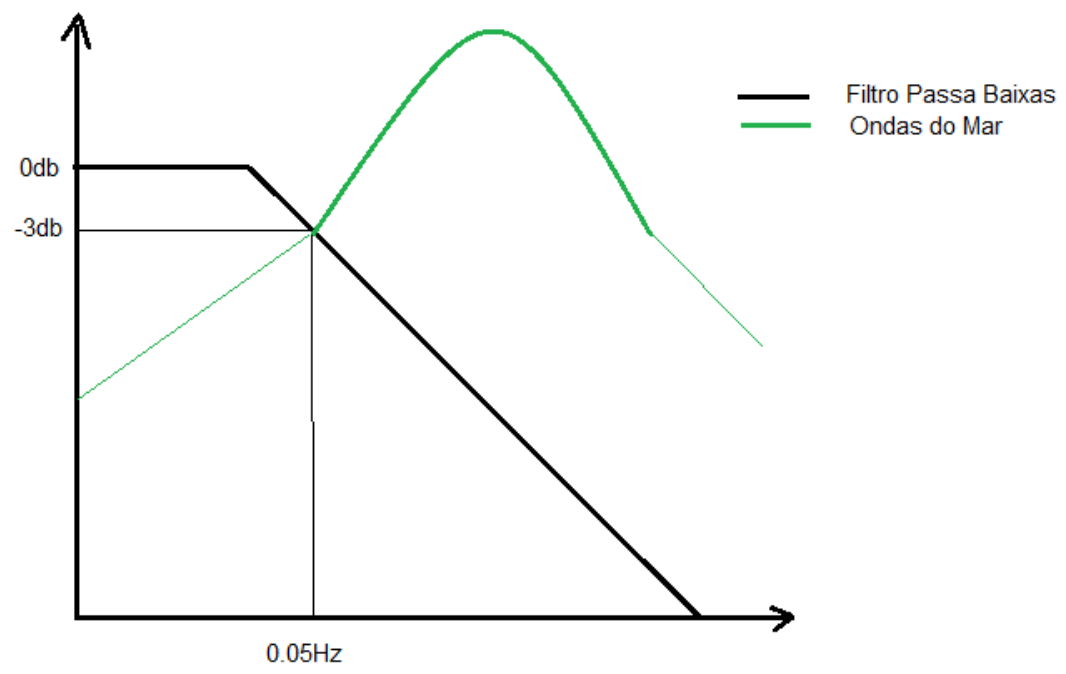

Figura 5.1: Filtro desejado e Espectro de onda do mar

mente, as caraterísticas das famílias de filtro foram descritas brevemente (Seção 2.6,). Esse filtro foi escolhido porque a sua resposta em frequência é maximamente plana na faixa de passagem, o ganho é unitário nessa faixa, não apresenta oscilações em nenhuma das faixas e tem uma atenuação aceitável durante a faixa de transição.

Na função de transferência do filtro de Butterworth nas Equações (2.9) (2.8), observa-se que para projetar esses filtros somente precisa-se escolher o valor da frequência natural do filtro. Este valor de frequência foi escolhido para obter uma frequência de corte de $0.056 \mathrm{~Hz}$ na resposta em frequência das funções de transferência dos compensadores. Assim, a frequência natural do filtro de Butterworth de segunda ordem foi de $0,026 \mathrm{~Hz}$ no caso sistema sem mola e para o filtro de Butterworth de terceira ordem foi de $0.028 \mathrm{~Hz}$ no caso do sistema com mola, esses valores de frequência foram calculados com as Equações (??) e (I.7) respectivamente.

\subsection{CONFIGURAÇÕES HIDROPNEUMATICAS ESCOLHIDAS}

Nesta seção, explicita-se porque o compensador foi projetado com o princípio físico hidropneumático além do porque foi escolhida a configuração do sistema de suspensão hidropneumáticas e a configuração do sistema de suspensão hidropneumática em série com uma mola.

$\mathrm{Na}$, Três tipos de suspensão foram descritos na Seção 2.1 e expostas suas vantagens e desvantagens. Os sistemas hidropneumáticos foram escolhidos pelas seguintes vantagens: desempenho aceitável com uma dimensão não muito grande; o amortecimento do sistema é variável para permitir um controle semiativo e adaptar o sistema às variações da massa; a variação da rigidez da mola é uma função não linear do deslocamento do sinal de entrada, isso permite proteger o sistema en caso do impacto por grandes deslocamentos; a rigidez da mola varia de forma não linear em função da massa, obtendo-se pequenas modificações do volume para grandes mudanças de carga.

Agora, têm-se muitas configurações de sistemas de suspensões hidropneumáticas, por exemplo 
[13]: o sistema de suspensão hidropneumático, o sistema hidropneumático em série ou paralelo com uma mola mecânica ou outro sistema hidropneumático, sistemas com acumuladores em serie ou paralelo etc.

As duas configurações escolhidas foram o sistema de suspensão hidropneumático (Seção 2.4) e o sistema de suspensão hidropneumático em série com uma mola mecânica (Seção 2.5). O sistema de suspensão sem mola foi escolhido por ser o mais simples e por trabalhar com o menor número de partes. Isso demostra que o sistema têm boa robustez no caso de falhas mecânicas ou elétricas, obtendo-se segurança no processo de perfuração.

O sistema de suspensão em série com uma mola mecânica foi escolhido porque é um sistema simples, que só tem mais um componente (a mola) em comparação com o outro sistema. Este sistema oferece boa segurança, mas a maior vantagem é que permite modificar a frequência natural do sistema ao mudar o valor da resistência hidráulica da válvula como foi visto na Equação (3.49).

\subsection{CONDIÇÕES DE TRABALHO DO COMPENSADOR}

Projeta-se o compensador para um processo de perfuração offshore de profundidade de $6 \mathrm{~km}$. O compensador começa trabalhar quando a broca estiver perto de entrar em contato com o chão marinho a uma profundidade de $2 \mathrm{~km}$. Os componentes suportados pelo compensador projetado são os mesmos da Tabela 2.2, sem somar o peso da coluna a massa suportada pelo compensador é aproximadamente 80t. O valor da massa da coluna é diferente do valor encontrado na Tabela 2.2, pois a profundidade trabalhada é diferente.

A massa da coluna de perfuração é calculada usando a Tabela 5.1, o volume é calculado com a altura, o radio interno e o radio externo. Finalmente, para obter a massa da coluna multiplica-se o volume pela densidade. Supõe-se que a composição de fundo da coluna (BHA do ingles BottomHole Assembly ) e drill pipes têm a mesma densidade. BHA tem uma altura de $0,4 \mathrm{~km}$ e um peso de 95t, para completar a coluna de perfuração são usados drill pipes de $1,6 \mathrm{~km}$ e de $5,6 \mathrm{~km}$ com massas de $54 \mathrm{t}$ e $185 \mathrm{t}$. Por tanto o peso mínimo da coluna é de $150 \mathrm{t}$ para uma profundidade de $2 \mathrm{~km}$ e de $280 \mathrm{t}$ para $6 \mathrm{~km}$.

A massa mínima suportada pelo compensador no processo offshore é de $230 \mathrm{t}$ para $2 \mathrm{~km}$ de profundidade (Figura 5.2 a). A máxima massa suportada pelo compensador é de 360t para a profundidade de $6 \mathrm{~km}$ (Figura $5.2 \mathrm{~b}$ ). O processo de perfuração descrito na introdução explica que são adicionados tubos na coluna para perfurar maiores profundidades gerando um aumento na massa suportada pelo compensador.

\subsection{PROJETANDO O COMPENSADOR}

Nesta seção, apresenta-se como foi projetado o compensador. Primeiro, a altura do cilindro e o valor máximo de pressão no acumulador são baseados em dados da literatura. Depois, com o valor da pressão máxima, projeta-se a área do cilindro. O volume do acumulador e a resistência 
Tabela 5.1: Pârametros para calcular a massa da Coluna [45]

\begin{tabular}{c|c|c}
\hline Parâmetro & Unidade & \\
\hline Densidade & $\left(\mathrm{kg} / \mathrm{m}^{3}\right)$ & 7850 \\
Diâmetro Interno dos drill pipes & $(\mathrm{m})$ & 0,1186 \\
Diâmetro externo dos drill pipes & $(\mathrm{m})$ & 0,1397 \\
Altura mínima dos drill pipes & $(\mathrm{km})$ & 1,6 \\
Altura máxima dos drill pipes & $(\mathrm{km})$ & 5,6 \\
Diâmetro Interno BHA & $(\mathrm{m})$ & 0,1186 \\
Diâmetro externo BHA & $(\mathrm{m})$ & 0,1397 \\
Altura BHA & $(\mathrm{km})$ & 0,4 \\
& & \\
\hline
\end{tabular}

Tabela 5.2: Valores dos pârametros para os compensadores no ponto de projeto

\begin{tabular}{c|c|c}
\hline Parâmetro & Sem mola & Com mola \\
\hline Pressão máxima $(P a)$ & 22,8 & 22,8 \\
Area do cilindro $\left(\mathrm{m}^{2}\right)$ & 0,16 & 0,16 \\
Massa projeto $(\mathrm{t})$ & 286 & 286 \\
Altura do cilindro $(\mathrm{m})$ & 7 & 7 \\
Volume projeto $\left(\mathrm{m}^{3}\right)$ & 76 & 76 \\
Resistência hidráulica $\left(M N s^{2} / \mathrm{m}^{5}\right)$ & 2,75 & 3,08 \\
Amortecimento do sistema $b_{2}(k N s / m)$ & 68,5 & 79,0 \\
Rigidez do acumulador $(k N / m)$ & 8,2 & 8,2 \\
Rigidez da mola mecânica $(k N / m)$ & 0 & 17,7 \\
& & \\
\hline
\end{tabular}

hidráulica são calculados com as expressões obtidas nas Seções 3.2 e 3.4. No entanto, antes desse cálculo, escolhe-se o valor da massa de projeto e com este valor são feitos todos os cálculos para se projetar o compensador. Os parâmetros anteriores são calculados ou escolhidos para as duas configurações. Para a configuração com mola, calcula-se somente o valor da rigidez da mola mecânica, único parâmetro diferente entre as duas configurações. A Tabela 5.2 contém os valores dos parâmetros dos compensadores sem e com mola para o ponto de projeto.

\subsubsection{PRESSÃO MÁXIMA PERMITIDA}

O valor máximo de pressão no acumulador é obtido quando o compensador suporta a massa máxima. Este valor é muito importante, porque para o compensador ser realizável, o valor máximo de pressão deve ser aceitável. Se esse valor for muito grande, a espessura das paredes que contem o óleo e o gás deveram ser também muito grande para suportar as forças que gera essa pressão, 


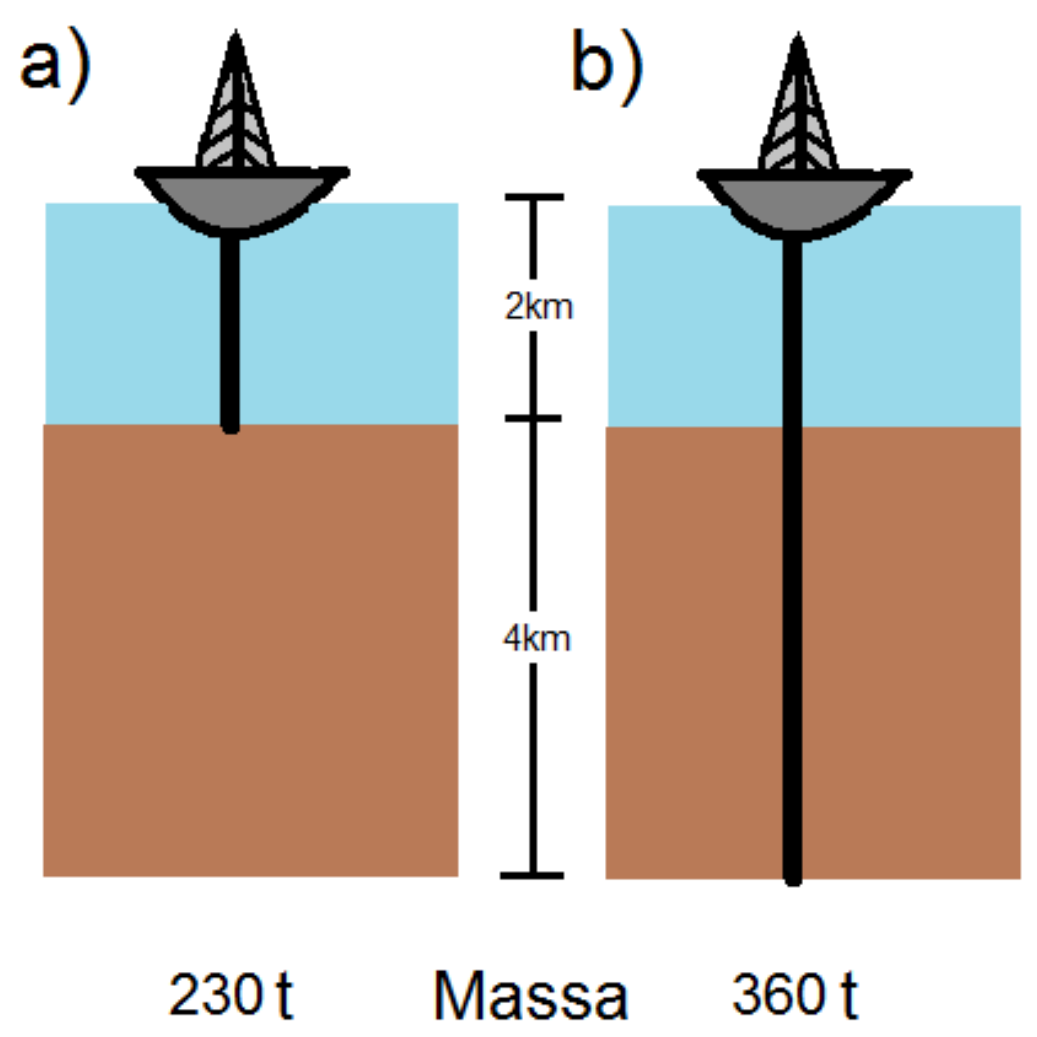

Figura 5.2: Processo de Perfuração A) Mínima profundidade. B) Máxima Profundidade

além de que uma pressão tão grande pode ocasionar acidentes. Por isso, toma-se o valor da pressão máxima de 25.31Pa, valor usado para projetar um compensador passivo de 570t [46]. Esse valor é maior do que 20,7Pa, valor de máxima pressão usado no compensador comercial para 670t [42].

\subsubsection{ALTURA DO CILINDRO}

O compensador deve ter o menor tamanho possível, então procura-se minimizar o comprimento do cilindro, mas o comprimento do cilindro também deve ser o suficientemente comprido para evitar que o embolo do cilindro atinja os extremos, pois o mesmo desloca-se como consequência do movimento do navio e do movimento da massa suportada. No pior dos casos, o embolo pode atingir os límites do cilindro e danificar o sistema. Para projetar a altura do cilindro, tem-se que a altura média das ondas na bacia de Campos é de $2,25 \mathrm{~m}$ (seção 2.8), então a altura pico à pico será de $5,5 \mathrm{~m}$ e adiciona-se $1,25 \mathrm{~m}$ em cada extremo para ter um intervalo de segurança. Como resultado a altura do cilindro é de $7 \mathrm{~m}$. Este valor é similar ao encontrado nos compensadores de heave comerciais, $7,65 \mathrm{~m}$ [43], [42]. 


\subsection{3 ÁREA}

O valor da área do cilindro é de $0,25 \mathrm{~m}^{2}$ para as duas configurações. Esse valor foi escolhido baseado nos dois critérios: primeiro, atingir uma pressão menor ou igual ao valor de pressão máxima (Subseção 5.4.1) e segundo, obter um volume do acumulador não muito grande.

Para as duas configurações dos sistemas de suspensão tem-se que a pressão estática é representada pela mesma expressão (Equações (3.3) e (3.33)), a pressão é inversamente proporcional à área do cilindro. Então, o mínimo valor de área permitido acontece com o valor de pressão máxima permitida 25,31Pa e o valor de massa máxima 360t. Substituído esses valores na Equação (3.33) é obtido o valor mínimo de área permitida de $0,16 \mathrm{~m}^{2}$. Nas Equações (3.27) e (3.55), observa-se que o volume é proporcional à área do cilindro, desse modo é bom escolher um pequeno valor de área para obter um pequeno valor de volume.

O valor da área escolhido foi de $0,16 \mathrm{~m}^{2}$, que é quase o valor de área permitida mínimo. Consequentemente, o valor máximo de pressão estática é 22,8Pa. Esta pressão está entre o intervalo de pressão máxima permitida, 25,31Pa, e a pressão do compensador comercial, $20,31 \mathrm{MN} / \mathrm{m}^{2}$.

\subsubsection{VOLUME DO ACUMULADOR}

A expressão para projetar o volume do acumulador tem uma caraterística muito especial para as duas configurações: essas expressões dependem de maneira indireta do valor da massa. De fato, o volume do acumulador é função somente dos parâmetros do filtro de Butterworth desejado, da gravidade e da área do cilindro, (3.27) para o sistema de suspensão hidropneumático, e (3.55) para o sistema de suspensão em série com uma mola mecânica.

O compensador projetado com a configuração da suspensão hidropneumática depende somente do inverso do quadrado da frequência natural do filtro de Butterworth de segunda ordem. Ainda, o amortecimento $z$ do filtro não tem relação com o volume do acumulador. Para projetar esse volume foi escolhida uma frequencia de corte de $0.05 \mathrm{~Hz}$ e com uma Equação (I.7) foi calculada a frequência natural, $0,026 \mathrm{~Hz}$. Como resultado, o volume obtido foi de $76 \mathrm{~m}^{3}$ e o valor da rigidez do acumulador de $8,2 \mathrm{kN} / \mathrm{m}$.

O compensador projetado com a suspensão hidropneumática em série com uma mola depende novamente do inverso da frequência natural do sistema, mas neste caso, também depende do amortecimento do filtro de Butterworth de terceira ordem. Para projetar o compensador foi usada uma frequência natural de 0,033Hz calculada com Equação (I.12) o valor do amortecimento $z$ para este filtro é de 0,5 ; assim o volume do acumulador é de $76 \mathrm{~m}^{3}$ e o valor da rigidez do acumulador é $8,2 \mathrm{kN} / \mathrm{m}$.

Estes dois compensadores não precisam trabalhar com sistemas ativos, mas os volumes dos acumuladores, $76 \mathrm{~m}^{3}$, são grandes em comparação com o volume do acumulador de compensadores que precisam sistemas ativos. Por exemplo, como o volume do acumulador da empresa Asker Solutions é de $13,5 m^{3}$ [42] para uma massa de $670 \mathrm{t}$, este compensador é ativo. O volume do acumulador de um compensador passivo para uma massa de $570 \mathrm{t}$ foi de $40 \mathrm{~m}^{3}$. Nesse caso se deve 
usar um sistema ativo para melhorar a resposta [46].

\subsubsection{MASSA DE PROJETO}

O compensador foi projetado para um valor de massa de 286t. Essa massa chama-se massa de projeto e pertence ao intervalo de massas que deve ser suportado pelo compensador de 230t até 360t. Esse valor de massa foi escolhido porque permite obter um comportamento aceitável do compensador em todo o intervalo de massa e um volume aceitável.

Foi visto que o volume para projetar o compensador são usados os parâmetros do filtro desejado; o valor de massa de projeto, porém, determina como muda o volume do acumulador quando a massa da coluna é modificada. Por exemplo, projeta-se o compensador com o valor máximo de massa suportada, o volume do acumulador terá nesse valor de massa o valor mínimo de volume e aumentará até a massa mínima. Caso contrário, quando projeta-se o compensador com o valor de massa mínima, o volume do acumulador será máximo nesse valor de massa e diminuirá até a massa máxima.

O ideal seria projetar o compensador com a massa mínima, conseguindo que o volume do acumulador sempre diminua; mas quando a massa aumenta, porém, o comportamento do compensador se afasta do comportamento desejado, pois o valor do ganho na frequência de ressonância do sistema aumenta. Por isso, escolhe-se um valor de massa de projeto que permite uma boa resposta do compensador no domínio da frequência para todo o intervalo de massa, além de que o volume do acumulador seja o mínimo possível para a massa mínima suportada. Com a Equação (5.1) encontra-se o valor da massa de projeto. Esta equação foi encontrada empiricamente depois de escolher varias massas de operação e ver onde se tinha um comportamento e um volume aceitável.

$$
m=m_{\min }+0.43\left(m_{\max }-m_{\min }\right)
$$

Para o valor de massa mínima $m_{\min }$ é 230 t e o valor de massa máxima $m_{\max }$ é $360 t$, obteve-se um valor de massa de projeto de $286 \mathrm{t}$.

\subsubsection{RESISTÊNCIA HIDRÁULICA}

O valor da resistência hidráulica está relacionado com o tipo de válvula e sua abertura. Esse é o parâmetro livre do projeto, já que pode ter valores entre zero e infinito, zero significa que a resistência é nula e a válvula está em posição aberta, infinito que a resistência hidráulica é tanta que a válvula considera-se fechada.

A resistência hidráulica para projetar o compensador é uma função dos parâmetros do filtro de Butterworth desejado, da gravidade, da área do cilindro e da massa, como pode ser visto na Eq. (3.28) para o sistema de suspensão hidropneumático e na Eq. (3.56) para o sistema de suspensão em série com uma mola mecânica.

Substituindo os valores nas equações anteriores, obtiveram-se os valores para a resistência hidráulica de $2,745 M N s^{2} / m^{5}$ para o compensador sem mola e de $3,08 M N s^{2} / m^{5}$ para o com- 
pensador com mola mecânica; na mesma ordem, os valores do coeficiente de amortecimento $b_{2}$ são $68,5 k N s / m$ e $79 k N s / m$. Para ter ideia do significado físico desses valores de resistência hidráulica, tem-se que para um fluxo de $1 \mathrm{~m}^{3} / \mathrm{s}$, gera-se um perca de pressão de $0.9 \mathrm{MN} / \mathrm{m}^{2}$ que é $4 \%$ do valor de pressão máxima no acumulador. O valor anterior de fluxo é considerado grande, permitindo supor um caso onde a queda de pressão será alta.

\subsubsection{RIGIDEZ DA MOLA}

A rigidez da mola mecânica é um parâmetro constante sempre que os limites das massas suportadas e o deslocamento encontrem-se no intervalo linear da mola. A expressão para calcular o valor da rigidez da mola Equação (3.55) é similar à expressão da rigidez hidropneumática do acumulador Equação (3.55).

O valor da rigidez da mola mecânica é de $24.6 \mathrm{kN} / \mathrm{m}$. Valores similares são usados para as molas dos sistemas de suspensão nos carros [47], [48], mas a massa de uma carro normal é no máximo de 1.5t e a massa suportada pelo compensador é de 360t. Esse valor de massa é 200 vezes maior que a massa do carro. Considerando a mola no intervalo linear, tem-se que a mola desloca-se $143 \mathrm{~m}$ quando suporta a massa máxima de $360 \mathrm{t}$.

O projeto do compensador com a configuração de suspensão hidropneumática em série com uma mola não é realizável, pois o valor de rigidez da mola é muito pequeno, causando uma compressão na mola o suficientemente grande para superar a tensão de escoamento e para entrar na região de deformação plástica da mola [49]. Nesta deformação, o material não segue mais a lei de Hooke e as deformações são permanentes, então a mola muda as suas caraterísticas. No pior caso, o deslocamento gera uma tensão que supera o limite de resistência à compressão e acontece uma fratura na mola. 


\section{Capítulo 6}

\section{RESULTADOS E ANÁLISES DOS RESULTADOS}

Neste capítulo, expõem-se os resultados do comportamento dos compensadores na Seção 6.1: na Subseção 6.1.1, para o compensador que foi projetado com a configuração hidropneumática sem mola, depois, para a o compensador que foi projetado com a configuração hidropneumática em série com uma mola mecânica, na Subseção 6.1.2. Finalmente na Seção 6.2, comparam-se os principais resultados das duas configurações.

\subsection{RESULTADOS}

Nesta seção, apresentam-se os resultados do comportamento dos compensadores projetados (sem mola e com mola). Estes resultados são: a magnitude da resposta em frequência, a resposta ao degrau, o valor da variável de controle $b_{2}$, o valor do volume do acumulador e a rigidez do acumulador. Todo isso, para o compensador com e sem controle, nos casos de massa máxima, massa mínima e massa de projeto (ver Subseção 5.4.5). O volume do acumulador e a rigidez do acumulador são calculados em todos os casos com as mesmas equações, Equação (3.60) para o volume e Equação (3.61) para rigidez do acumulador.

A magnitude da resposta em frequência foi escolhida como resultado porque o comportamento desejado do compensador é baseado fundamentalmente nessa resposta (ver Seção 5.1), onde se consegue observar os valores de parâmetros importantes como a frequência de corte, o ganho na faixa de passagem que pode ocasionar ressonância e ademais o comportamento do sistema para todo o espectro das possíveis frequências das ondas do mar.

A resposta do compensador ao degrau mostra o comportamento no caso dinâmico e permite mostrar mais informação sobre o comportamento do compensador. Além disso, essa resposta é importante porque todos os sinais podem ser discretizados e representados como uma sequência de degraus cuja amplitude é o valor da amostragem. 


\subsubsection{COMPENSADOR SEM MOLA}

\subsubsection{Massa de projeto de 286t}

Substituem-se os valores da Tabela 5.2 na Equação (3.21) para obter a função de transferência do compensador na Equação (6.1). Os polos sugeridos pelo filtro de Butterworth de segunda ordem são $0.1197 \pm 0,1197 \mathrm{j}$. A parte real dos polos é a mesma que o zero do sistema.

$$
T f=\frac{0,2394(s+0,1197)}{\left(s^{2}+0,2394 s+0,02867\right)}
$$

A Fig. 6.1 apresenta a magnitude da resposta em frequência da função de transferência. A frequência de corte é de $0,056 \mathrm{~Hz}$, o ganho máximo é $2,0 \mathrm{~dB}$ e acontece na frequência de $0,02 \mathrm{~Hz}$ e existe um ganho maior que $0 \mathrm{~dB}$ no intervalo de frequências de $0,005 \mathrm{~Hz}$ até $0,065 \mathrm{~Hz}$.

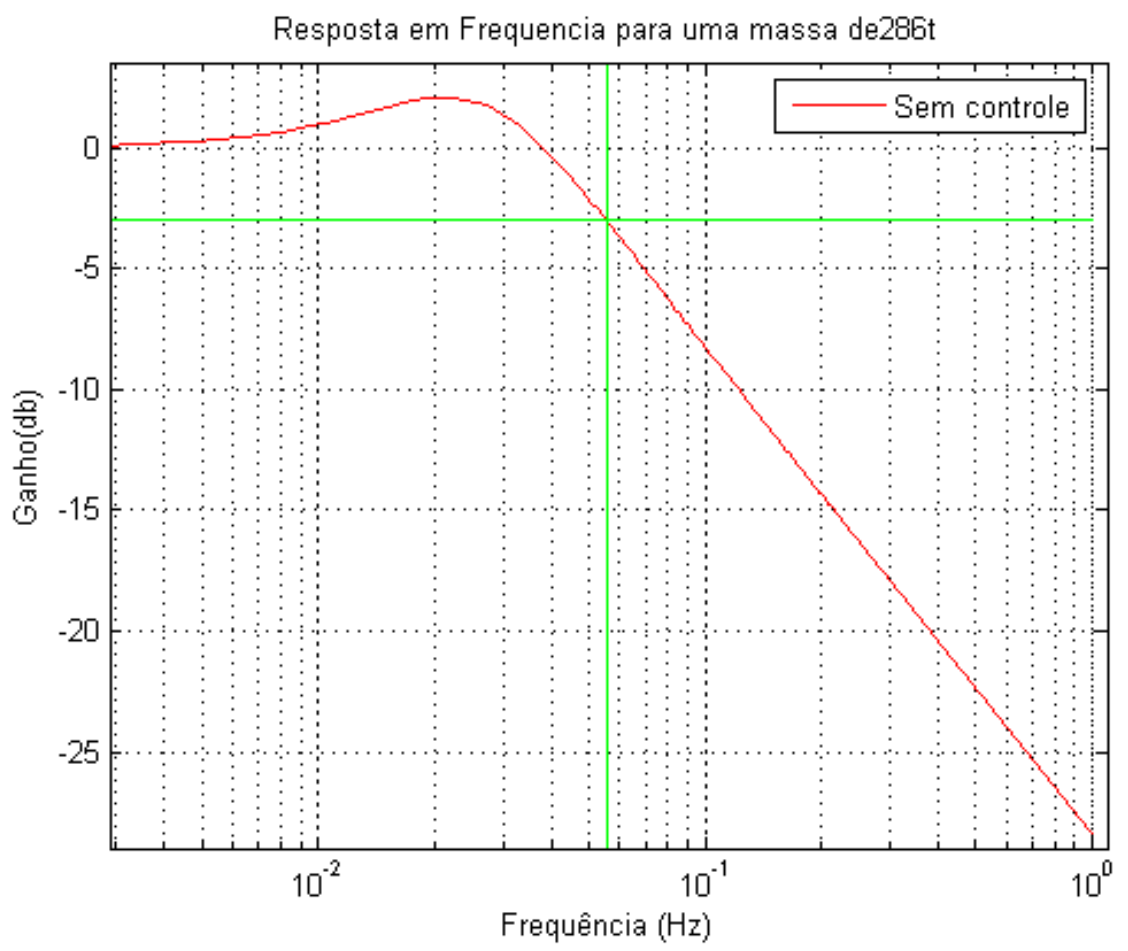

Figura 6.1: Resposta em frequência para a massa de projeto, compensador sem mola

A resposta do compensador ao degrau é mostrada na Fig. 6.2. O sobre-sinal máximo é 20\%, o tempo de subida é 7s e o tempo de acomodação do sistema é 35s.

\subsubsection{Massa máxima de 360t}

O valor do volume do acumulador para uma massa de $360 t$ é de $64 m^{3}, 15 \%$ menor que o volume no caso da massa de projeto. O valor da rigidez do acumulador $k_{2}$ é de $12,1 \mathrm{KN} / \mathrm{m}$. A rigidez aumentou $43 \%$ em comparação com o valor desse parâmetro para a massa de projeto. O valor do amortecimento $b_{2}$ é de $11,7 \mathrm{kNs} / \mathrm{m}, 11 \%$ maior que o valor no ponto de projeto, sendo que esse 


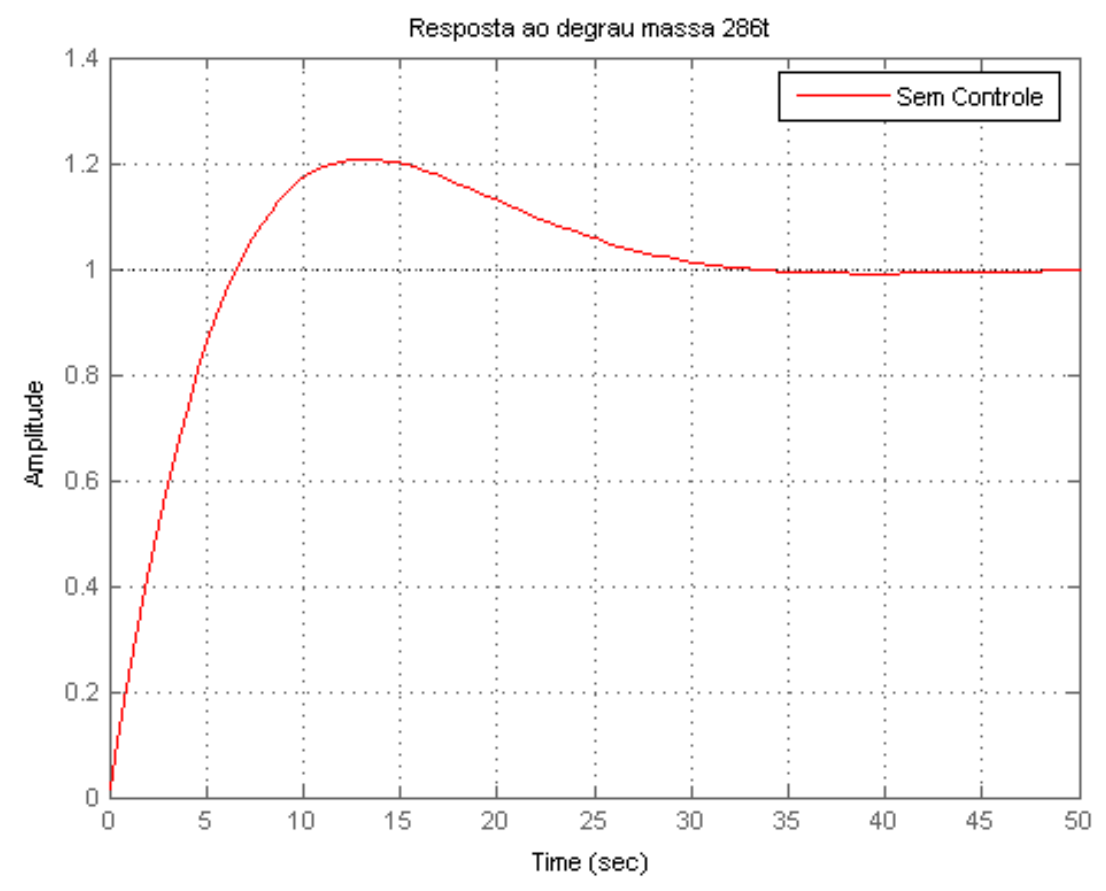

Figura 6.2: Resposta ao degrau para a massa de projeto, compensador sem mola.

valor de amortecimento é calculado por Equação (4.4). Os valores de $K_{2}$ e $b_{2}$ são substituídos na Eq. (3.21) para calcular as funções de transferência.

A Fig. 6.3 apresenta a resposta em frequência para o compensador sem e com controle. Sem controle, a resposta obtida respeita o valor de frequência de corte, mas o valor do ganho máximo é de $3,2 \mathrm{~dB}$. Por outro lado, a resposta do compensador com o controlador leva a frequência de corte ao limite permitido $(0,056 \mathrm{~Hz})$ com um ganho máximo de $2,8 \mathrm{~dB}$ : o valor do ganho máximo é diminuído em $14 \%$ pelo controle. As duas respostas têm intervalos de frequência entre $0,004 \mathrm{~Hz}$ e $0,044 \mathrm{~Hz}$, onde o ganho é maior que 0dB.

A resposta ao degrau sem e com controle é mostrada na Fig. 6.4. Com e sem controle, o tempo de acomodação é de 60s, o tempo de subida é $7 \mathrm{~s}$. Sem controle, o sobre-sinal máximo é de $29 \%$ e com controle é $26 \%$. A resposta do compensador com controle tem um sobre-sinal máximo $3 \%$ menor em comparação com a resposta sem controle.

\subsubsection{Massa mínima de 230t}

Na massa mínima, o compensador tem o maior volume no acumulador, $88 \mathrm{~m}^{3}, 15 \%$ maior que o volume do acumulador para a massa de projeto. O valor da rigidez do acumulador $k_{2}$ é de $5,6 \mathrm{KN} / \mathrm{m}, 46 \%$ menor em comparação com o valor desse parâmetro para a massa de projeto. O valor do amortecimento calcula-se com a Equação (4.4), o resultado é de 59,5kN $/ \mathrm{m}, 15 \%$ menor que o valor no ponto de projeto. Substituem-se os valores de $K_{2}$ e $b_{2}$ na Equação (3.21) e calcula-se a função de transferência. 


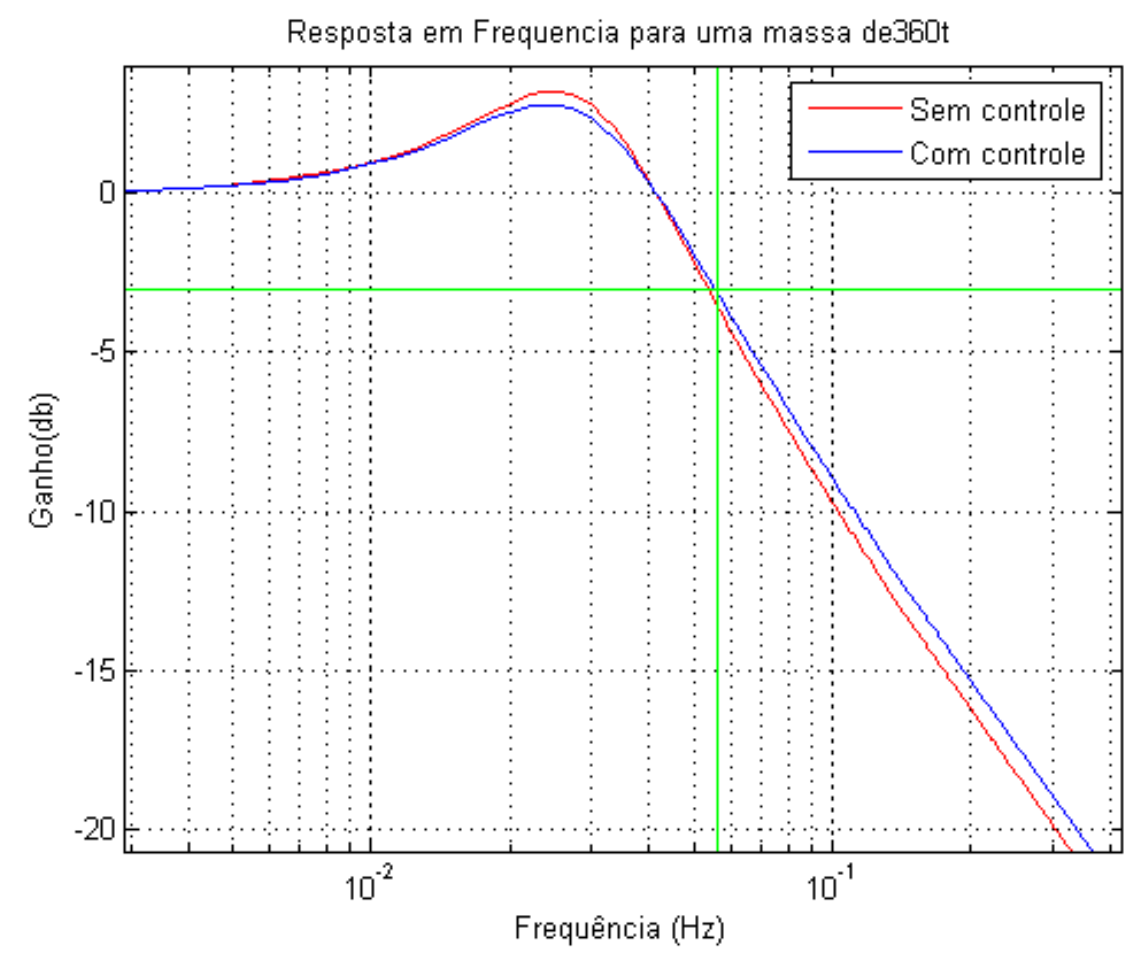

Figura 6.3: Resposta em frequência para a massa máxima, compensador sem mola

A Fig. 6.5 mostra a resposta em frequência para o compensador sem e com controle. Com controle, tem-se uma frequência de corte de $0,056 \mathrm{~Hz}$ e um ganho máximo de $1,7 \mathrm{~dB}$. O compensador sem controle tem um ganho máximo de $1,3 \mathrm{~dB}$ e uma frequência de corte de $0,063 \mathrm{~Hz}$. O ganho sem controle é menor que o ganho com controle, mas a frequência de corte é maior que a frequência de corte requerida pelo controle. Por isso, prefere-se a resposta com o controlador.

A Fig. 6.6 apresenta a resposta ao degrau para o compensador com e sem controle. O compensador com controle tem um tempo de acomodação de 40s, que é mesmo tempo de acomodação do compensador sem controle. Enquanto ao valor do sobre-sinal máximo do compensador com controle é de 18\%, 4\% maior que o valor de resposta do compensador sem controle. Os tempos de subida são quase os mesmos para as duas respostas.

\subsubsection{COMPENSADOR COM MOLA}

\subsubsection{Massa de projeto $286 \mathrm{t}$}

Os valores da Tabela 5.2 são substituídos na Equação (3.21), obtendo-se a função de transferência do compensador na Equação (6.2): o filtro de Butterworth de terceira ordem sugere os seguintes polos oscilantes $0,1037 \pm 0,1037 \mathrm{j}$. O zero é cancelado pela parte real do polo oscilante.

$$
T f=\frac{0.085984(s+0.1037)}{(s+0.2073)\left(s^{2}+0.2073 s+0.04299\right)}
$$

A resposta da magnitude em frequência da anterior função de transferência é mostrada na Fig. 


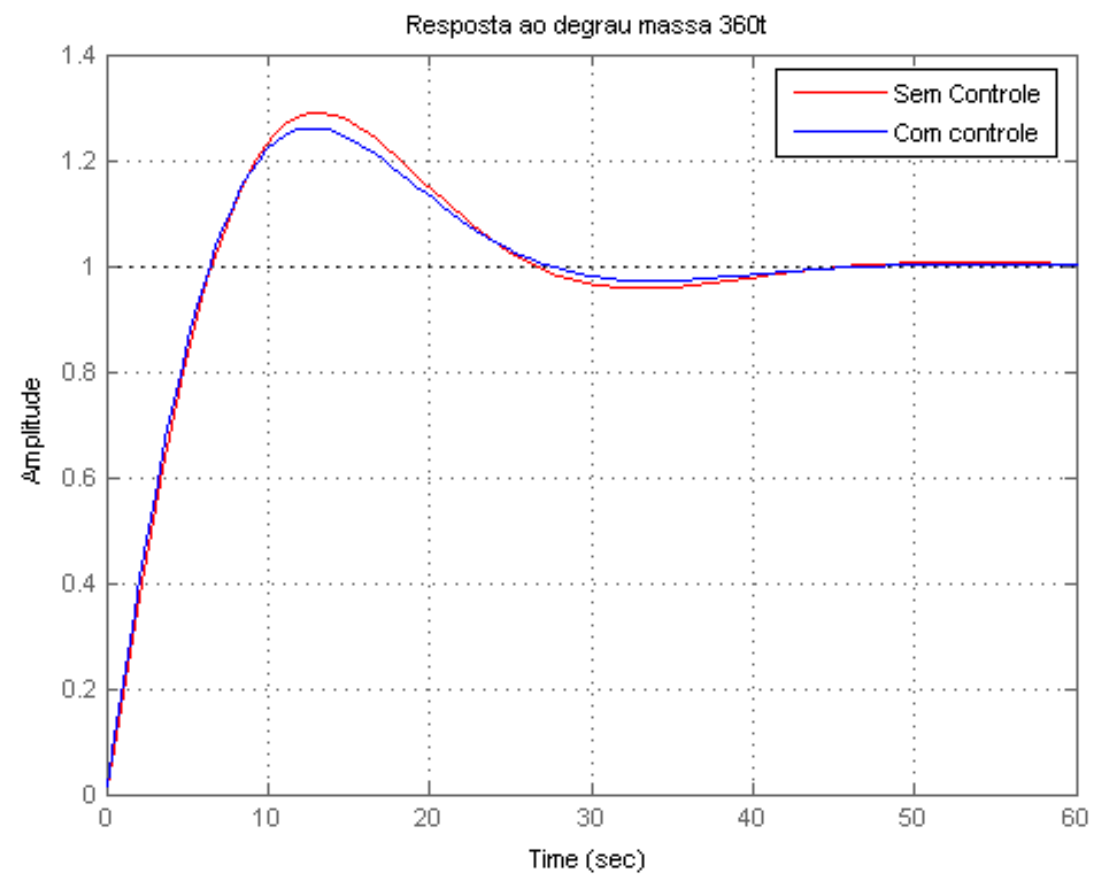

Figura 6.4: Resposta ao degrau para a massa máxima, compensador sem mola

6.7: o ganho máximo é de $4,5 \mathrm{~dB}$ em $0,02 \mathrm{~Hz}$ e a frequência de corte é de $0,056 \mathrm{~Hz}$. Existe um intervalo de frequências para as quais o valor de ganho é maior que zero, entre $0,04 \mathrm{~Hz}$ e $0,003 \mathrm{~Hz}$. A banda de atenuação não apresenta oscilações, só uma queda constante.

Na Fig. 6.8, observa-se que a resposta do compensador ao degrau tem um tempo de acomodação de 50 s, um sobre-sinal máximo de $43 \%$ e um tempo de subida 7,5 s.

\subsubsection{Massa máxima de 360t}

Quando a massa suportada pelo compensador é trocada pelo valor da massa máxima, o valor do volume é de $64 \mathrm{~m}^{3}$. Consequentemente, o valor da rigidez do acumulador $k_{2}$ muda para $12,1 \mathrm{KN} / \mathrm{m}$, aumentando em $48 \%$. O controle troca o valor do amortecimento para $14,9 \mathrm{KNs} / \mathrm{m}$, sendo que esse valor é calculado com a Eq. (4.7) e é $88 \%$ maior que o valor no ponto de projeto. Os valores de $k_{2}$ e $b_{2}$ são substituídos na Eq. (3.21) para calcular a função de transferência.

A Fig. 6.9 mostra a resposta em frequência para o compensador sem e com controle. Com controle, o valor da frequência de corte é de $0,056 \mathrm{~Hz}$ e o valor do ganho máximo é de $6,4 \mathrm{~dB}$. Sem controle, a frequência de corte obtida é de $0,046 \mathrm{~Hz}$ e o ganho máximo é de $6,4 \mathrm{~dB}$. Sem controle, a resposta é aceitável, mas o controle consegue manter a frequência de corte no intervalo desejado e diminuir o valor do ganho máximo em $4 \%$.

A Fig. 6.10 mostra a resposta ao degrau do compensador com e sem controle. O compensador sem controle tem um tempo de acomodação de $85 \mathrm{~s}, 6 \%$ maior que o tempo de acomodação da resposta ao degrau com controle que é de 90 s. O valor do sobre-sinal máximo e o tempo de subida 


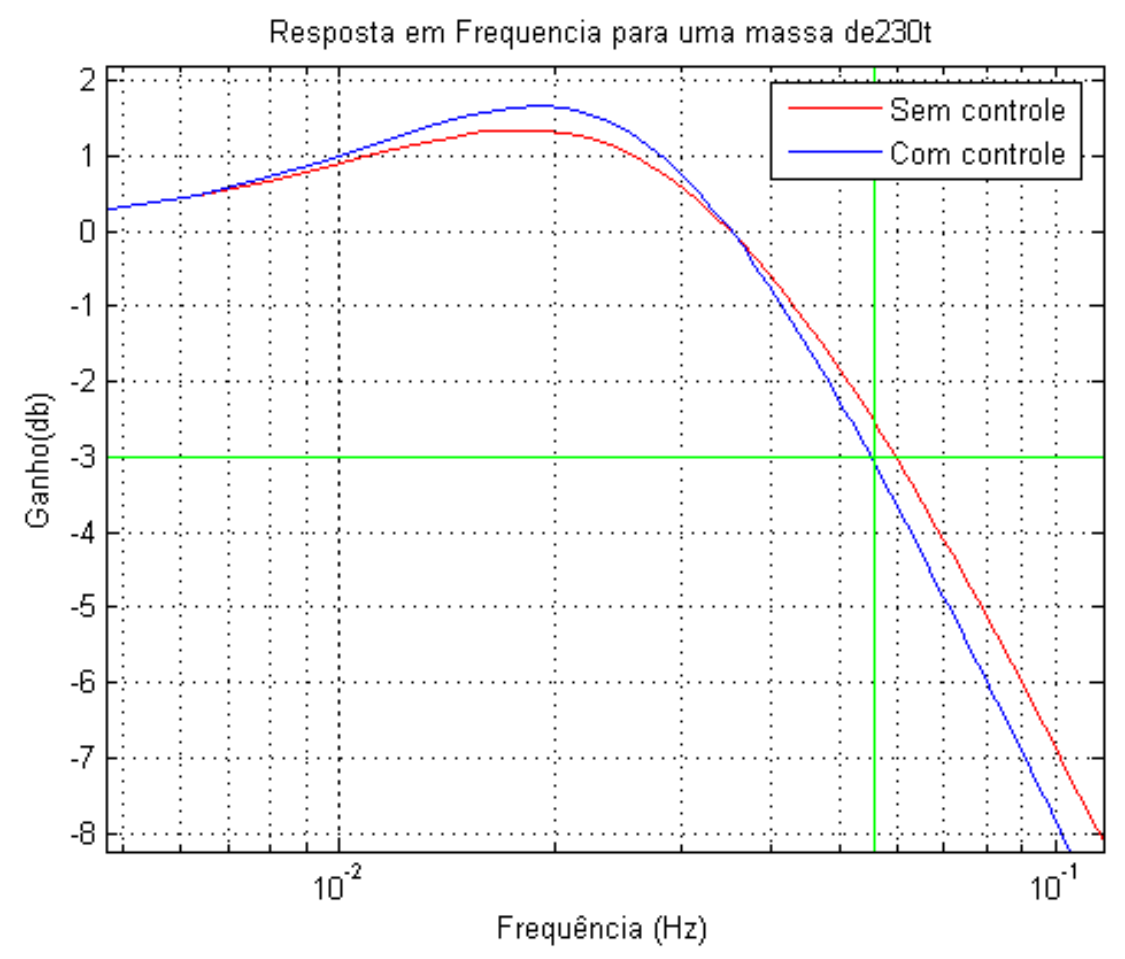

Figura 6.5: Resposta em frequência para a massa mínima

são quase os mesmos para o compensador com e sem controle, $54 \%$ e 8 s respectivamente.

\subsubsection{Massa mínima de 230t}

No começo da perfuração a massa mínima que deve suportar o compensador é de 230t, o volume do acumulador neste caso é de $89 \mathrm{~m}^{3}$, um aumento de $17 \%$ em comparação com o volume para a massa de projeto. A rigidez do acumulador $k_{2}$ tem um valor de $5,6 \mathrm{KN} / \mathrm{m}, 68 \%$ menor que o valor desse parâmetro no caso de projeto. O valor do amortecimento, calculado com a Equação (4.7), é de $78,0 \mathrm{KN} \mathrm{s} / \mathrm{m}, 27 \%$ menor que o valor no ponto de projeto. Calcula-se a função de transferência substituindo os valores de $K_{2}$ e $b_{2}$ na Equação (3.21).

A magnitude da resposta em frequência do compensador sem e com controle são mostradas na Fig. 6.11. Com controle, tem-se uma frequência de corte de 0,056 e um ganho máximo de 3,6dB. O compensador sem controle tem um ganho de $3,3 \mathrm{~dB}$ e uma frequência de corte de $0,063 \mathrm{~Hz}$. A resposta com controle é melhor porque permite atingir a frequência de corte desejada e ter um ganho máximo similar ao ganho da resposta sem controle.

As respostas com e sem controle ao degrau são apresentadas na Fig. 6.12. As respostas são similares, com um tempo de acomodação é de $45 \mathrm{~s}$, o sobre-sinal máximo de $36 \%$ e o tempo de subida é de $7,5 \mathrm{~s}$. 


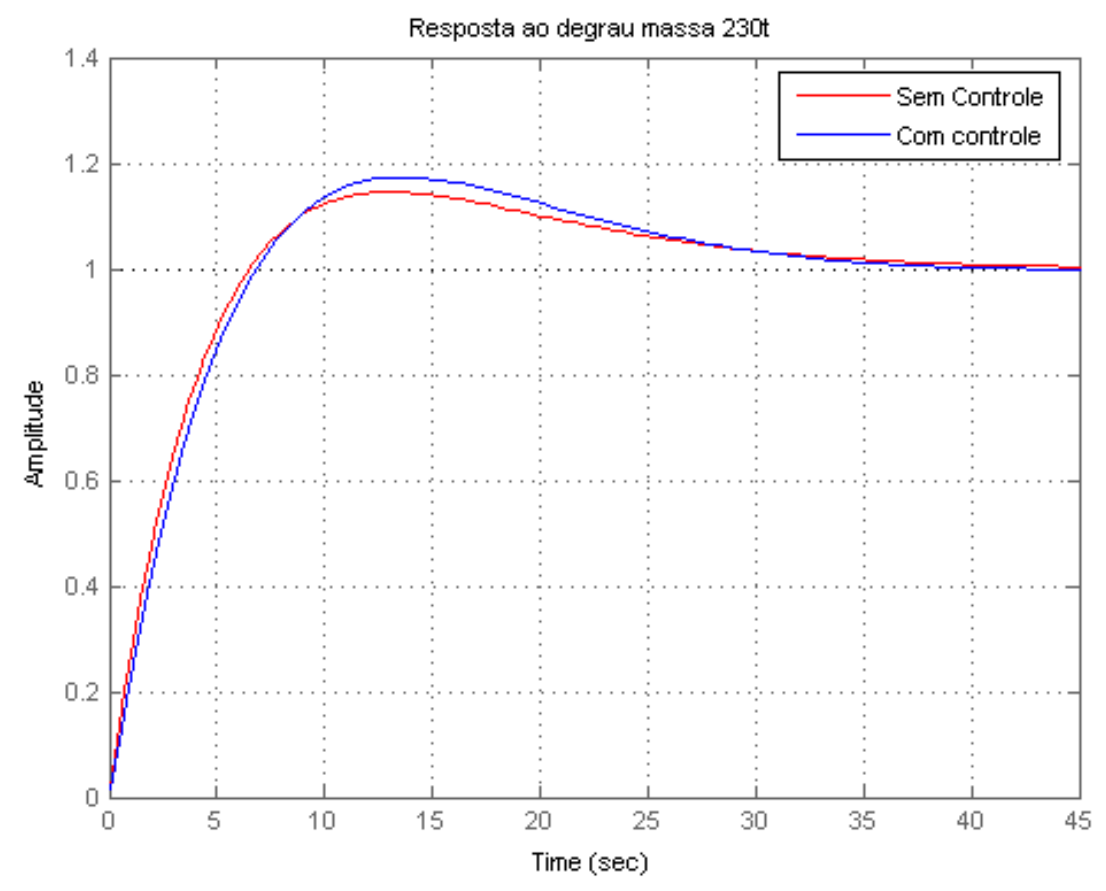

Figura 6.6: Resposta ao degrau para a massa mínima, compensador sem mola

\subsection{ANÁLISES DE RESULTADOS}

Nesta seção são discutidos e analisados os resultados anteriores, focando-se em três pontos: comparação da resposta em frequência dos compensadores com a resposta desejada, comparação entre o desempenho dos dois controladores e finalmente uma comparação entre os dois compensadores. As Tabelas 6.1 e 6.2 contêm os principais resultados que resumem o comportamento dos compensadores.

O comportamento desejado foi descrito na Seção 5.1. Na resposta em frequência do compensador sem controle não se consegue obter a frequência de corte desejada em alguns casos, mas com controle, consegue-se atingir esse critério. O comportamento na faixa de atenuação é aceitável, pois não apresenta oscilações e o ganho sempre diminui. O decaimento é aproximadamente -20dB por década para o compensador sem mola e $-40 \mathrm{~dB}$ por década para o compensador com mola. Enquanto a faixa de passagem apresenta o comportamento é diferente do desejado.

A resposta em frequência desejada tem um ganho $0 \mathrm{~dB}$ na faixa de passagem, mas todas as respostas obtidas têm um ganho máximo maior que 0dB nessa faixa; o intervalo de ganho máximo encontra-se entre $3,2 \mathrm{~dB}$ e $1,3 \mathrm{~dB}$ para o compensador sem mola e entre $6,8 \mathrm{~dB}$ e $3,3 \mathrm{~dB}$ para o compensador com mola.

O ganho máximo é maior que 0dB para o compensador, devido ao uso dos polos do filtro de Butterworth, pois esse filtro tem uma resposta plana (ver Seção 2.6), mas as funções de transferência dos compensadores tem um zero que as funções de transferência do filtros não possuem, portanto o comportamento do compensador não pode ser igual ao do filtro. 


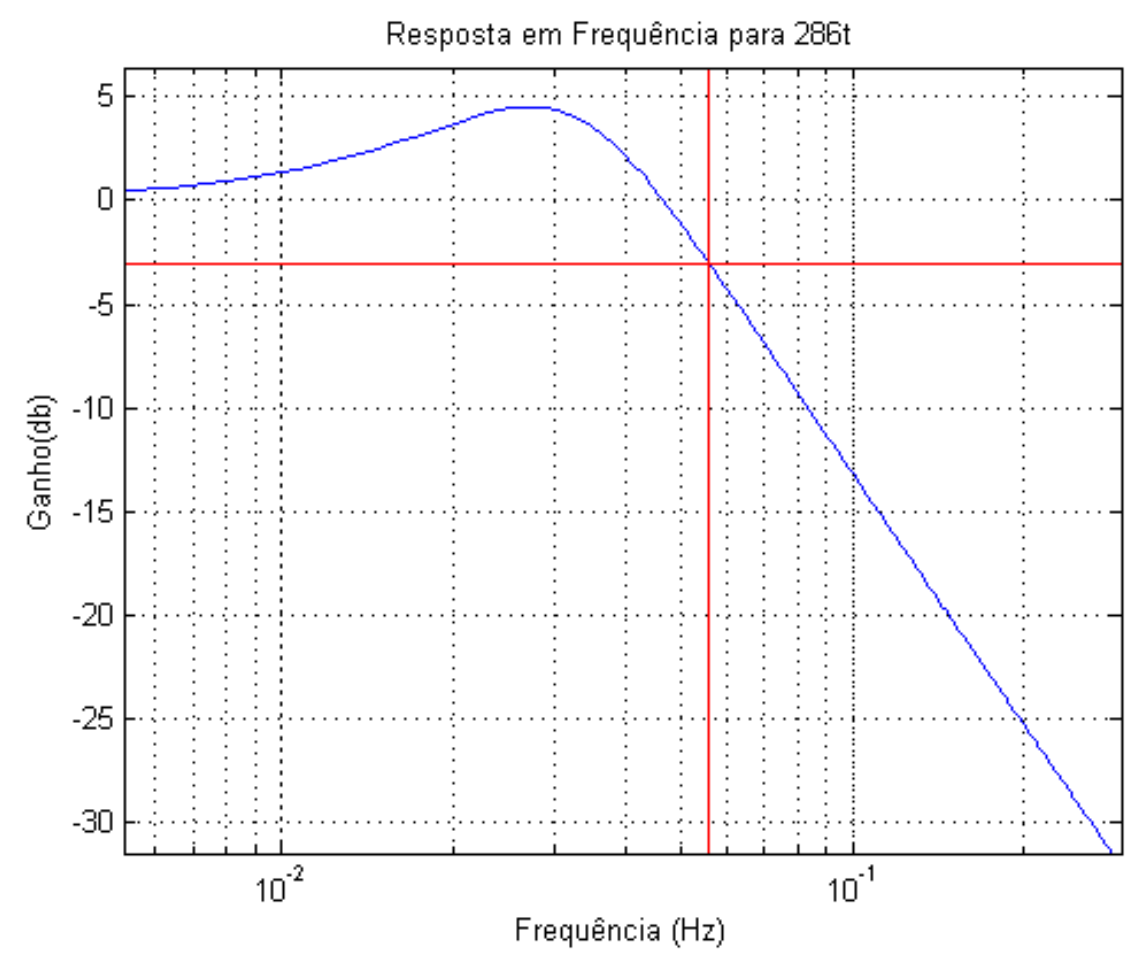

Figura 6.7: Resposta em frequência para a massa de projeto, compensador com mola

Como o comportamento é diferente do desejado na faixa de passagem, existe um intervalo de frequências com o ganho maior que 0dB. Nesse intervalo acontece ressonância e para o ganho máximo tem-se o caso mais critico desta ressonância; se o valor do ganho não for muito grande, porém, a resposta é aceitável porque nesse intervalo de frequência as ondas do mar tem pouca energia (ver Seção 2.8). Apesar disso, não é recomendável ter um ganho muito grande para essas frequências. A literatura recomenda colocar um sistema ativo para um compensador passivo se o ganho máximo na resposta de Bode for igual que 12dB [46].

Após executar a comparação com a resposta desejada, agora, analisa-se o desempenho do controle para os seguintes parâmetros: frequência de corte, ganho máximo obtido na resposta em frequência; tempo de acomodação e sobre-sinal máximo obtidas nas respostas ao degrau. A notação para as variáveis anteriores nas tabelas 6.1 e 6.2 é a seguinte: $W_{c}, G_{m}, M_{p}$ e $T_{s}$, respectivamente.

Antes de analisar as variáveis, descreve-se o que acontece com a frequência de corte ao mudar a massa e como atua o controle semiativo. Ao diminuir a massa, a frequência de corte do sistema aumenta e a rigidez do acumulador diminui. Ao aumentar a massa, a frequência diminui e a rigidez da mola aumenta (ver a frequência de corte do sistema sem controle nas Tabelas 6.1 e 6.2). Isso é coerente com o que foi visto na revisão bibliográfica (ver a Fig. 2.7 e Fig. 2.6).

Tendo em conta, o controle é fundamental no caso em que a massa suportada pelo compensador é menor que a massa de projeto, dado que o principal objetivo do controle é manter a frequência menor ou igual que a frequência de corte desejada. Nesse caso o amortecimento, variável de controle, é diminuída de forma não linear. Caso contrário, quando a massa suportada pelo compensador é maior que a massa de projeto, a frequência de corte diminui e fica no intervalo 


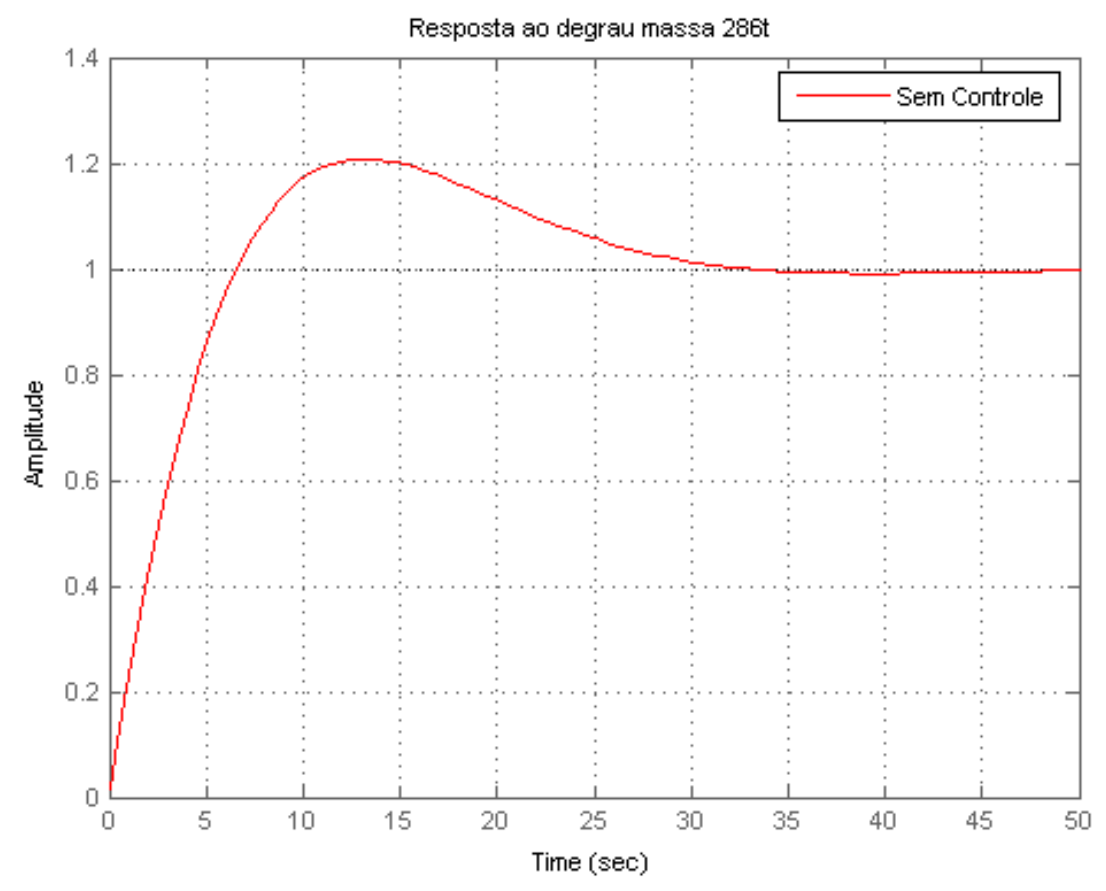

Figura 6.8: Resposta ao degrau para a massa de projeto, compensador com mola

desejado, o controle aumenta o amortecimento, gerando que o valor do ganho máximo na resposta em frequência diminuía para essas.

Retornando com a análise dos parâmetros, começa-se com a frequência de corte e o tempo de acomodação. Para os dois compensadores suportando em todo o intervalo de massas, o controle conseguiu atingir o valor de frequência desejado $(0,056 \mathrm{~Hz})$ e obter um tempo de acomodação quase igual que o tempo do sistema sem controle.

Continuando com o ganho máximo e o sobre-sinal máximo, o desempenho desses parâmetros com o controle depende se a massa suportada pelo compensador é maior ou menor que a massa de projeto. Quando a massa é maior que a massa de projeto, o ganho máximo e o sobre-sinal máximo dos compensadores sem controle são sempre menores do que com controle. Caso contrario, para uma massa menor que a massa de projeto, o ganho e sobre-sinal máximos do compensador com mola sem controle são maiores que com controle, mas para o compensador sem mola acontece o oposto: sem controle esses valores são menores que com controle.

O maior ganho máximo da resposta em frequência dos compensadores foi obtido para a máxima massa suportada. Esse ponto é crítico, porque nele é obtida a maior ressonância que pode acontecer durante a perfuração. Com controle, o ganho foi reduzido em $6 \%$ para o compensador com mola e em $14 \%$ para o compensador sem mola. Então, como a frequência de corte é garantida para os dois compensadores, vê-se que o controle apresenta melhor resposta para o compensador sem mola, pois o valor do ganho máximo é menor para este compensador no caso de máxima massa.

Analisou-se o desempenho do controle nos dois compensadores. Daí em diante, compara-se o 


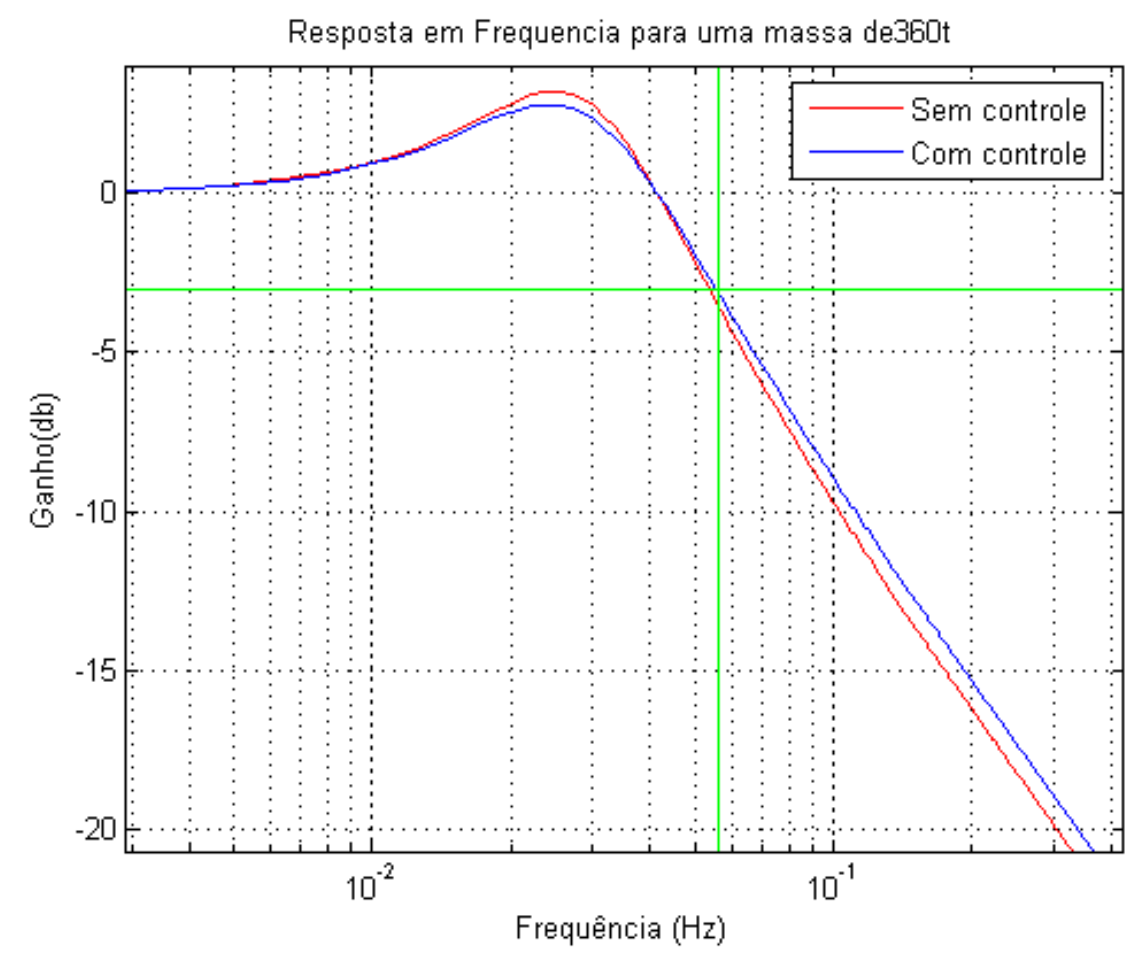

Figura 6.9: Resposta em frequência para a massa máxima, compensador com mola

Tabela 6.1: Resumo comportamento compensador sem mola

\begin{tabular}{c|c|c|c|c|c|c|c|c|c}
\hline \multicolumn{4}{c}{ Sem controle } & \multicolumn{4}{c}{ Com Controle } \\
\hline $\begin{array}{c}\text { Massa } \\
(\mathrm{t})\end{array}$ & $\begin{array}{c}\text { Volume } \\
\left(m^{3}\right)\end{array}$ & $\begin{array}{c}G_{m} \\
(\mathrm{~dB})\end{array}$ & $\begin{array}{c}W_{c} \\
(\mathrm{~Hz})\end{array}$ & $\begin{array}{c}M_{p} \\
(\%)\end{array}$ & $\begin{array}{c}T_{s} \\
(\mathrm{~s})\end{array}$ & $\begin{array}{c}G_{m} \\
(\mathrm{~dB})\end{array}$ & $\begin{array}{c}W_{c} \\
(\mathrm{~Hz})\end{array}$ & $\begin{array}{c}M_{p} \\
(\%)\end{array}$ & $T_{s}$ \\
$(\mathrm{~s})$
\end{tabular}

desempenho do controlador com o objetivo de escolher o compensador com o melhor comportamento e as melhores caraterísticas e comparam-se as respostas ao degrau, a resposta da magnitude em frequência e o valor do volume que deve ter o acumulador.

Comparando o comportamento do compensador com mola com o comportamento do compensador sem mola, este último tem melhor resposta em frequência e melhor resposta ao degrau, pois os valores de ganho máximo e sobre-sinal máximo são quase a metade que os valores desses parâmetros para o compensador com mola, nos casos com e sem controle. Além disso, o tempo de acomodação é quase o mesmo para os dois compensadores no ponto de massa mínima, no ponto de projeto este tempo é $30 \%$ menor para o compensador sem mola e na massa máxima este tempo é o dobro para o compensador com mola.

O único parâmetro físico que muda ao mudar a massa é o volume do acumulador porque o valor do amortecimento é mudado pelo controle. O volume para o compensador sem mola deve 


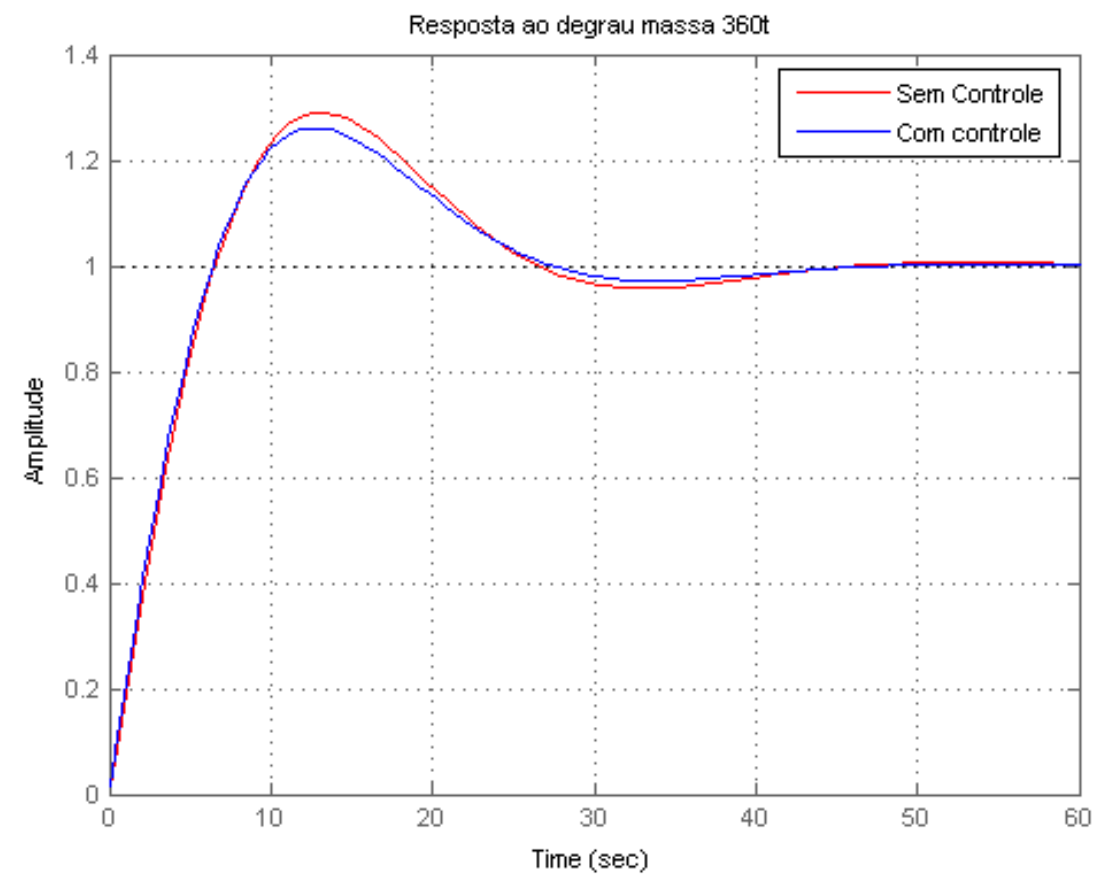

Figura 6.10: Resposta ao degrau para a massa máxima, compensador com mola

Tabela 6.2: Resumo comportamento compensador com mola

\begin{tabular}{c|c|c|c|c|c|c|c|c|c}
\hline \multicolumn{4}{c}{ Sem controle } & \multicolumn{4}{c}{ Com Controle } \\
\hline $\begin{array}{c}\text { Massa } \\
(\mathrm{t})\end{array}$ & $\begin{array}{c}\text { Volume } \\
\left(m^{3}\right)\end{array}$ & $\begin{array}{c}G_{m} \\
(\mathrm{~dB})\end{array}$ & $\begin{array}{c}W_{c} \\
(\mathrm{~Hz})\end{array}$ & $\begin{array}{c}M_{p} \\
(\%)\end{array}$ & $\begin{array}{c}T_{s} \\
(\mathrm{~s})\end{array}$ & $\begin{array}{c}G_{m} \\
(\mathrm{~dB})\end{array}$ & $\begin{array}{c}W_{c} \\
(\mathrm{~Hz})\end{array}$ & $\begin{array}{c}M_{p} \\
(\%)\end{array}$ & $\begin{array}{c}T_{s} \\
(\mathrm{~s})\end{array}$ \\
\hline 286 & 76 & 4,5 & 0,056 & 43 & 50 & & & & \\
230 & 89 & 3,3 & 0,063 & 45 & 36 & 3,6 & 0,056 & 45 & 36 \\
360 & 64 & 6,4 & 0,046 & 54 & 85 & 6,8 & 0,056 & 54 & 90 \\
\hline
\end{tabular}

ser de $88 \mathrm{~m}^{3}$ e para o compensador com mola dever ser de $89 \mathrm{~m}^{3}$. O valor da variável de controle tiveram valores entre o intervalo de $14,9 \mathrm{Ns} / \mathrm{m}$ e $78,0 \mathrm{Ns} / \mathrm{m}$ para o compensador com mola, e entre $11,7 \mathrm{Ns} / \mathrm{m}$ e $59,5 \mathrm{Ns} / \mathrm{m}$ para o compensador sem mola. Os intervalos são tão similares que provavelmente uma válvula servo comandada com as mesmas caraterísticas conseguira trabalhar adequadamente nos dois compensadores. 


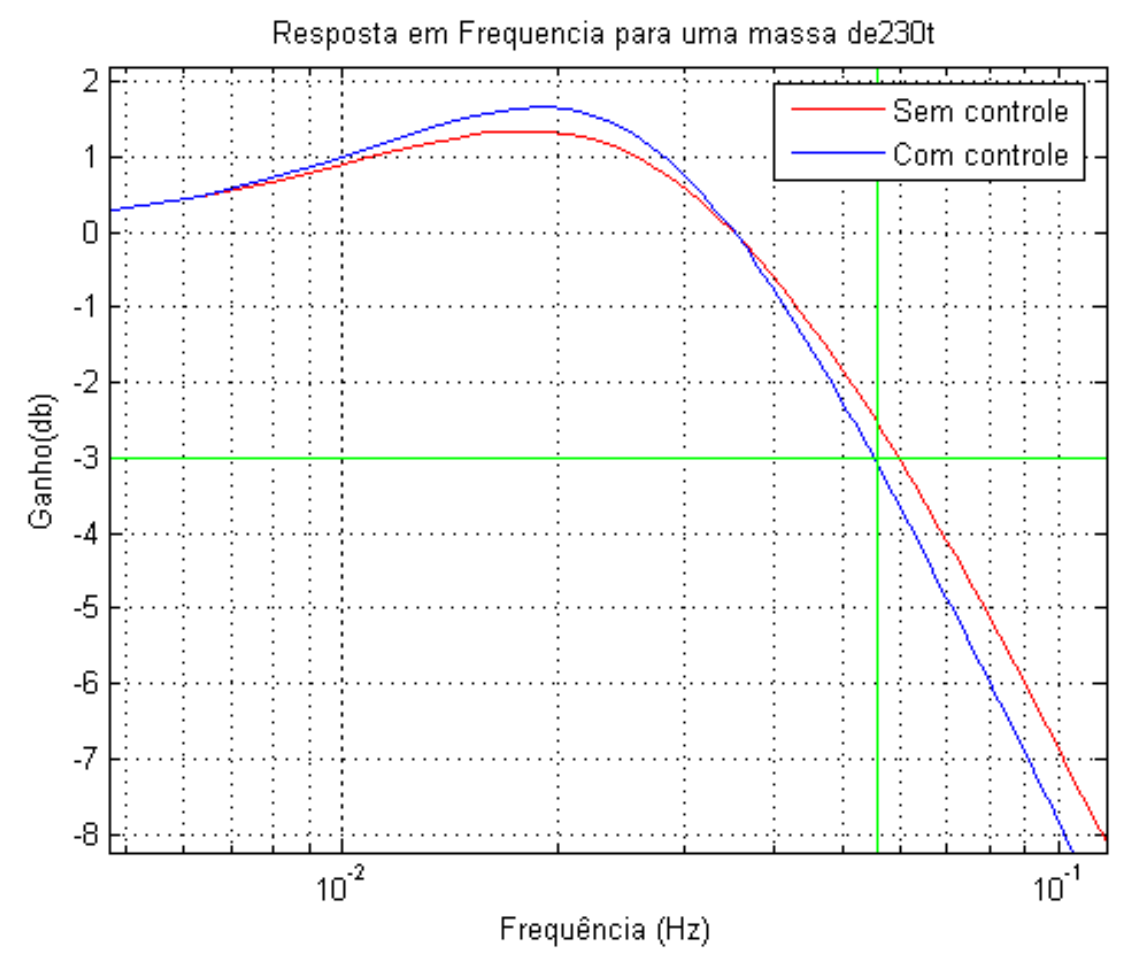

Figura 6.11: Resposta em frequência para a massa mínima, compensador com mola

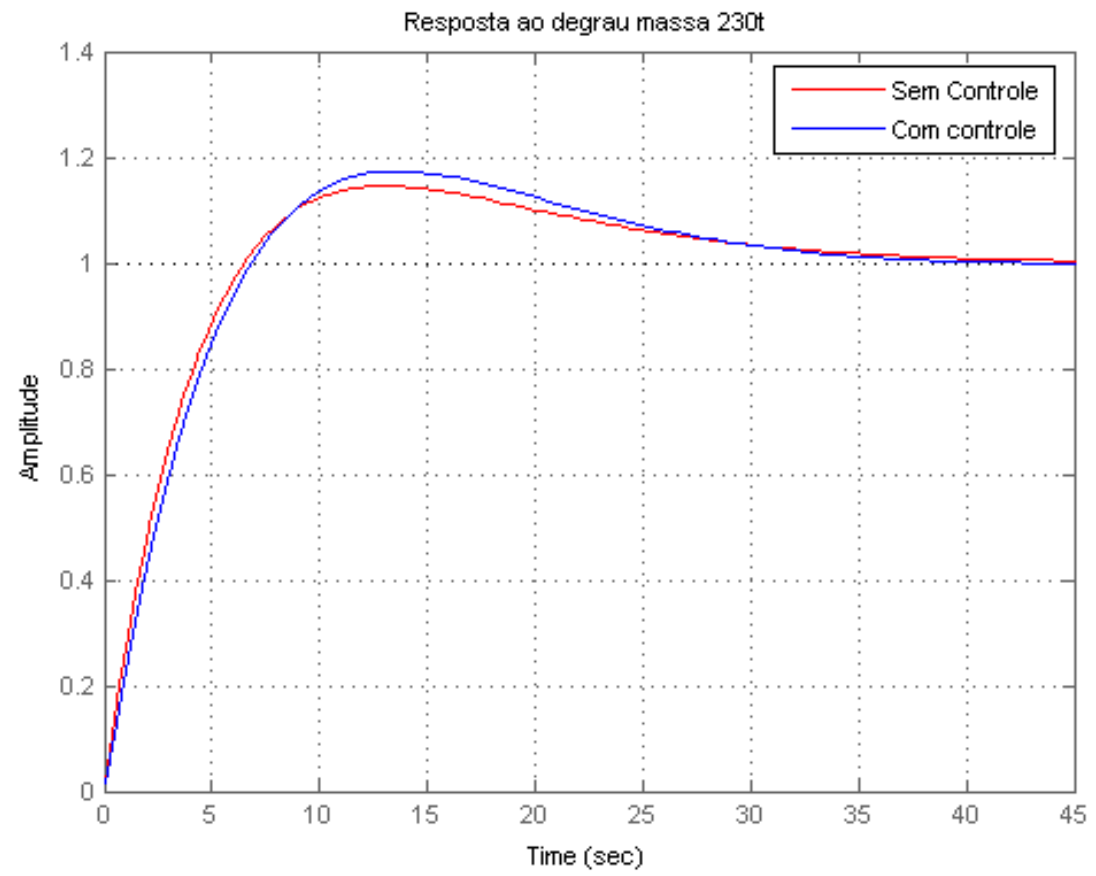

Figura 6.12: Resposta ao degrau para a massa mínima, compensador com mola 


\section{Capítulo 7}

\section{COMPENSADOR COM CREMALHEIRA}

Neste apêndice, propõe-se e desenvolve-se uma ideia para melhorar o comportamento do compensador e diminuir o tamanho do acumulador. Esta ideia é colocar um sistema de cremalheira na saída do compensador hidropneumático e fazer um controle semiativo. O apêndice esta organizado de forma similar à dissertação, introdução, modelagem, controle, projetando o compensador, resultados e conclusões.

\subsection{INTRODUÇÃO}

No compensador hidropneumático com cremalheira na saída, a parte hidropneumática comportase como foi descrito na Seção 2.4. Por isso, nesta parte só descreve-se o sistema de cremalheira.

Os sistemas de cremalheiras são usados em sistemas de ferrovias, elevadores e mecanismos de direção de automóveis e outros veículos. A principal função desses sistemas é converter movimento circular em traslacional, mas no caso dos trens, o principal objetivo da cremalheira é aumentar o atrito para permitir que o trem consiga subir montanhas de alta inclinação. O primeiro sistema de cremalheira foi utilizado na Inglaterra, numa ferrovia no Reino Unido, por uma locomotiva a vapor em 1812. As locomotivas são equipadas com uma ou mais rodas dentadas, que engrenam com um trilho de cremalheira. Isto permite que os trens operem em terrenos com inclinação acima de $7^{\circ}$, que é o valor máximo para o transporte ferroviário com base em aderência [50].

A Figura 7.1 mostra o esquema básico do compensador com cremalheira. A única diferença com o compensador hidropneumático simples é que este compensador tem uma cremalheira colocada na saida do compensador. O objetivo da cremalheira na saída do compensador é gerar um atrito cujo coeficiente $b_{1}$ é constante. Os movimentos na saída têm uma amplitude menor que a amplitude na entrada do compensador. Para uma amplitude menor o desgaste e o esforço mecânico da cremalheira é menor, por isso a cremalheira foi colocada na saída do compensador. 


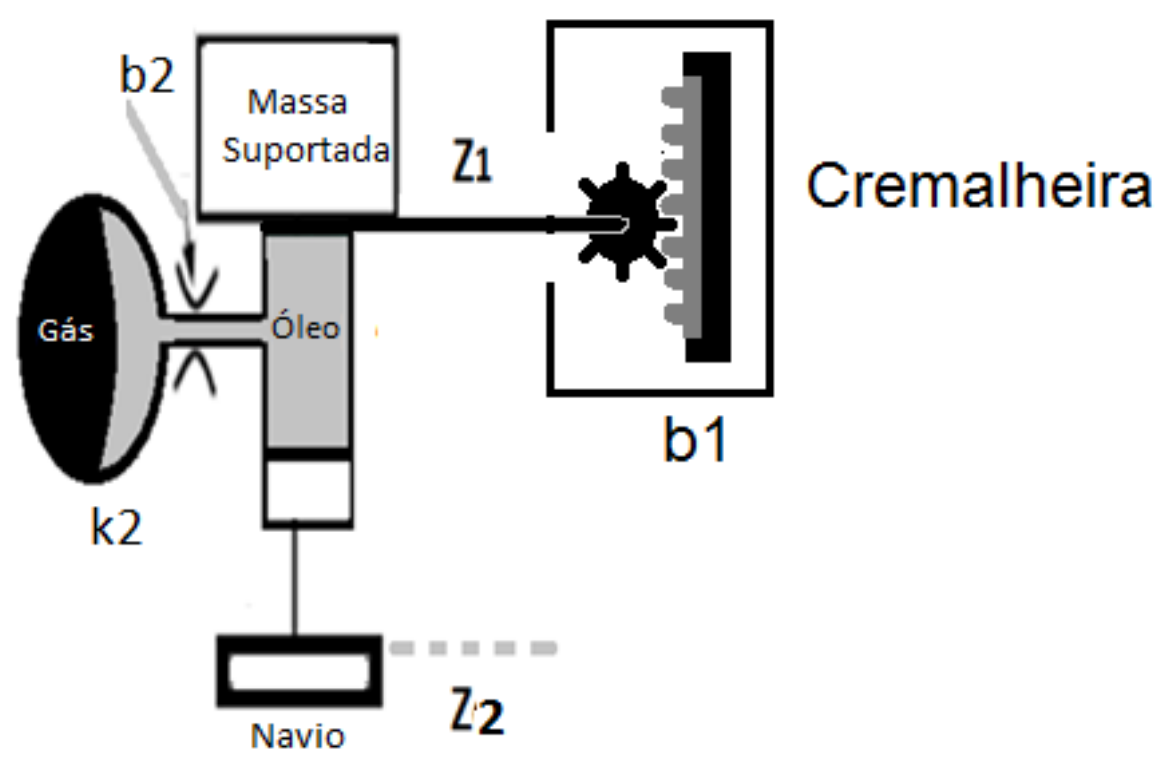

Figura 7.1: Esquema do compensador com cremalheira

\subsection{MODELAGEM}

A inércia da cremalheira não é considerada, pois é muito pequena; considera-se, porém, a força de atrito $b_{1} z_{1}^{\prime}$ Onde $b_{1}$ é a constante de atrito e $z^{\prime}$ a velocidade da coluna. Esta força é proporcional à velocidade do movimento de heave da coluna de perfuração, mas na direção oposta. Adicionando esta força na equação dinâmica da massa suportada pelo compensador (ver Equação (3.4)), a expressão obtida é:

$$
z_{1}^{\prime \prime}(t)=P_{c}(t) S v-m g-b_{1} z_{1}^{\prime}(t)
$$

Realizando o mesmo processo e tendo em conta as mesmas suposições feitas na Seção 3.1, obteve-se a função de transferência para o compensador com cremalheira:

$$
\frac{Z_{1}(s)}{Z_{2}(s)}=\frac{\left(\frac{b_{2}}{m} s+\frac{k_{2}}{m}\right)}{\left(s^{2}+\frac{\left(b_{2}+b_{1}\right)}{m} s+\frac{k_{2}}{m}\right)}
$$

Esta função é quase a mesma que a função de transferência do compensador sem mola (ver Equação (3.21)), a única diferença é que no denominador aparece a constante de atrito, devido ao amortecimento na saída do sistema, que é consequência do amortecimento gerado pela válvula e a cremalheira. 


\subsection{CONTROLE}

Este compensador tem uma cremalheira, mas continua sendo um sistema hidropneumático. Foi visto na Seção 2.3 que o comportamento dos sistemas hidropneumáticos varia quando a massa suportada é modificada. Por isso, o objetivo do controle é manter o comportamento desejado (ver Seção 5.1) quando a massa é variada. Este é o mesmo objetivo dos controles desenvolvidos no Capítulo 4 e tem a mesma variável de controle, mas este controle tem duas partes.

A Figura 7.2 apresenta o esquema de controle e o que acontece quando a massa é mudada. Quando a massa é modificada (massa nova) alguns parâmetros do compensador são modificados, como: frequência natural, frequência de corte, rigidez da mola e o volume do acumulador. Então, o controle tenta manter o comportamento desejado mudando o valor do amortecimento do sistema. Tem-se duas estratégias de controle, a primeira é obter o melhor comportamento possível sem levar em consideração o valor da frequência de corte e a segunda é somente garantir o valor da frequência de corte de 0,056Hz. As duas estratégias serão explicadas.

O controle trabalha da seguinte forma. Primeiro, o controle de melhor resposta calcula o valor de amortecimento, depois é avaliado se a resposta em frequência obtida para esse amortecimento tem um valor de frequência de corte maior que a frequência de corte permitida, se for esse o caso, o valor do amortecimento é calculado para garantir a frequência de corte requerida, no caso contrario, o valor de amortecimento será o valor calculado pelo controle de melhor resposta.

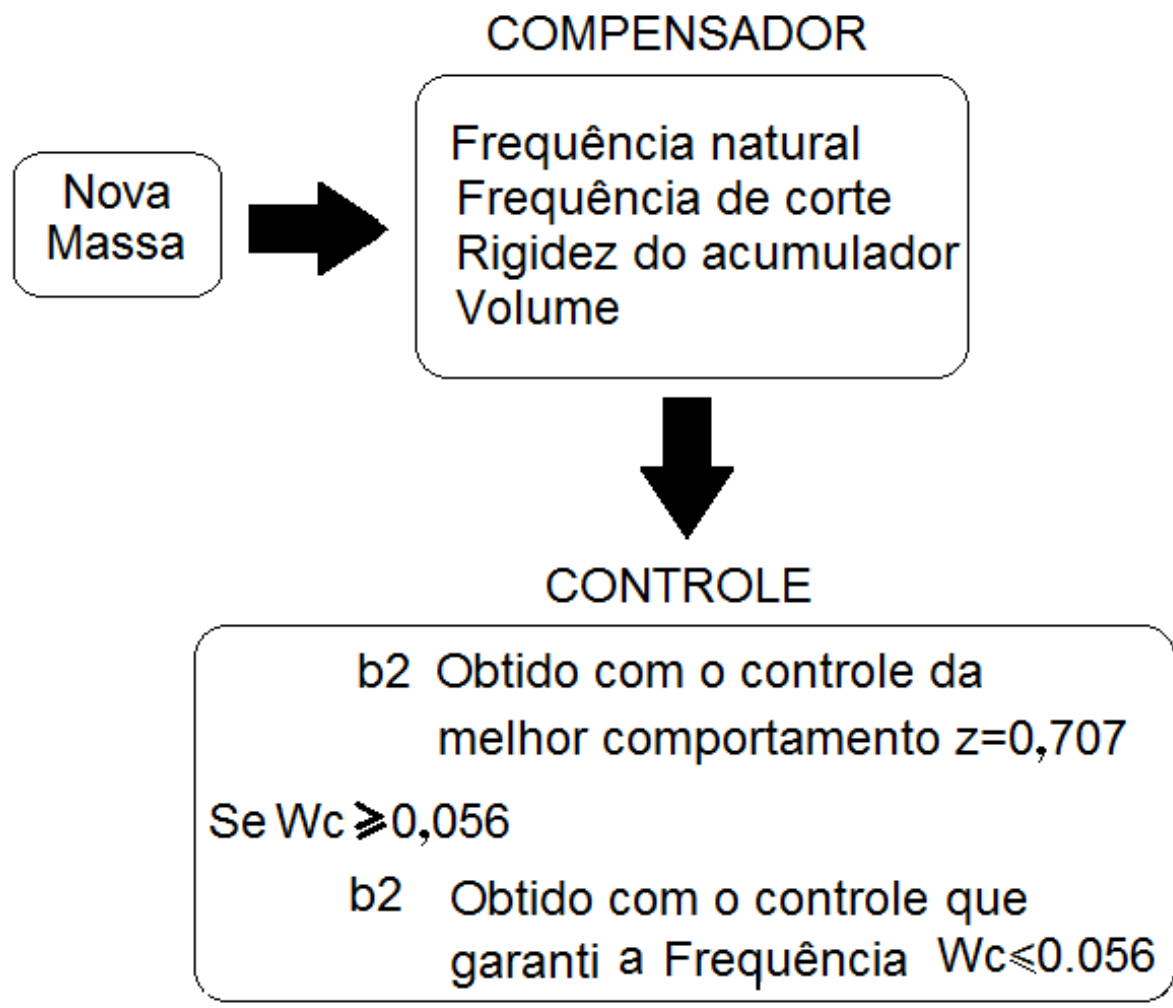

Figura 7.2: Esquema do controle implementado para o compensador com cremalheira 
O único objetivo do controle da melhor resposta é obter um coeficiente de amortecimento $z=0,707$ como recomenda o filtro de Butterworth. Este tem a resposta mais plana na faixa de passagem e uma aceitável atenuação durante a faixa de transição (ver Subseção 2.6.1). Usando a Equação (7.6) e isolando o valor do amortecimento encontra-se a expressão do controlador.

$$
b_{2}=2 z w_{n} m-b_{1}
$$

Para o controle que garante a frequência de corte, segue-se o mesmo processo feito na Seção 4.1 e adiciona-se a ação da cremalheira cujo valor de atrito é constante para todas as massas. Encontra-se a Equação (7.4) para achar o valor do amortecimento em função da massa suportada que garante a frequência de corte desejada. Na Seção 4.1, no último passo foi encontrada a expressão do amortecimento, mas por facilidade na visualização prefere-se deixar a equação de segundo grau sem resolver.

$$
\begin{array}{r}
\left(\frac{w^{2}\left(\|x\|^{2}-1\right)}{m^{2}}\right) b_{2}^{2}+\left(\frac{2 w^{2}\|x\|^{2} b_{1}}{m^{2}}\right) b \\
+\left(\frac{\left(\|x\|^{2}-1\right) k_{2}^{2}}{m^{2}}-\frac{2 k_{2} w^{2}\|x\|^{2}}{m}+w^{4}\|x\|^{2}+\frac{w^{2} b_{1}^{2}\|x\|^{2}}{m^{2}}\right)=0
\end{array}
$$

As raízes da equação anterior para o amortecimento $b_{2}$ são os possíveis valores da variável de controle. Como a equação de segundo grau vai ter duas soluções, tomam-se sempre as reais positivas e a solução cujo valor está perto do valor de amortecimento no ponto de projeto. Ao projetar o compensador na seguinte seção garante-se que sempre vai existir um valor real positivo para $b_{2}$ que soluciona a equação anterior.

\subsection{PROJETANDO O COMPENSADOR}

A função de transferência do compensador é projetada seguindo a metodologia proposta nesta dissertação. O denominador da função deve ter os pólos do filtro de Butterworth. Para projetar a função de transferência encontram-se as relações entre o denominador da função de transferência do compensador e a função de transferência do filtro, como foi feito na Seção 3.2. As relações obtidas são as seguintes:

$$
\begin{gathered}
k_{2}=w_{n}^{2} m \\
b_{2}+b_{1}=2 z w_{n} m
\end{gathered}
$$

A expressão da rigidez $k_{2}$ é a mesma que para o compensador sem cremalheira (ver Equação (3.26)). A expressão para o amortecimento é diferente (ver Equação (3.25)): o amortecimento total 
Tabela 7.1: Valores dos pârametros para os compensador com cremalheira no ponto de projeto

\begin{tabular}{c|c|c}
\hline Parâmetro & Simples & Com cremalheira \\
\hline Pressao máxima $\left(M N / m^{2}\right)$ & 22,8 & 22,8 \\
Area do cilindro $\left(m^{2}\right)$ & 0,16 & 0,16 \\
Altura do cilindro $(\mathrm{m})$ & 7 & 7 \\
Massa projeto $(\mathrm{t})$ & 286 & 286 \\
Amortecimento do sistema $b_{2}(k N s / m)$ & 68,5 & 49,9 \\
Atrito da cremalheira $(k N s / m)$ & 0 & 40,7 \\
Rigidez do acumulador $(k N / m)$ & 8,2 & 14,4 \\
Volume projeto $\left(m^{3}\right)$ & 76 & 43 \\
\end{tabular}

do sistema é a soma de $b_{2}$ e $b_{1}$. A relação entre esses dois parâmetros além de garantir os pólos recomendados pelo filtro de Butterworth deve aumentar o valor do zero da função de transferência do compensador.

Quanto maior for o valor do zero em comparação com a parte real dos pólos do denominador, o comportamento do compensador será mais próximo ao comportamento do filtro de Butterworth. Em teoria, o valor do zero pode ser aumentado ao aumentar o valor do atrito da cremalheira $b_{1} \mathrm{e}$ diminuir o valor do atrito do $b_{2}$, mas na prática não é adequado ter um valor de atrito da cremalheira maior do que o atrito da válvula, pois os sistemas mecânicos sofrem desgastes rapidamente e existe o risco do sistema ser danificado. Considerando isso, impõe-se o seguinte critério de projeto: o atrito da cremalheira no ponto de operação deve ser $82 \%$ do valor do atrito gerado pela válvula.

Resumindo, o compensador foi projetado usando a metodologia desta dissertação e adicionando o critério de $82 \%$ para ter a relação entre o atrito da cremalheira e o amortecimento da válvula no ponto de projeto. Os seguintes parâmetros foram projetados da mesma forma que na Seção 5.4: pressão máxima permitida, a altura do cilindro, a área do cilindro, a pressão máxima e a massa de projeto. No começo da Tabela 7.1 observa-se que esse valores são iguais para o compensador com e sem cremalheira. Os outros parâmetros deste compensador (atrito da cremalheira, rigidez do acumulador e volume do acumulador) são projetados de diferente forma e os valores são diferente como apresenta a Tabela 7.1. Na continuação explica-se como foram projetados esses três parâmetros.

No ponto de operação, a soma do atrito da cremalheira e o amortecimento da válvula devem garantir o valor da Equação (7.6): tendo em conta isso e o critério do $82 \%$, o valor para o atrito da cremalheira é $0,45\left(2 z w_{n} m\right)$ e o valor do amortecimento da válvula é $0,55\left(2 z w_{n} m\right)$. Portanto, os valores obtidos no ponto de projeto são $64,5 \mathrm{kNs} / \mathrm{m}$ para o amortecimento da válvula e $52,7 \mathrm{kN} / \mathrm{m}$ para o atrito da cremalheira.

O valor do volume do acumulador foi $43 m^{3}$, este foi projetado com a Equação (7.5). A frequência natural do sistema foi $0,0357 \mathrm{~Hz}$, valor mínimo de frequência que permite que a resposta do 
controle semiativo atinja a frequência de corte desejada para todo o intervalo de massa e garante o mínimo valor de volume. Para valores maiores de frequência natural, o controle para a massa máxima não conseguiu manter as condições e foi sugerido um valor de amortecimento com uma parte imaginária. Esta parte foi diferente do projeto do compensador sem cremalheira, nesse projetou-se a frequência de corte e obteve-se o valor da frequência natural.

O valor do volume deste compensador é $43 \%$ menor que o valor do volume do compensador sem cremalheira. Consequentemente, o valor da rigidez do acumulador é maior para o compensador com cremalheira $14,4 \mathrm{kN} / \mathrm{m}$ e a mola do compensador simples é mais macia com uma rigidez de $8,2 \mathrm{kN} / \mathrm{m}$.

\subsection{RESULTADOS}

Os resultados apresentados são: a magnitude da resposta em frequência, o valor da variável de controle $b_{2}$ para os dois controles, o valor do volume do acumulador e a rigidez do acumulador para os casos de massa máxima, massa mínima e massa de projeto (ver Subseção 5.4.5). O volume do acumulador e a rigidez do acumulador são calculados em todos os casos com as mesmas equações da Seção 3, pois no acumulador acontece o mesmo que já foi descrito nessa seção. Com a Equação (3.60) calcula-se o volume e com a Equação (3.61) a rigidez do acumulador. Os resultados da resposta em frequência com os dois controles são apresentadas para mostrar que cada controle gera um comportamento adequado para um intervalo diferente de massa.

\subsubsection{MASSA 286t}

Substituem-se os valores da Tabela 7.1 na Equação (7.2) para obter a função de transferência do compensador da Equação (7.7). Com uma frequência natural de $0.0357 \mathrm{~Hz}$ os pólos sugeridos pelo filtro de Butterworth de segunda ordem são 0,1586 \pm 0,1586j. O zero da função é 0.2884, 1,8 vezes o valor da parte real dos pólos do compensador, lembrando que o zero do compensador sem cremalheira e sem mola era igual à parte real dos pólos.

$$
T f=\frac{0.17445(s+0.2884)}{\left(s^{2}+0.3172 s+0.05031\right)}
$$

A Figura 7.3 apresenta a magnitude da resposta em frequência da função de transferência. A frequência de corte é de $0,046 \mathrm{~Hz}$, pois para valores de frequência natural de projeto maiores o controle na massa máxima não atingiu os requerimentos, o ganho máximo é $0,35 \mathrm{~dB}$ e acontece na frequência de $0,017 \mathrm{~Hz}$, o valor do ganho máximo para o compensador sem cremalheira é 5,7 vezes o valor do ganho para este compensador.

\subsubsection{MASSA $360 \mathrm{t}$}

O valor do volume do acumulador para a massa máxima de $360 \mathrm{t}$ é de $37 \mathrm{~m}^{3}$. O valor da rigidez do acumulador $k_{2}$ é de $21,3 K N / m$. O valor de $b_{2}$ é calculado para cada controle, obtendo 


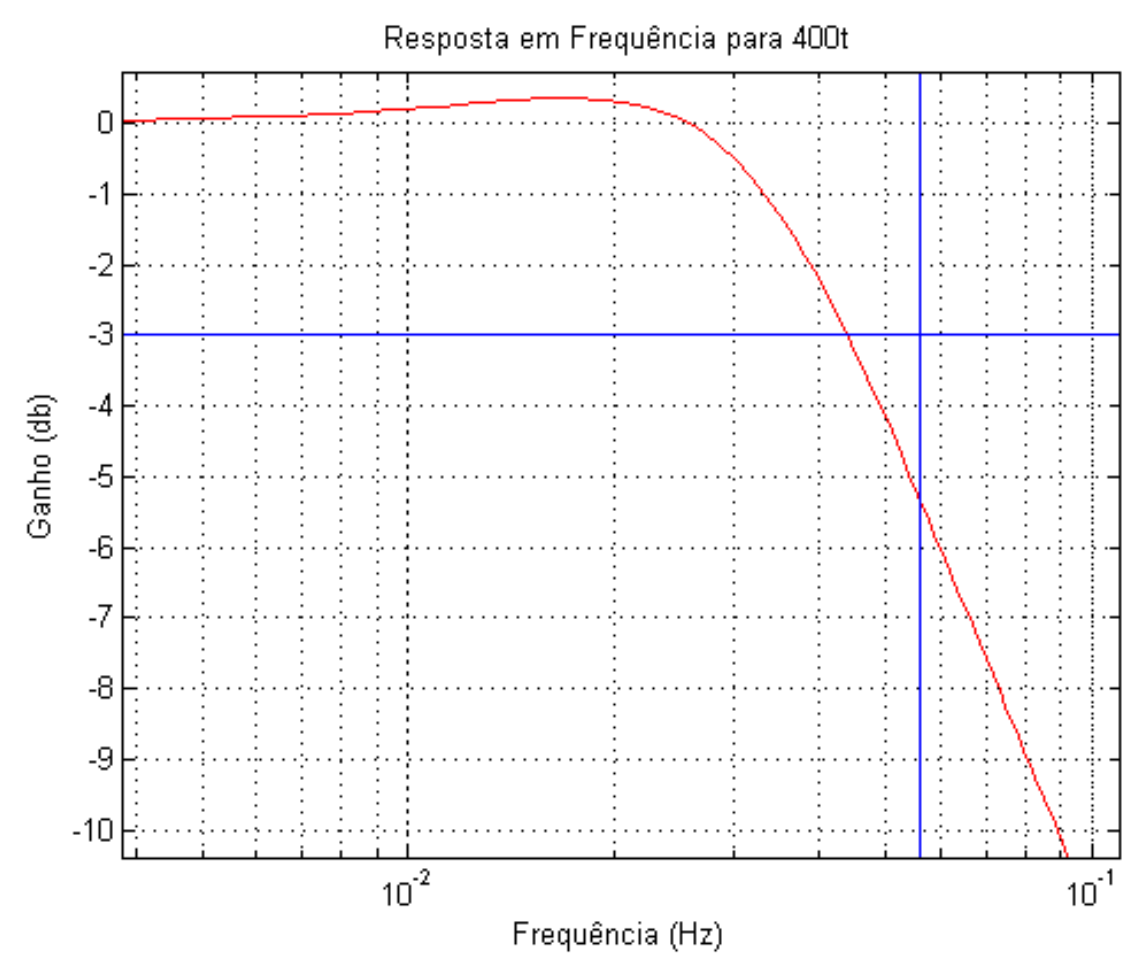

Figura 7.3: Resposta em frequência para a massa de projeto, compensador com cremalheira

8,3kNs/m com a Equação (7.4) do controle que garante a frequência de corte e $4,9 \mathrm{kNs} / \mathrm{m}$ com a Equação (7.3) do controle da melhor resposta. Esses valores são substituídos na Eq. (7.2) para calcular as funções de transferência.

A Figura 7.4 mostra a resposta em frequência do compensador sem controle e com as duas estratégias de controles. Sem controle, a resposta obtida respeita o valor de frequência de corte $0,056 \mathrm{~Hz}$ e tem um ganho máximo de $1,7 \mathrm{~dB}$, o coeficiente de amortecimento $z=0,51$ e o zero de 0,4279. Com a estratégia de controle que garante frequência de corte é obtida a mesma resposta que sem controle. Para o controle da melhor resposta $z=0,707$, a resposta em frequência tem uma frequência de corte de $0,058 \mathrm{~Hz}$ maior que a frequência de corte requerida. Por isso, para esse valor de massa e para valores maiores do que 340t, o valor de amortecimento escolhido é o valor calculado pela estratégia de controle que garante a frequência de corte e para as massas menores o valor é dado pelo controle de melhor resposta.

\subsubsection{MASSA 230t}

Na massa mínima, o compensador tem o maior volume no acumulador, $50 \mathrm{~m}^{3}$. O valor da rigidez do acumulador $k_{2}$ é de $9,3 \mathrm{KN} / \mathrm{m}$. O valor do amortecimento calcula-se com a Equação (7.4) para o controle que garante a frequência de corte e com a Equação (7.3) para o controle da melhor resposta, os valore são $101,9 k N s / m$ e $26,6 k N s / m$ respectivamente. Esses valores são substituídos na Eq. (7.2) para calcular as funções de transferência.

A Fig. 7.5 mostra a resposta em frequência para o compensador sem e com as duas estratégias 


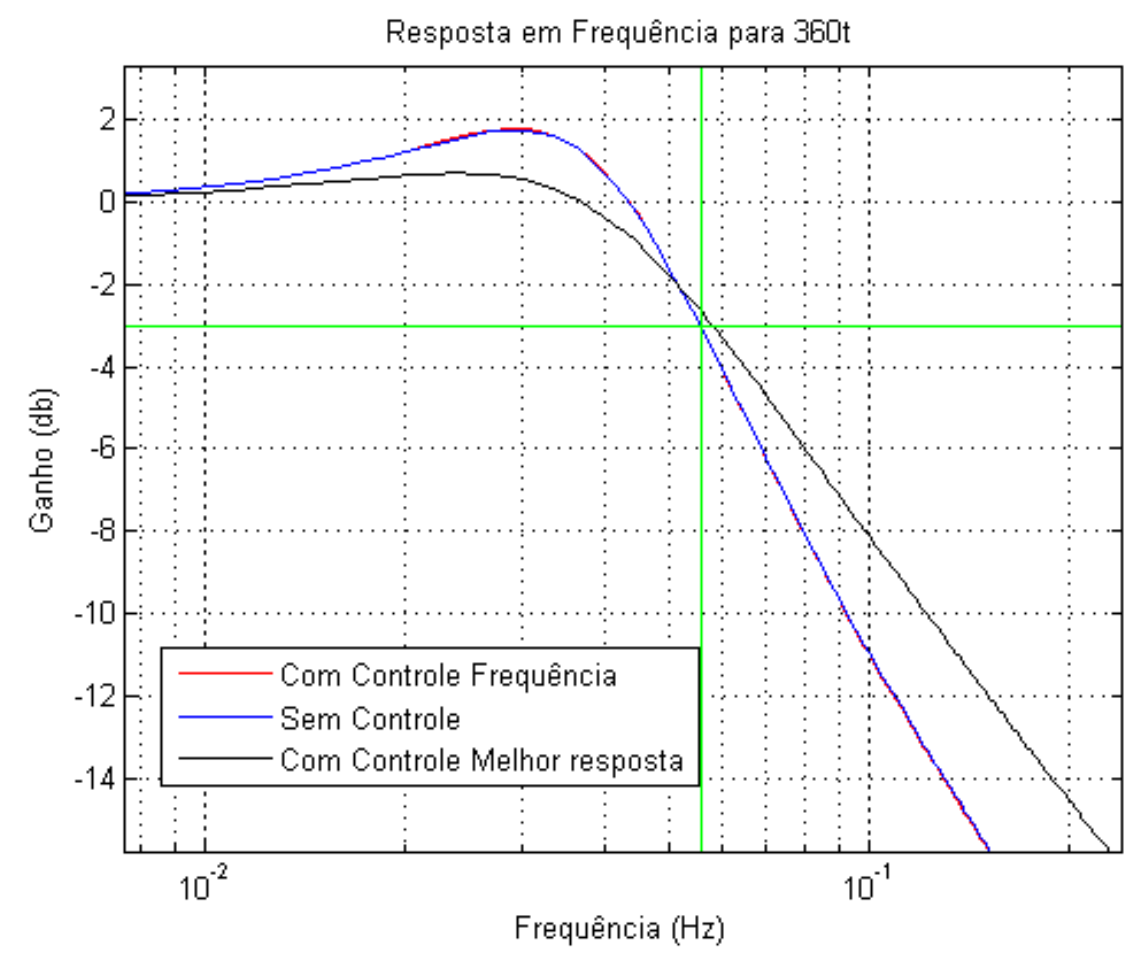

Figura 7.4: Resposta em frequência para a massa máxima, compensador com cremalheira

de controle. As três respostas têm a frequência de corte no intervalo desejado (menor ou igual do que $0,056 \mathrm{~Hz}$ ) e um ganho de $0 \mathrm{~dB}$ na banda de passagem, mas a maior atenuação na banda de transição é atingida pela resposta do controle de melhor resposta, quase a mesma que a resposta do filtro desejado.

O amortecimento $z$ para o compensador sem controle é de 0,95 e o valor do zero é $0,0,043$; para o controle que garante a frequência de corte o amortecimento é de 1,6 e o zero é de 0,056 ; para o controle da melhor resposta o amortecimento é de 0,7 e o valor do zero é 0,043 . Com o amortecimento de 0,7 além de obter o denominador desejado, consegue-se aumentar o valor do zero, por isso a resposta nesse caso é a melhor.

\subsection{CONCLUSÕES}

Foi adicionado um elemento mecânico ativo no compensador, mas o compensador continua sendo um compensador com as mesmas vantagens como: consumo mínimo de energia, robustez no caso de falhas eletromecânicas e facilidade no controle de posição de referencia quando a massa é modificada. O volume do acumulador requerido pelo compensador é de $50 \mathrm{~m}^{3}$. A cremalheira reduz o volume do acumulador $44 \%$ em comparação com o compensador sem cremalheira.

A combinação das duas estratégias de controle garante que para todo o intervalo de massas a frequência de corte sempre estará no intervalo de frequência de corte desejado e um ganho máximo menor que $1,7 \mathrm{~dB}$. O uso da cremalheira diminuiu $1,5 \mathrm{~dB}$ o ganho máximo no caso da massa máxima 


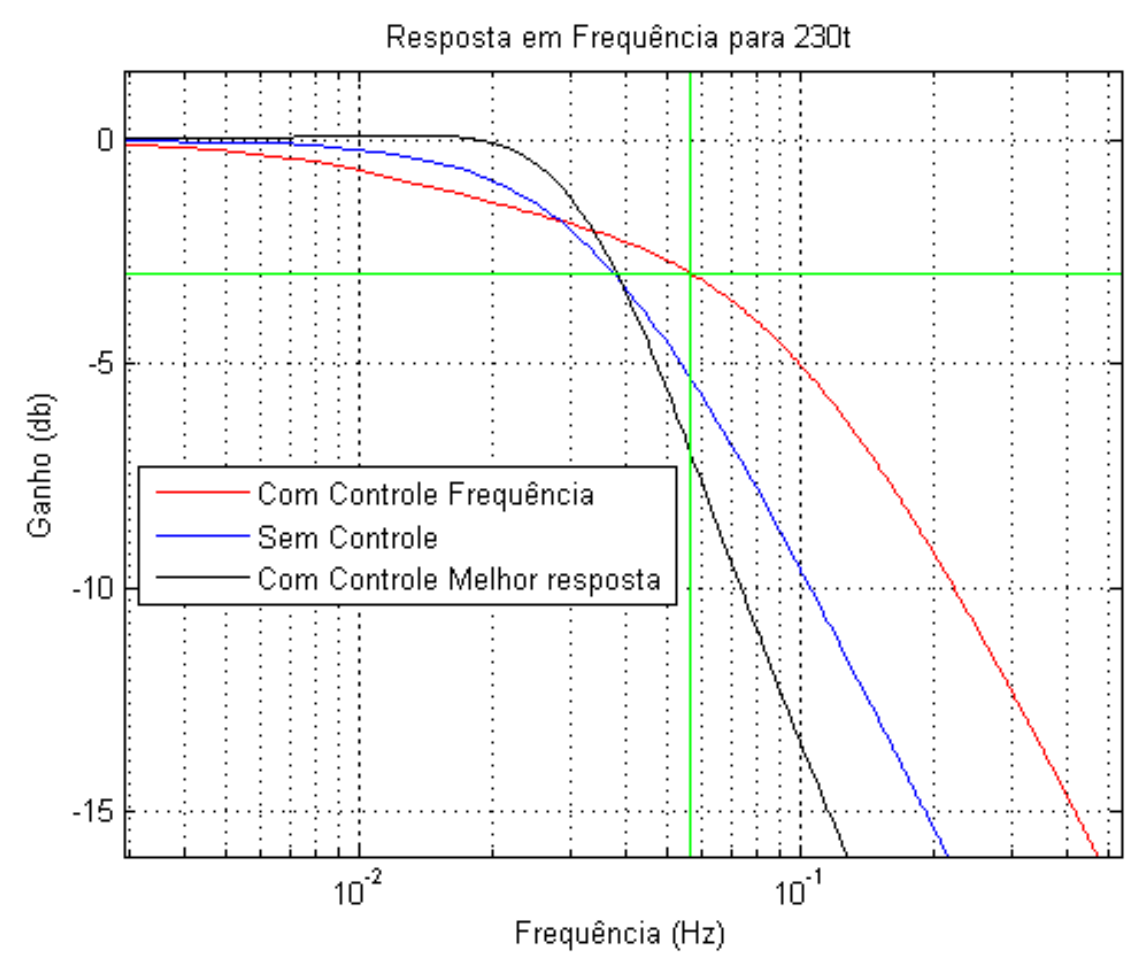

Figura 7.5: Resposta em frequência para a massa mínima, compensador com Cremalheira

e um $1 \mathrm{~dB}(100 \%)$ para a massa mínima.

Para massas maiores do que 340t, o controle da melhor resposta apresenta frequências de corte superiores à frequência de corte desejada, por isso, no intervalo de 340t até 360t o controle escolhido é o controle que garante a frequência de corte desejada. Para massas menores ou iguais do que $340 \mathrm{t}$ o primeiro controle apresenta melhores resultados. Em cada intervalo o controle implementado apresenta vantagem, assim o controle que garante a frequência de corte sempre tem um ganho máximo menor do que o ganho sem controle e o controle da melhor resposta tem a resposta com uma atenuação maior que o sistema sem controle, mantendo um ganho aceitável na faixa de passagem. 


\section{Capítulo 8}

\section{COMPENSADOR COM CONTROLE SEMIATIVO CONTINUO}

No apêndice anterior e na Seção 4, o amortecimento para atingir o comportamento desejado é calculado pelo controle cada vez que a massa suportada muda, esse valor fica constante até mudar novamente o valor da massa. Neste apêndice, o valor de amortecimento é calculado para cada instante de tempo, ainda que a massa suportada permaneça constante.

O compensador neste apêndice é o compensador sem mola e sem cremalheira, descrito na Seção 2.4 e a modelagem está na Seção 3.1, adiciona-se a modelagem da queda de pressão gerada por uma placa de orifício, explicasse detalhadamente o controle proposto, nos resultados é mostrada a resposta em frequência do compensador e finalmente estão as conclusões.

\subsubsection{PERDA DE PRESSÃO POR PLACA DE ORIFÍCIO.}

Uma placa de orifício consiste numa placa perfurada situada no interior de uma tubulação. Existem algumas válvulas servo-comandadas que trabalham de forma similar, onde o tamanho do orifício é mudado para modificar a queda de pressão.

De acordo com a Lei de Bernoulli da conservação de energia, no orifício haverá um aumento da velocidade do fluído e uma redução na pressão estática $\triangle P_{12}$. Depois de passar pela restrição, haverá uma recuperação parcial da pressão estática $\triangle P_{23}$, mas no final existirá uma perda permanente $\triangle P_{\text {permanente }}$ em comparação com a pressão inicial (ver Figura 8.1).

Para encontrar a expressão que representa a queda permanente de pressão pelo orifício, primeiro calcula-se e soma-se a queda de pressão gerada pelo orifício $\triangle P_{12}$ com a pressão que é recuperada $\triangle P_{12}$.

$$
\triangle P_{\text {permanente }}=\triangle P_{12}+\triangle P_{23}
$$

Com a Lei de Bernoulli e considerando as perda de carga por fricção adiciona-se o coeficiente 


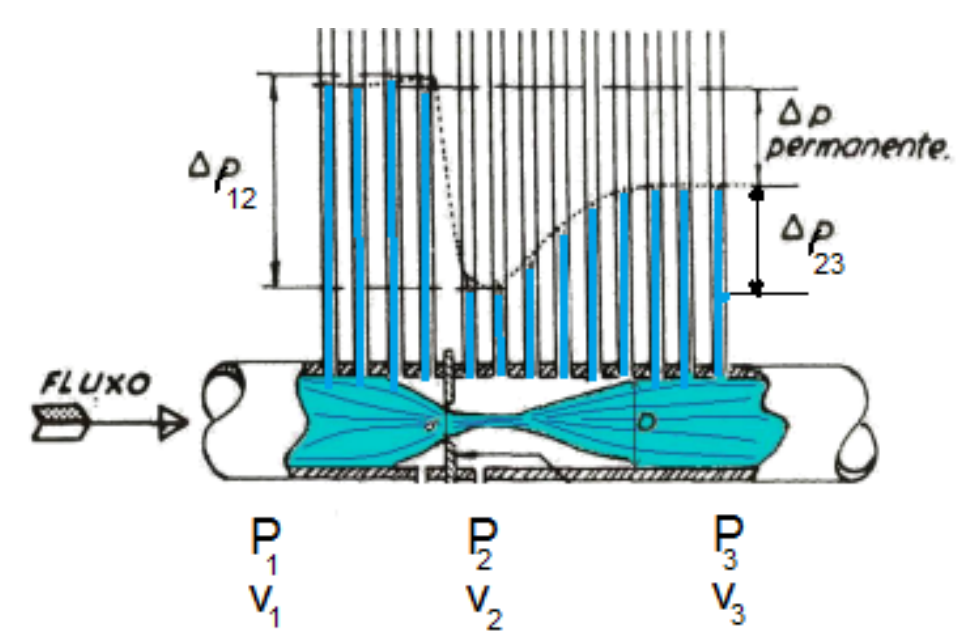

Figura 8.1: Perda de carga de uma válvula de orifício

de orifício, obtendo a queda de pressão no orifício

$$
\triangle P_{12}=\frac{\rho}{2 g C_{o}^{2}}\left(v_{1}^{2}-v_{2}^{2}\right)
$$

Agora com a lei de conservação da massa é obtida a expressão da velocidade antes do orifício $v_{1}$ em função da velocidade do líquido no orifício $v_{2}$

$$
v_{2}=\frac{d_{1}^{2}}{d_{2}^{2}} v_{1}
$$

Subtituindo a expressão anterior da velocidade no orifício na equação da queda de pressão $\triangle P_{12}$

$$
\triangle P_{12}=\frac{\rho}{2 g C_{o}^{2}}\left(1-\left(\frac{d_{1}}{d_{2}}\right)^{4}\right) v_{1}^{2}
$$

De forma similar é obtida a expressão para a pressão recuperada depois do orifício

$$
\triangle P_{23}=\frac{\rho}{2 g}\left(\left(\frac{d_{1}}{d_{2}}\right)^{4}-1\right) v_{1}^{2}
$$

Somando as duas expressões anteriores, foi obtida a queda de pressão que produz a placa de orifício, dessa expressão foi obtido o diâmetro que deve ter o orifício da placa para gerar uma queda de pressão desejada.

$$
d_{2}=d_{1}\left(1-\frac{2 g \triangle P_{\text {permanente }}}{\rho v_{1}^{2}\left(\frac{1}{C_{o}^{2}-1}\right)}\right)^{(-0.25)}
$$

\subsection{CONTROLE}

Foi visto na Seção 2.3 que o comportamento dos sistemas hidropneumáticos varia quando a massa suportada é modificada. Por isso, para cada massa o controle calcula a função de transferência desejada, os parâmetros desta função são usados para calcular o amortecimento que deve 
ter o sistema em cada instante de tempo para obter uma resposta em frequência similar à resposta desejada, garantindo sempre a frequência de corte. A Figura 8.2 mostra um esquema para facilitar a compreensão do controle.
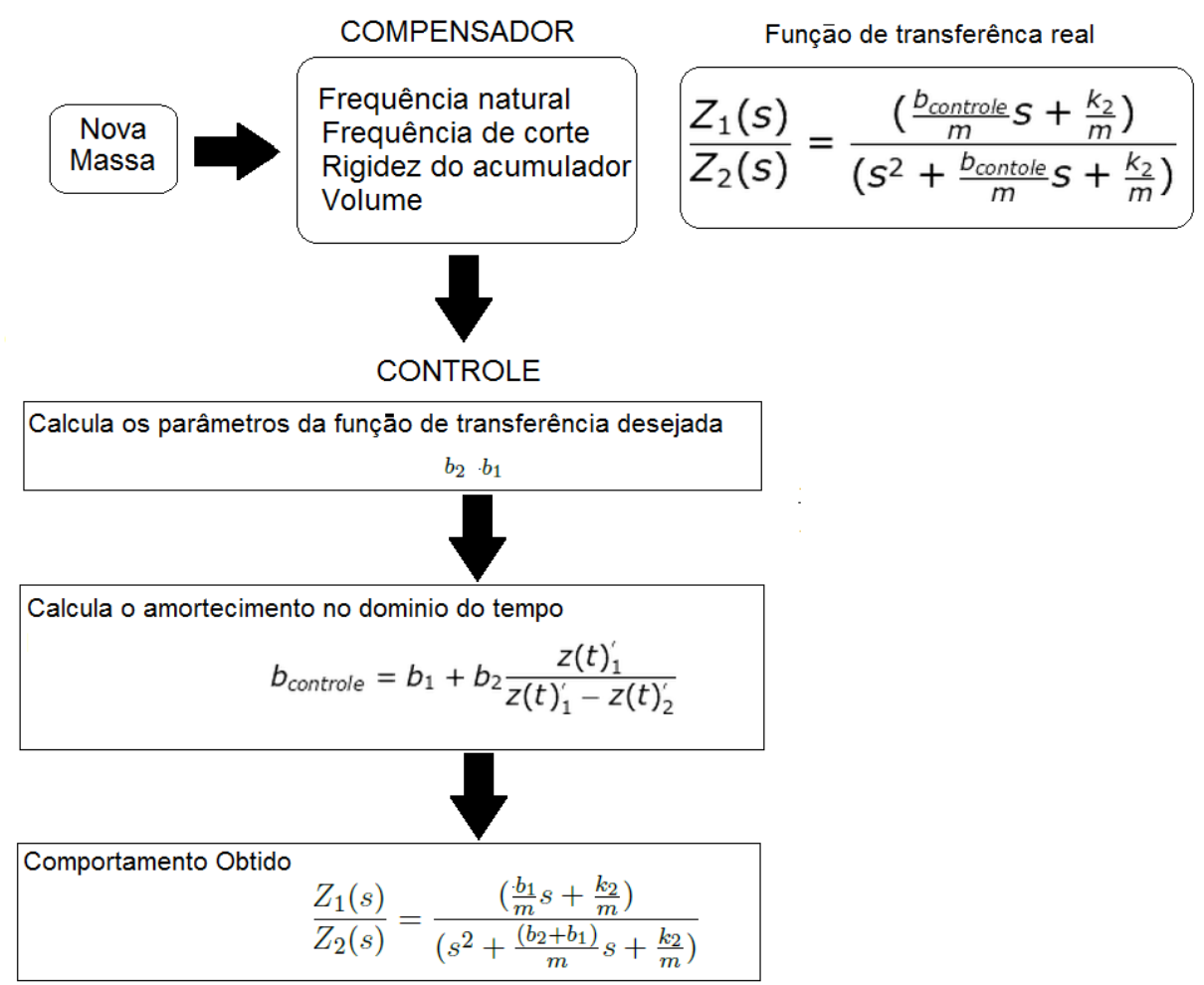

Figura 8.2: Esquema do controle continuo no tempo

\subsubsection{FUNÇÃO DESEJADA.}

A função de transferência desejada é a função de transferência do compensador com cremalheira que foi projetado no Apêndice anterior (ver Equação (7.2)). No compensador com cremalheira, o valor do atrito da cremalheira é constante para todos os valores de massa. Neste caso, o valor do atrito da cremalheira é calculado para cada massa, obtendo-se uma função de transferência desejada diferente para cada massa. A relação entre o valor do atrito da cremalheira $b_{1}$ e o amortecimento da válvula $b_{2}$ é diferente da relação encontrada no apêndice anterior, pois o critério usado para escolher essa relação não é valido neste caso.

No compensador com cremalheira, o atrito da cremalheira no ponto de operação foi de 0.82 vezes o valor do amortecimento da válvula, $45 \%$ o valor do amortecimento total do denominador da função de transferência, essas relações foram escolhidas com o objetivo de diminuir o desgaste na cremalheira evitando o risco do sistema resultar danificado, mas neste compensador não existe uma cremalheira mecânica para proteger. Então, o valor de amortecimento da cremalheira $b_{1}$ é 5.67 vezes o valor do atrito gerado pela válvula, $85 \%$ do amortecimento total da função de transferência no denominador. As expressões para o amortecimento da válvula e o atrito da cremalheira são 
representadas pelas seguintes equações:

$$
\begin{gathered}
b_{2}=2 z w_{n} m(1-0.85) \\
b_{1}=2 z w_{n} m(0.85)
\end{gathered}
$$

Com as relações anteriores, consegue-se aumentar o valor do zero de forma que o comportamento do compensador é quase o comportamento do filtro desejado, ver análise feita na Seção 7.4. Isso pode ser visto na Figura 8.3 que apresenta o comportamento do filtro de Butterworth desejado e o comportamento obtido com a função de transferência do compensador com cremalheira. Neste caso a frequência natural tem o mesmo valor que a frequência de corte desejada, $0.056 \mathrm{~Hz}$.

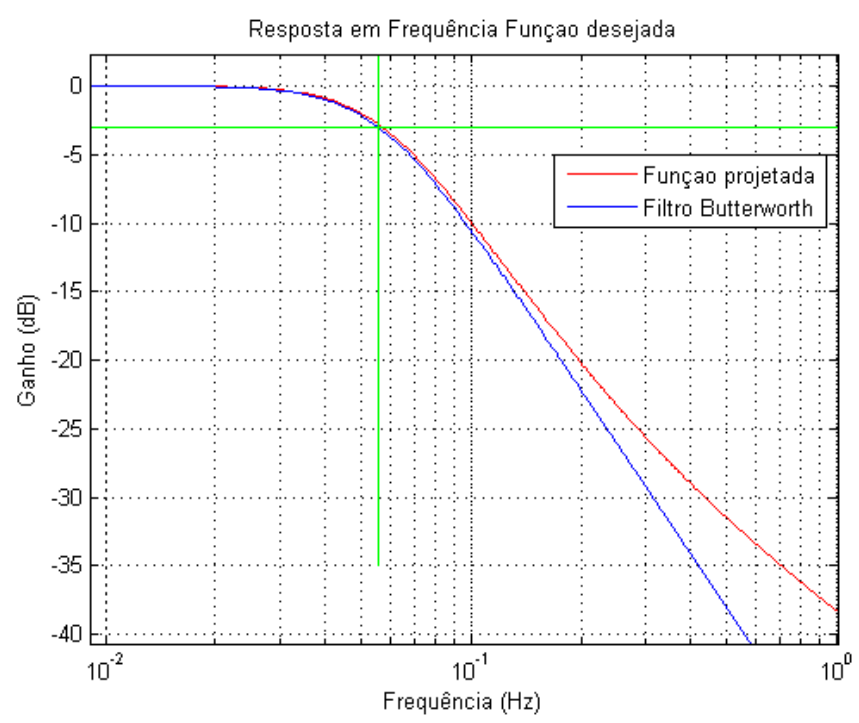

Figura 8.3: Resposta em frequência do filtro desejado e da função de transferência do compensador com cremalheira

\subsubsection{OBTENDO A FUNÇÃO DESEJADA}

Expandindo a equação de transferência do compensador sem mola (Equação (3.21)), levando no domínio do tempo e mudando $b_{2}$ por $b_{\text {controle }}$ para não confundir com o $b_{2}$ usado na função de transferência do compensador com cremalheira, é obtida a seguinte expressão:

$$
z(t)_{1}^{\prime \prime}+\left(z(t)_{1}^{\prime}-z_{2}(t)^{\prime}\right) \frac{b_{\text {controle }}}{m}+\left(z(t)_{1}-z(t)_{2}\right) \frac{k_{2}}{m}=0
$$

O objetivo do controle é obter a função de transferência do compensador com cremalheira, mediante a manipulação do fator de amortecimento $b_{\text {controle }}$, a equação do compensador no domínio do tempo é a seguinte:

$$
z(t)_{1}^{\prime \prime}+\left(z(t)_{1}^{\prime}-z_{2}(t)^{\prime}\right) \frac{b_{2}}{m}+z(t)_{1}^{\prime} \frac{b_{1}}{m}+\left(z(t)_{1}-z(t)_{2}\right) \frac{k_{2}}{m}=0
$$

A expressão do controle para calcular o amortecimento $b_{c}$ ontrole que gera a resposta desejada é a seguinte:

$$
b_{\text {controle }}(t)=b_{1}+b_{2} \frac{z(t)_{1}^{\prime}}{z(t)_{1}^{\prime}-z(t)_{2}^{\prime}}
$$


Tabela 8.1: Valores dos pârametros para os compensadores no ponto de projeto com controle continuo

\begin{tabular}{c|c}
\hline Parâmetro & Compensador \\
\hline Pressão máxima $\left(M N / m^{2}\right)$ & 22,8 \\
Área do cilindro $\left(m^{2}\right)$ & 0,16 \\
Massa projeto $(\mathrm{t})$ & 286 \\
Altura do cilindro $(m)$ & 7 \\
Volume projeto $\left(m^{3}\right)$ & 10,4 \\
Diâmetro da válvula aberta $(m)$ & 0,069 \\
Diâmetro da válvula quase fechada $(m)$ & 0,016 \\
Amortecimento do sistema em saturação máxima $b_{2}(M N s / m)$ & 2 \\
Amortecimento do sistema em saturação mínima $b_{2}(M N s / m)$ & 0,05 \\
\hline
\end{tabular}

Substituindo a anterior expressão na Equação (3.21) é obtida a Equação (8.10). Em teoria, o valor de amortecimento calculado permite obter a função de transferência desejada, mas acontece que o amortecimento calculado pode ser negativo ou ter uma magnitude muito grande. Fisicamente, o amortecimento só tem sentido para valores positivos e deve ter um limite superior, já que a válvula não pode ficar totalmente fechada. Portanto, coloca-se uma saturação no sistema que tem um valor mínimo de $0.05 \mathrm{MNs} / \mathrm{m}$ e um valor máximo de $2 \mathrm{MNs} / \mathrm{m}$, na seguinte seção explica-se como foi encontrado esse valor máximo.

\subsection{PROJETANDO O COMPENSADOR}

Os seguintes parâmetros do compensador foram projetados da mesma forma que na Seção 5.4: pressão máxima, área cilindro, altura do cilindro, massa de projeto, volume do cilindro, rigidez do acumulador, mas o amortecimento da válvula servo-comandada tem uma análise diferente a Tabela 8.1 apresenta todos os valores do compensador no ponto de projeto com controle.

O volume e a rigidez do acumulador têm diferentes valores em comparação com o compensador projetado na Seção 5.4. Este compensador foi projetado com um valor de frequência natural de $0.073 \mathrm{~Hz}$, devido a que o controle permite que o comportamento seja o comportamento da função de transferência desejada.

Foi dito no controle que a válvula servo-comandada apresentara saturação. A válvula escolhida pode estar totalmente aberta com um diâmetro de $0,069 \mathrm{~m}$, quase fechada com um diâmetro de $0,016 \mathrm{~m}$ ou uma posição intermedia. Para uma velocidade relativa entre a base e a massa suportada pequena de $0,05 \mathrm{~m} / \mathrm{s}$ a queda de pressão com a válvula quase fechada é de 4atm. Para uma velocidade relativa grande de $0,5 \mathrm{~m} / \mathrm{s}$ a queda de pressão com a válvula aberta é de $1 \mathrm{~atm}$.

Com a válvula aberta é obtido o mínimo amortecimento do compensador $0,05 \mathrm{MNs} / \mathrm{m}$ que 
indica a saturação mínima da válvula, para calcular esse valor foi escolhido o valor de velocidade relativa máximo e calculou-se a queda de pressão. No caso contrario, com a válvula quase fechada tem-se o valor de amortecimento máximo $2 M N s / m$ (saturação máxima da válvula), este valor foi calculado com a velocidade relativa mínima e com a queda de pressão que gera o menor diâmetro de abertura para essa velocidade. Para calcular o amortecimento, calcula-se a resistência hidráulica com a Equação 3.8 substitui-se na Equação 3.17.

\subsection{RESULTADOS}

Os resultados apresentados são a resposta em frequência do compensador e os valores de coeficiente de amortecimento $z$ para a massa máxima, massa mínima e massa de projeto. Para a massa máxima é mostrada a resposta do compensador para uma onda real.

A resposta em frequência é diferente da resposta desejada porque a saturação da válvula não permite que o valor do amortecimento $b_{\text {controle }}$ seja o requerido pelo controle em todos os instantes de tempo e adiciona uma não linearidade no sistema. Por isso, a resposta do compensador com o controle e com a saturação da válvula é simulado em Simulink. A simulação é feita varias vezes para uma entrada sinusoidal de $1 \mathrm{~m}$ e diferentes valores de frequência, registrando-se a amplitude do deslocamento da massa suportada. Com esses dados é traçado a resposta em frequência do sistema.

Para todas as massas a função de transferência desejada atinge a frequência de corte com um amortecimento menor do que $z=1$, mas o controle feito para obter a função de transferência com esse amortecimento, não consegue atingir a frequência de corte. Provavelmente, deve-se a que a saturação da válvula não permite obter os valores requeridos pelo controle em todos os instantes de tempos.

Observado isso, a solução foi uma correção do amortecimento $z$, aumentou-se o valor desse parâmetro na função de transferência desejada. A Figura 8.4 mostra os valores de amortecimento que garantem a frequência de corte desejada, foram usados três valores de massas.

Feita a correção no amortecimento foi calculada a resposta em frequência para as massas mínima 230t, máxima 360t e de projeto 286t. Os resultados da resposta em frequência são mostrados para as três massas na Figura 8.5. Observa-se que as respostas são similares à resposta do filtro de Butterworth desejado, pois não apresentam oscilações em nenhuma das faixas, além disso o ganho é zero na faixa de passagem e a atenuação na faixa de transmissão é aceitável.

A resposta em frequência do compensador que teve a menor atenuação foi a resposta para 360t. Então, para essa massa é simulada a resposta do compensador quando a plataforma está sendo deslocada pelas ondas do mar. A Figura 8.6 apresenta o movimento da plataforma (sinal tomado do [46]) e a resposta do compensador. A resposta é ótima, pois o compensador consegue atenuar o sinal de forma que a resposta tem um valor máximo equivalente a $25 \%$ do valor máximo no sinal de entrada. 


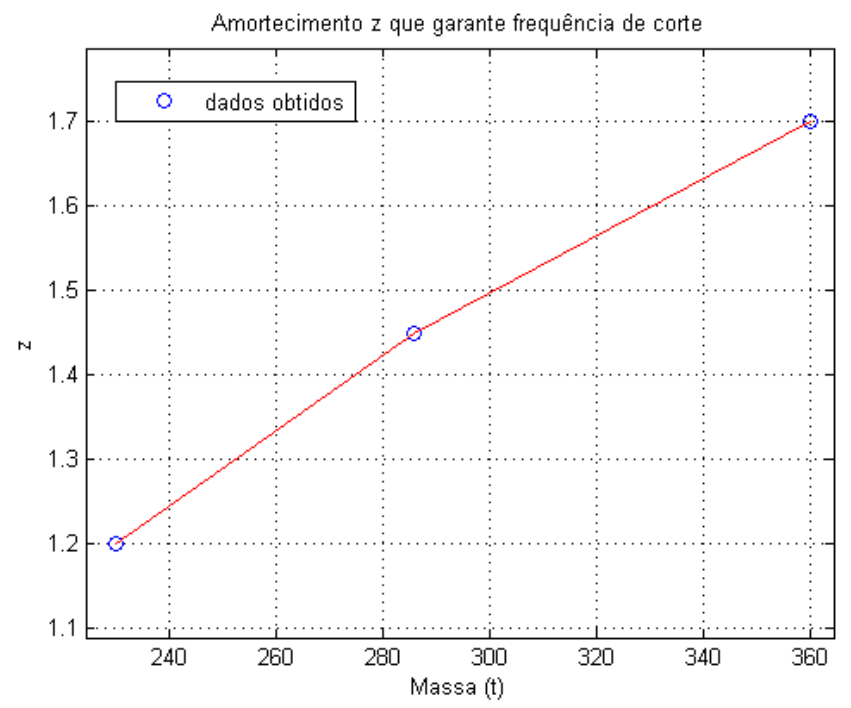

Figura 8.4: Esquema do controle continuo no tempo

\subsection{CONCLUSÕES}

O compensador projetado tem um volume de $12 \mathrm{~m}^{3}$, diminuindo num $87 \%$ em comparação com o mesmo sistema sem controle continuo. O volume ainda pode ser diminuído, mas deve-se estudar a variação do comportamento e o requerimento da válvula.

A resposta em frequência foi melhorada, pois o controle conseguiu manter a frequência de corte desejada para todo o intervalo de massa com um ganho de zero na faixa de passagem. A resposta em frequência do compensador é similar à resposta do filtro de Butterworth.

Os valores dos parâmetros físicos do sistema indicam que é realizável, pois o tamanho do acumulador encontra-se perto do intervalo de volume dos compensadores comerciais e a abertura da válvula em saturação é um valor aceitável.

A tecnologia desenvolvida apresenta vantagens tais como: possibilidade de melhor se adaptar às variações no peso da coluna de perfuração; baixo consumo de energia, pois o único elemento que precisa energia é a válvula de servo; continuidade na perfuração no caso de falha (fácil e barata a implementação de um sistema redundante). 


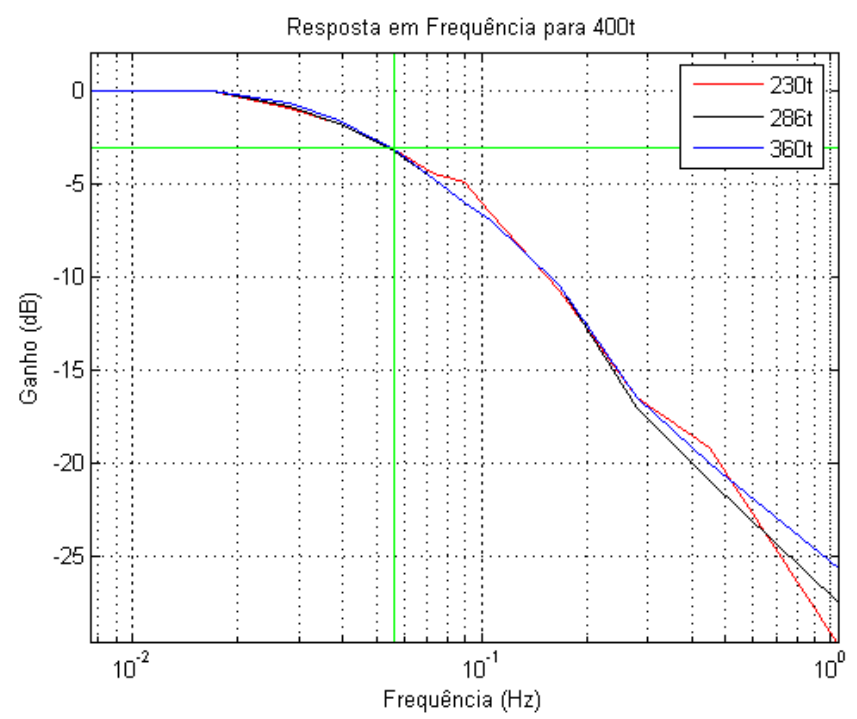

Figura 8.5: Resposta em frequência do compensador com controle continuo

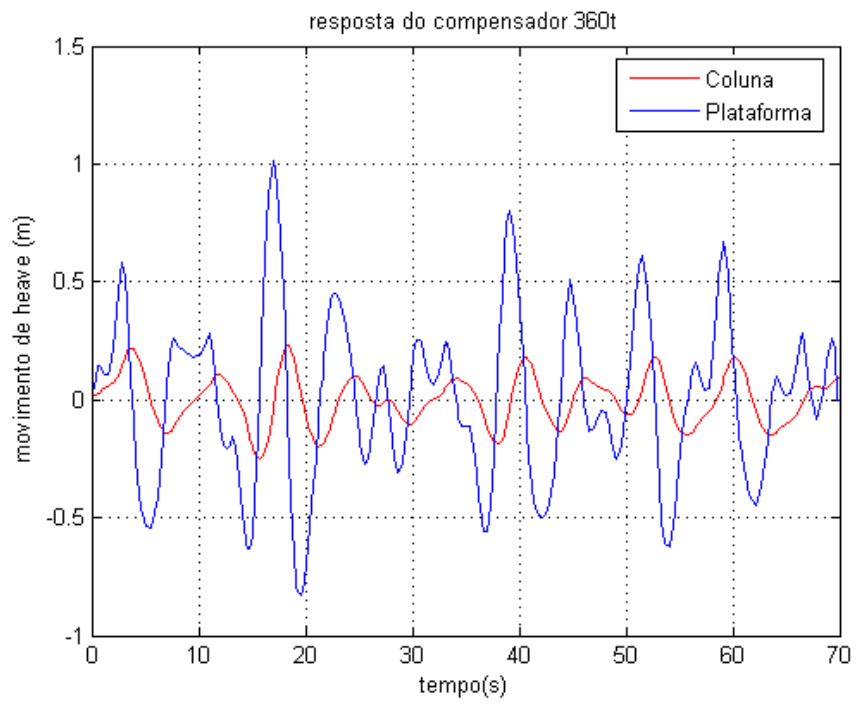

Figura 8.6: Resposta do compensador para um deslocamento da plataforma gerado pelo movimento das ondas do mar 


\section{Capítulo 9}

\section{Conclusões}

As conclusões desta pesquisa são as seguintes:

- Foi feita a modelagem do sistema de suspensão hidropneumático sem e com mola para obter a função de transferência de cada compensador. Relacionaram-se os denominadores dessas funções de transferência com os denominadores das funções de transferência do filtro de Butterworth, encontrando-se a relação dos parâmetros do compensador em função dos parâmetros do filtro. Isso permitiu calcular os valores dos parâmetros dos compensadores para obter o comportamento desejado.

- Identificou-se a resposta desejada do compensador, analisaram-se suas condições de trabalho para uma profundidade de $6 \mathrm{~km}$. Baseado nisso projetaram-se os compensadores com as duas suspensões hidropneumáticas, usando os polos sugeridos pelo filtro de Butterworth para atingir o comportamento desejado.

- O valor da rigidez da mola mecânica projetado supera o limite de resistência e durante a compressão acontece a fratura na mola, portanto o compensador com a suspensão hidropneumática em série com uma mola não é realizável ao seguir a metodologia desta pesquisa.

- Foi encontrada a relação que descreve a variação dos parâmetros dos compensadores em função da massa suportada pelo compensador. Baseado nisso, desenvolveu-se uma estratégia de controle semiativo usando só uma válvula servo comandada. Isso permite mudar o valor da rigidez do sistema adaptando o compensador para cada novo valor de massa. Esta solução é simples, robusta às falhas elétricas ou mecânicas, e garante a segurança do processo de perfuração no intervalo de massas suportadas pelo compensador (230t e 360t).

- O controle conseguiu manter as condições de operação, garantindo sempre uma frequência de corte menor ou igual que $0,056 \mathrm{~Hz}$, um ganho máximo na resposta em frequência no intervalo de $6,8 \mathrm{~dB}$ e $3,6 \mathrm{~dB}$ para o compensador com mola e entre $2,8 \mathrm{~dB}$ e $1,3 \mathrm{~dB}$ para o compensador sem mola. O controle semiativo diminuiu o volume do acumulador, pois um compensador passivo teria a mesma resposta em frequência (frequência de corte $0.056 \mathrm{~Hz}$ e maior ganho máximo de $4 \mathrm{~dB}$ ) com um acumulador $9 \%$ maior que o acumulador obtido para o compensador sem mola quando é aplicado o controle semiativo. 
- O compensador sem mola apresentou uma melhor resposta em frequência e ao degrau. A resposta em frequência teve um ganho máximo de quase a metade que a resposta em frequência do compensador com mola. A resposta ao degrau do compensador sem mola teve um sobre-sinal máximo 50\% menor que o sobre-sinal da resposta ao degrau para o compensador com mola. Além disso, o tempo de acomodação ficou quase constante no valor de $45 \mathrm{~s}$ para qualquer massa, menor que o valor do tempo de acomodação da resposta do compensador com mola que esteve entre $36 \mathrm{~s}$ e $85 \mathrm{~s}$.

- O volume do acumulador para o compensador sem mola é de $88 m^{3}$ e para o compensador com mola é de $89 \mathrm{~m}^{3}$. Estes valores são grandes em comparação com os compensadores ativos comerciais cujos volumes encontram-se entre $10 \mathrm{~m}^{3}$ e $20 \mathrm{~m}^{3}$, mas se as condições de operação do compensador foram menos rigorosas, o volume do acumulador dos compensador projetado seria menor. Por exemplo, para obter a mesma frequência de corte $0.056 \mathrm{~Hz}$ e um ganho máximo na frequência de ressonância de $6 \mathrm{~dB}$ em vez de $3.1 \mathrm{~dB}$, o volume do acumulador do compensador sem mola é reduzido em $24 \%$.

- O compensador sem mola é realizável, tem a frequência de corte desejada e um baixo valor de ganho máximo para a resposta em frequência 4dB. Portanto, ao aplicar o controle semiativo desenvolvido nesta pesquisa, este compensador não precisa de um sistema ativo.

Como trabalho futuros são proposto os seguintes trabalhos e feitas algumas sugestões:

- Aplicar os diferentes algoritmos de controle semiativo para controlar posição, velocidade, aceleração e força sobre a broca, usando o mesmo atuador. O objetivo seria diminuir o volume do acumulador e manter um desempenho aceitável.

- A única propriedade da coluna tida em conta nesta modelagem foi a massa. Sugere-se adicionar outras propriedades da coluna na modelagem, como a rigidez da coluna e a força de arrasto.

- Incorporar a técnica de controle proposta no Apêndice ll e adoptar para aplicação nos casos do pré-sal. Tendo em vista q não que esses resultados não foram totalmente explorados, pois foram obtidos após da submissão da primeira versão da dissertação.

- Com a finalidade de corroborar a modelagem feita e o controle proposto nesta dissertação, esta sendo desenvolvido um modelo em escala do compensador que trabalha com o principio de suspensão hidropneumática sem mola. Esta pesquisa está sendo realizada como trabalho de conclusão de curso em engenharia mecânica do aluno Tassio Melo. Contando com a orientação do Doutor Eugenio Fortaleza e recebendo sugestões como aporte da presentes pesquisa. 


\section{REFERÊNCIAS BIBLIOGRÁFICAS}

[1] ANP. Brazil, 2012. Anuário Estatístico Brasileiro do Petróleo, Tabela 2.9 Produão de petróleo, Acesso em 3 de 9 de 2012, Disponível em: http://www.anp.gov.br/?pg=60983\#Se__o_ 1.

[2] CHAKRABARTI, S. K. Handbook of offshore engineering. In: . Plainfield, Illinois: Elsevier, 2005. v. 1 , p. 1-8.

[3] W. D. STEVENSON. Heave Compensating devices for marine USE. 03 1976. 3.946.559.

[4] HATleSKOG, T.; DUNNiGAN, W. The crone suspension:modelling and stability analisys. IEEE Journal of Oceanic Engineering, v. 32, n. 3, p. 593-602, 2007.

[5] ALVES, T.; MARK, D. Flambagem de coluna parcialmente enterrada uma análise entre a soluão numérica e a analítica. Proceedings of 4to Congreso Internacional y 2do Congreso Nacional de Métodos Numéricos en Ingeniería y Ciencias Aplicadas, 2007.

[6] THOMAS, J. E. Fundamento de engenharia de petróleo. In: . Rio de Janeiro: Interciência, 2004. p. 55.

[7] THOMAS, J. E. Fundamento de engenharia de petróleo. In: . Rio de Janeiro: Interciência, 2004. p. 102.

[8] OliveiRA, D.; CASTRO, J. Tecnologia dos métodos de controle de poe blowout. Trabalho conclusão de curso. Universidade Federal de Rio de Janeiro, Engenharia de petróleo, 2011.

[9] CAPELARI, T. Dispositivo com rigidez não-linear na instalaão de módulos submarinos em águas profundas. Dissertação (Mestrado) - Universidade Federal de Rio de Janeiro, 2007.

[10] HATLESKOG, T.; DUNNIGAN, W. Active heave crown compensation sub-system. OCEANS 2007 - Europe, p. 1-6, 2007.

[11] MELLO, E. S. Modelo de sistema passivo de compensasão de heave para operaôes de instalaão de equipamentos submarínos em águas ultraprofundas. 15-19 p. Dissertação (Mestrado) Universidade Federal de Rio de Janeiro, 2004.

[12] BARROSO, I.; CAZÓN, J. [S.l.], 2002. Evolución de la suspensión en vehículos citroen, Acceso em 06 de 06 2013, Disponível em: http://www.manualesdemecanica.com/manuales/Manualesde-taller/citroen/Documento-técnico-evolución-suspensión-citroen-(español)/. 
[13] BAUER, W. Hydropneumatic suspension systems. In: . Weinheim: Springer, 2011. p. $3,6,7,10,23,25-28,111,28-50,181$.

[14] MCNARY, J.; PERSON, A.; WETMORE, S. Marine riser system with dual purpose lift and heave compensator mechanism. Google Patents, 1979. US Patent 4,176,722. Disponível em: $<$ http://www.google.com.br/patents/US4176722>.

[15] HAO, J.; YANCONG, L. Research on new drill string heave compensation system for floating drilling platform. Fluid Power and Mechatronics (FPM), 2011 International Conference on, p. $791-795,2011$.

[16] ZHANG, X.; LIU, S. Simulation research on the semi-active heave compensation system based on h robust control. Intelligent System Design and Engineering Application, p. 378 - 382, 2010.

[17] HATLESKOG, J.; DUNNIGAN, W. Heave compensation simulation for non-contact operations in deep water. OCEANS 2006, p. 1-6, 2006.

[18] HATLESKOG, T.; ROBICHAUX, R. Semi-active heave compensation system for marine vessels. Google Patents, 1993. US Patent 5,209,302. Disponível em: $<$ http://www.google.com/patents/US5209302>.

[19] GILIOMME, C. L. Chapter 2, Historical and literature overview. Tese (Doutorado) - University of Pretoria, 2005.

[20] NIETO, A. J. Caracterización y Control Activo de una Suspensión Neumática. Tese (Doutorado) - Universidad de Castilla-la Mancha, Escuela Técnica Superior de Ingenieros Industriales, Departamento De Mecánica Aplicada E Ingeniería De Proyectos., 2010.

[21] OHKI, T. Apparatus for adjusting vehicle height. Google Patents, jul. 3 2007. US Patent 7,237,780. Disponível em: <http://www.google.com.br/patents/US7237780>.

[22] BALDI, M. Desenvolvimento de um sistema de suspensõ hidropneumática para uso em máquinas agrícolass. Dissertação (Mestrado) - Universidade Estadual de Campinas, 2004.

[23] SARAMI, S. Development and Evaluation of a Semi-active Suspension System for Full Suspension Tractors. Tese (Doutorado) — Technical University of Berlin, 2009.

[24] EMAMI, M. D.; MOSTAFAVI, S. A. Modeling and simulation of active hydropneumatic suspension system through bond graph. Mechanika, v. 17, p. $312-317,2011$.

[25] R, J.; C, S. Hydro-pneumatic strut. Google Patents, out. 3 1961. US Patent 3,002,743. Disponível em: <http://www.google.com/patents/US3002743>.

[26] MOREAU, X.; ALTET, O. The crone suspension:modelling and stability analisys. ASME, S (Paper No. DETC2003/VIB-48381 S7852), p. 172-200, 2003.

[27] ALIRAND, M.; LACHAIZE, H.; LEBRUN, M. Study and analysis of an active self levelling suspension. Proceedings of the International Congress IEEE, International Conference on Systems, Man and Cybernetics, p. 88-97, 1993. 
[28] ELMADANY, M. M. Active damping and load leveling for ride improvement. Computers and tructures, p. 88-97, 1988.

[29] LAMHATTY, Y. F. Analog and digital filters. In: . Plainfield, Illinois: PrenticeHall series in electrical and computer engineering, 1979.

[30] [S.1.], 2005. University of Berkeley. Lecture 2 Filter, Acesso em 19 de 02 de 2014, Disponível em: http://www-inst.eecs.berkeley.edu/ ee247/fa05/lectures/L2_f05.pdf.

[31] BUTTERWORTH, S. On the theory of filters amplifiers. Wireless Engineer, v. 7, p. 536-541, 1930.

[32] MARTÃ̄円NEZ, M.; GÃŞMEZ, L. [S.1.], 2010. University of Valencia, Curso Filtros Digitales, Acesso em 19 de 02 de 2014, Disponível em: http://ocw.uv.es/ingenieria-y-arquitectura/filtrosdigitales/tema_2._revision_de_los_tipos_de_filtros_analogicos_mas_comunes.pdf .

[33] GUGLIELMiNO, E.; STAMMERS, W. Semi-active suspension control. In: . London: Springer, 2008. p. 65-71.

[34] OGATA, K. Ingnierde control moderna. In: . Madrid: Pearson EducaciÂşn, 1998.

[35] STEWART, R. H. Introduction to physical oceanography. In: . Texas: [s.n.], 2008. p. 284-289.

[36] FERNANDEZ, A. M. Ande fadiga de estruturas offshore tipo topside estudo de caso. p. 56-59. Trabalho conclusão de curso. Universidade Federal de Rio de Janeiro, Engenharia civil, 2011.

[37] ODP. [S.1.]. Ocean Drilling Program, Active heave Compensator, Acesso em 22 de 02 de 2014, Disponível em: http://www-odp.tamu.edu/publications/tnotes/tn31/pdf/ahc.pdf .

[38] SKAARE, B.; EGELAND, O. Parallel force/position crane control in marine operations. IEEE Journal of Oceanic Engineering, VOL. 31, NO. 3, JULY 2006, v. 31, p. 599-613, 2006.

[39] NEUPERT, J.; MAHL, T. A heave compensation approach for offshore cranes. 2008 American Control Conference, p. 538-543, 2008.

[40] J.HAAO; VANGEN, S. The effect of friction in passive and active heave compensation of crown block mounted compensator. Proceedings of the 2012 IFAC Workshop on Automatic Control in Offshore Oil and Gas Production, Norway, p. 316-320, 2012.

[41] HATLESKOG, J.; DUNNIGAN, W. Active heave crown compensation sub-system. OCEANS 2007 - Europe, p. 1-6, 2007.

[42] SOLUTIONS, A. Drilling Technologies. 2013. Disponível em: $<$ http://www.akersolutions.com/Documents/Drilling $\$ 20$ Compensators $\$ 20$ and\%20tensioners.pdf $>$.

[43] [S.1.], 2012. Control Flow, Acesso em 22 de 02 de 2014, Disponível em: http://www.controlflow.com/pdf/ControlFlowMotionCompensation.pdf.

[44] MEYER, C. D. Matrix analysis and applied linear algebra. In: . Philadelphia: Siam, 2000. p. 270. 
[45] CAYRES, B. Numerical and experimental analysis of nonlinear torsional dynaics of a drilling system. Dissertação (Mestrado) — Pontifãycia Universidade CatÂşlica do Rio de Janeiro, 2013.

[46] NI, J.; LUI, S. The simulation research on passive heave compensation system for deep sea mining. IEEE International Conference on Mechatronics and Automation, p. 5111 - 5116, 2009.

[47] LEAL, M. F.; VANGEN, S. Determinaão experimental e numérica de parâmetros associados a dinâmica de veículos. 13 POSMEC - Simpósio do Programa de Pós-Graduaão em Engenharia Mecânica, Uberlândia, Brasil, p. 1-3, 2003.

[48] COSTA, J. A. Estudo da rigidez torcional do quadro de um formula sae por análise de elementos finitos. Dissertação (Mestrado) - Centro Universitário do instituto Mauá de tecnologia, 2012.

[49] UGURAL, A. C. Mecânica dos materiais. In: . [S.1.]: Gen|LTC, 2007. p. 86.

[50] CAVENDISH, M. C. How it works: Science and technology. In: . [S.l.]: Marshall Cavendish, 2003. v. 11. 
ANEXOS 


\section{DIAGRAMAS ESQUEMÁTICOS}

Neste apêndice encontra-se a relação entre a frequência de corte desejada e os parâmetros do filtro de Butterworth, permitindo calcular o valor da frequência natural do filtro de Butterworth para obter a frequência de corte desejada. As relações são encontradas para o compensador com e sem mola mecânica. Estas relações são usadas no Capitulo 5 para projetar o compensador. O processo para encontrar estas relações é similar ao processo feita no Capitulo 4 para achar o valor do amortecimento.

\section{I.1 Frequência natural do Compensador sem mola.}

Usando as equações que relacionam o filtro de Butterworth com os parâmetros do compensador no ponto de projeto ( Equação (3.25) e Equação (3.26)), coloca-se a função de transferencia do compensador (Equação (3.21))em termos dos parâmetros do filtro de Butterworth:

$$
\frac{Z_{1}(s)}{Z_{2}(s)}=\frac{\left(2 z w_{n} s+w_{n}^{2}\right)}{\left(s^{2}+2 z w_{n} s+w_{n}^{2}\right)}
$$

Aplica-se na equação anterior a propriedade da norma, Equação (4.1). Encontra-se a magnitude da função de transferência do compensador sem mola ao quadrado na seguinte equação:

$$
\|x\|^{2}=\frac{\left(w_{n}^{2}+2 z w_{n} w j\right)}{\left(w_{n}^{2}-w^{2}+2 z w_{n} w j\right)} \frac{\left(w_{n}^{2}-2 z w_{n} w j\right)}{\left(w_{n}^{2}-w^{2}+-2 z w_{n} w j\right)}
$$

Para a frequência de corte desejada o ganho deve ser -3dB (amplitude de 0,7). Então, substituise o valor de frequência $w$ da anterior equação por $w_{c}$. Deixa-se claro que o valor do ganho $x$ para esta função é 0,7 .

$$
\|x\|^{2}=\frac{\left(w_{n}^{2}+2 z w_{n} w_{c} j\right)}{\left(w_{n}^{2}-w_{c}^{2}+2 z w_{n} w_{c} j\right)} \frac{\left(w_{n}^{2}-2 z w_{n} w_{c} j\right)}{\left(w_{n}^{2}-w_{c}^{2}+-z w_{n} w_{c} j\right)}
$$

Ordenando equação anterior equação:

$$
\|x\|^{2}=\frac{\left(w_{n}^{4}+4 z^{2} w_{n}^{2} w_{c}^{2}\right)}{\left(\left(w_{n}^{2}-w_{c}^{2}\right)^{2}+4 z^{2} w_{n}^{2} w_{c}^{2}\right)}
$$

Agora é feita a seguinte substituição para relacionar a frequência natural com a frequência de corte

$$
w_{c}=d w_{n}
$$

Usando a substituição anterior e reescrevendo, chega-se numa expressão que depende somente de $d$. 


$$
\|x\|^{2} d^{4}+\left(4\|x\|^{2} z^{2}-2\|x\|^{2}-4 z^{2}\right) d^{2}+\left(\|x\|^{2}-1\right)=0
$$

Substituindo o valor recomendado para o amortecimento pelo filtro de Butterworth $z=0.707$ e o valor da amplitude $x=0.7$ é solucionada a equação anterior, o resultado obtido relaciona a frequência natural com a frequência de corte para este filtro.

$$
w_{n}=\frac{w_{c}}{2,078}
$$

\section{I.2 Frequência natural do Compensador com mola.}

No caso do compensador com mola mecânica, o processo é similar ao feito para o compensador sem mola. Com as equações da Seção 3.4 que relacionam os parâmetros do filtro com os parâmetros do compensador com mola (Equações (3.52), (3.53) e (3.54)), expressa-se a função de transferência do compensador com mola (Equações (3.47)) em função dos parâmetros do fltro de Butterworth de terceira ordem:

$$
\frac{Z_{1}(s)}{Z_{2}(s)}=\frac{\left(2 z w_{n}^{2}+w_{n}^{2}\right) s+w_{n}^{3}}{s^{3}+\left(w_{n}+2 z w_{n}\right) s^{2}+\left(2 z w_{n}^{2}+w_{n}^{2}\right) s+w_{n}^{3}}
$$

Aplica-se na equação anterior a propriedade da norma, Equação (4.1). A magnitude da função de transferência do compensador com mola ao quadrado é a seguinte:

$$
\begin{aligned}
\|x\|^{2}= & \left(\frac{w_{n}^{3}+w_{n}^{2}(2 z+1) w j}{\left(w_{n}^{3}-w_{n}(2 z+1) w^{2}\right)^{2}+\left(w_{n}^{2}(2 z+1) w-w^{3}\right)}\right) * \\
& \left(\frac{w_{n}^{3}-w_{n}^{2}(2 z+1) w j}{\left(w_{n}^{3}-w_{n}(2 z+1) w^{2}\right)^{2}-\left(w_{n}^{2}(2 z+1) w-w^{3}\right)}\right)
\end{aligned}
$$

Substitui-se o valor de frequência da equação anterior por $w_{c}$ e deixa-se claro que o valor do ganho $x$ para esta função é 0,7 .

$$
\|x\|^{2}=\left(\frac{w_{n}^{6}+w_{n}^{4}(2 z+1)^{2} w_{c}^{2} j}{\left(w_{n}^{3}-w_{n}(2 z+1) w_{c}^{2}\right)^{2}+\left(w_{n}^{2}(2 z+1) w_{c}-w_{c}^{3}\right)^{2}}\right)
$$

Ordenando um pouco a equação anterior e usando a substituição da Equaçao (I.5), chega-se numa expressão que depende de $d$.

$$
\|x\|^{2} d^{6}+\|x\|^{2}\left(4 z^{2}-1\right) d^{4}+\left(\|x\|^{2}\left(4 z^{2}-1\right)-(2 z+1)^{2}\right) d^{2}+\left(\|x\|^{2}-1\right)=0
$$

Substituindo o valor que recomenda o filtro de Butterworth de terceira ordem para o amortecimento $z=0,5$, o valor da amplitude $x=0,7$ e encontrando a raiz positiva real da equação anterior é obtida a expressão que relaciona a frequência natural com a frequência de corte para este filtro:

$$
w_{n}=\frac{w_{c}}{1,7}
$$

